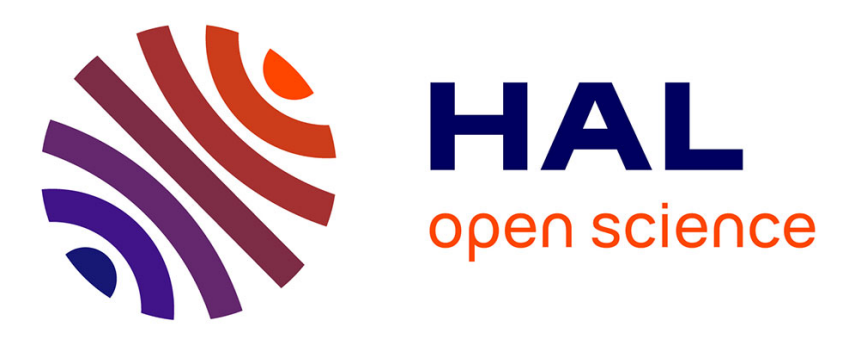

\title{
Current Applications of Artificial Metalloenzymes and Future Developments
}

Jean-Pierre Mahy, Frédéric Avenier, Wadih Ghattas, Rémy Ricoux, Michele Salmain

\section{- To cite this version:}

Jean-Pierre Mahy, Frédéric Avenier, Wadih Ghattas, Rémy Ricoux, Michele Salmain. Current Applications of Artificial Metalloenzymes and Future Developments. Enzymes for Solving Humankind's Problems, pp.363 - 411, 2020, 10.1007/978-3-030-58315-6_12 . hal-03100142

\section{HAL Id: hal-03100142 \\ https://hal.science/hal-03100142}

Submitted on 20 Jan 2021

HAL is a multi-disciplinary open access archive for the deposit and dissemination of scientific research documents, whether they are published or not. The documents may come from teaching and research institutions in France or abroad, or from public or private research centers.
L'archive ouverte pluridisciplinaire HAL, est destinée au dépôt et à la diffusion de documents scientifiques de niveau recherche, publiés ou non, émanant des établissements d'enseignement et de recherche français ou étrangers, des laboratoires publics ou privés. 


\title{
Current Applications of Artificial Metalloenzymes and Future Developments
}

\author{
Jean-Pierre Mahy 1
}

Frédéric Avenier 1

Wadih Ghattas 1

Rémy Ricoux $z 1$

Michèle Salmain 2四

Email: michele.salmain@sorbonne-universite.fr

1 Institut de Chimie Moléculaire et Des Matériaux D’Orsay (ICMMO), UMR 8182, CNRS, Université Paris Sud, Université Paris-Saclay, Paris, France

2 Sorbonne Université, CNRS, Institut Parisien de Chimie Moléculaire (IPCM), Paris, France

\section{Abstract}

In between traditional homogeneous metal catalysts and enzyme catalysts, a new class of hybrid catalysts named artificial metalloenzymes resulting from the controlled embedding of transition metal species (ions, synthetic inorganic or organometallic complexes) within natural, geneticallyengineered or even de novode novo protein scaffolds currently undergoes a tremendous development at the academic level. This family of hybrid assemblies ideally combines the features of their individual components, allowing a wide range of chemical reactions, including new-to-nature reactions, to be catalyzed under mild, eco-compatible conditions with high chemo- and/or stereoselectivity. This chapter intends to summarize the most remarkable achievements in artificial metalloenzyme design and properties 
with emphasis put on industrially relevant chemical reactions, including oxidations, imine reductions, $\mathrm{C}-\mathrm{C}$ and $\mathrm{C}-\mathrm{N}$ bonds formation. It also gives an up-to-date survey on the most advanced applications of artificial metalloenzymes in cascade reactions and in vivein vivo catalysis.

\section{Keywords}

\section{Oxidation}

Reduction

Polymerization

Metathesis

Cascade reactions

In vivoIn vivo catalysis

Uncaging

Carbene insertion

Directed evolution

\section{Abbreviations list}
$\mathrm{ADH}$
alcohol dehydrogenase;
ArM
artificial metalloenzyme;
ATH
asymmetric transfer hydrogenation;
ATHase
artificial transfer hydrogenase;
$\mathrm{Az}$
azurin;
BSA
bovine serum albumin;
Cod
cyclooctadiene;
$\mathrm{CODH}$
carbon monoxide dehydrogenase;
Cyt
cytochrome;
DAAO
D-aminoacid oxidase;
DF
Due Ferri;
EDA
ethyl diazoacetate;
Ee
enantiomeric excess;
FhuA
ferric hydroxamate uptake protein component A; 
Fr

ferritin;

hCA II human carbonic anhydrase isoform II;

HRP horseradish peroxidase;

HSA human serum albumin;

LAAO L-aminoacid oxidase;

LmrR lactococcal multidrug-resistant regulator;

MAO monoaminoxidase;

$\mathrm{Mb} \quad$ myoglobin;

MP8 microperoxidase 8;

Nbd norbornadiene;

NB nitrobindin;

OmpA outer membrane protein A;

PA phenylacetylene;

Phen 1,10-phenanthroline;

PPIX protoporphyrin IX;

ROMP ring-opening metathesis polymerization;

SAV streptavidin;

scdSAV single chain dimeric SAV;

TEV protease tobacco etching virus protease;

TOF turnover frequency;

TON turnover number;

WT wild-type;

Xln xylanase

\section{Introduction}

In the present context of worldwide consciousness regarding the necessity to preserve our habitat, it is now obvious that any human activity has to take into consideration its impact on the environment. This is particularly true for the chemical industry, which is at the origin of most manufactured products, and therefore withstands a huge part of the responsibility for tomorrow's wellness of the planet. After about two centuries of prosperity and wild enterprise, the chemical industry is now facing the daunting challenge to rethink most of its 
well-proven processes and promote the development of environmentally friendly new ones meeting standards for sustainable growth. While chemists still struggle to meet these standards, nature has already solved the problem by evolving natural enzymes, including metalloenzymes, which are capable of performing efficient catalytic processes using harmless reactants under mild conditions. Such biocatalysts can indeed perform selective reactions in aqueous medium at ambient temperature and under atmospheric pressure. Yet, the use of natural enzymes in biocatalytic processes shows some limitations such as thermal instability, substrate specificity, or restriction to natural reactions. Evolving these natural enzymes by replacing the original cofactor with a synthetic catalyst or simply inserting an artificial metal complex into a protein scaffold by covalent or supramolecular ("Trojan Horse") anchoring affords a new class of catalysts that ideally combine the robustness and wide range of reactions achieved by chemical catalysts with the ability of enzymes to work under mild conditions, in aqueous medium, and with high selectivity. Insertion of a synthetic metal complex into a protein gives rise to so-called artificial metalloenzymes (ArMs) that eventually catalyze both natural and non-natural reactions under eco-compatible conditions. The selectivity, the efficiency, and the stability of these ArMs can then be optimized by chemical engineering of the metal complex and/or biochemical engineering of the protein scaffold, notably using the powerful technique of directed evolution. The present chapter gives an overview of the wide range of reactions catalyzed by ArMs but also goes beyond by describing how ArMs can be involved in cascade reaction processes, as well as in in vivo catalysis for both natural and abiotic reactions.

\section{Biotechnological Applications of Artificial Metalloenzymes}

Biotechnological applications of ArMs are potentially endless since the obvious long-term objective is to replace all the contemporary polluting and energyconsuming chemical processes by environmentally friendly new ones. This subchapter surveys the variety of reactions that have successfully been catalyzed by ArMs so far at the laboratory level, covering both the fields of oxidation and reduction reactions as well as polymerization reactions.

\subsection{Oxidations}


Nowadays, most of the industrial stoichiometric oxidations of hydrocarbons involve harsh conditions using strong polluting oxidants, under high pressure and temperature conditions, and occur with low selectivity. There is thus a crucial need to develop new catalysts that would allow oxidations to take place under mild eco-compatible conditions, in water as a solvent, and with high selectivity. Nature has elegantly solved this problem by using the very sophisticated biocatalysts that are metalloenzymes, including heme and nonheme iron enzymes, that can catalyze the highly selective oxidation of chemicals at room temperature and under atmospheric pressure [1,2]. These enzymes can activate molecular dioxygen $\theta_{z}$ at their active site transition metal center, most frequently an iron(III) ion. Mimicking metalloenzymes thus appears to be a logical strategy for developing new catalysts that would catalyze oxidation reactions with excellent selectivity and a high turnover number (TON) under mild conditions. Researchers have long been preparing synthetic models in which a metal ion is inserted into a ligand mimicking the first coordination sphere of this metal ion in the native enzyme [3]. This strategy was particularly successful, for example, to prepare metalloporphyrins, including $\mathrm{Fe}, \mathrm{Mn}, \mathrm{Cr}$, $\mathrm{Co}, \mathrm{V}$... metal ions in their center, that have been used as very efficient catalysts for the oxidation of organic compounds by various organic and inorganic oxidants such as $\mathrm{PhI}=\mathrm{O}, \mathrm{H}_{2} \mathrm{O}_{2}, \mathrm{KHSO}_{5}, \mathrm{NaIO}_{4} \ldots$ with efficiencies rivaling those of enzymes themselves $[4,5,6,7]$. However, several problems still remained to be solved as most of the metal catalysts were only soluble in organic solvents and the stereoselectivity of the reactions catalyzed was generally low. Taking advantage of the chiral environment of proteins and their solubility in water, researchers have prepared ArMs by incorporating metal ions or synthetic metal complexes into proteins following the strategies detailed in the introduction of this chapter $[8,9]$. This allowed them to obtain new watersoluble metal-based hybrid biocatalysts that catalyzed various oxidation reactions. Among those, ArMs possessing a peroxidase activity have already been extensively reviewed $[10,11,12,13]$. The present paragraph will then focus on ArMs designed to catalyze the selective oxidation of substrates of synthetic interest, starting from the most easily oxidizable ones including alcohols, amines, and sulfides to the most difficult to oxidize substrates such as aromatics, alkenes, and alkanes.

\subsubsection{Alcohol Oxidation}


In 2004, Kaplan and De Grado first reported the de novode novo design of diiron protein with four helical bundles displaying phenol oxidase activity [14]. For this, they started from the Due Ferri (DF) family of de novo-designed diiron proteins in which the combination of two Fe(II) ions within a single site, allowed to perform two-electron chemistry with $\mathrm{O}_{2}$, thereby avoiding the formation of oxygen radicals. Indeed, the diiron center reacts quickly with $\mathrm{O}_{2}$, with the concomitant formation of di-Fe(III) species where the two iron(III) ions are bound by an oxo bridge and the reduction of molecular oxygen. They focused on DFtet, a four-chain heterotetrameric helical bundle whose structure, sequence, and catalytic properties were originally designed by a computational method that not only considered the stabilization of the desired fold, but also the destabilization of likely alternatives [15]. Combinations of different monomer units and the introduction of mutations at the active site led to highly active variants, the best ArM (G4-DFtet) catalyzing the two-electron oxidation of 4-aminophenol into the corresponding quinone-mono-imine compound with high efficiency (Fig. 1) $\left(k_{\text {cat }} / K_{M}=1500 \mathrm{M}^{-1} \mathrm{~min}^{-1}\right)$.

\section{Fig. 1}

Reactions catalyzed by de novede novo-designed di-iron protein with four helical bundles from the Due Ferri (DF) family: oxidation of 4-aminophenol into the corresponding quinone-mono-imine [15], oxidation of a larger catechol derivative, 3,5-di-tert-butyl-catechol (3,5-DTBC) [16], N-hydroxylation of arylamines [17, $18]$ 


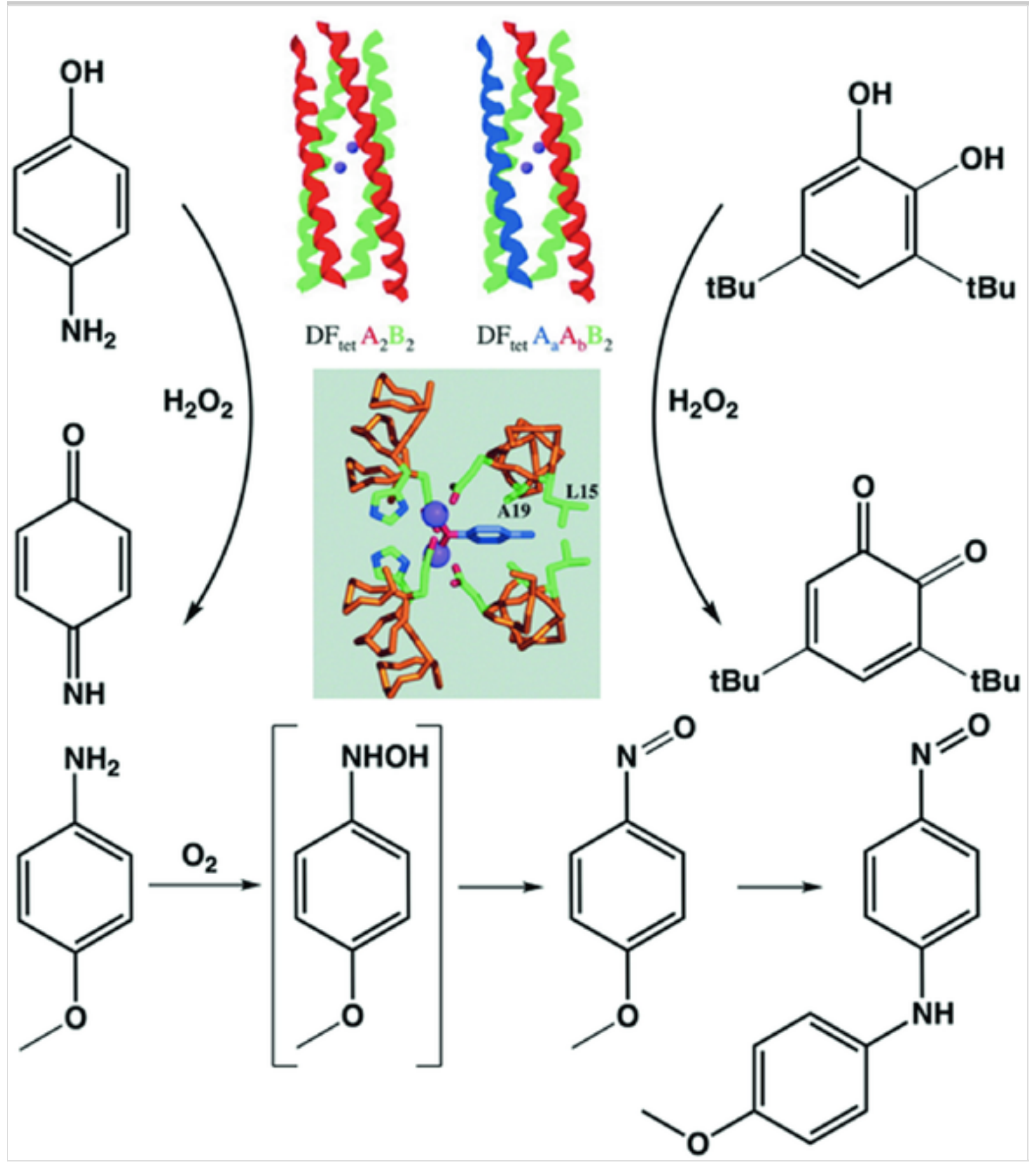

In 2009, Lombardi et al. also designed an artificial oxidase using a scaffold from the same Due Ferri family (DF1) inspired by highly complex natural dimetal proteins. DF1 is a dimeric protein in which each monomer consists of a helix-loop-helix structure [16]. The metal-binding site consists of four glutamate and two histidine residues as first-shell ligands, which are positioned in the core of the protein by hydrogen bonding interactions with two aspartate, tyrosine, and lysine residues. The authors were able to introduce beneficial 
mutations at the metal cofactor and phenol binding sites, which led to destabilization of the protein fold of the analog G4-DFtet. This problem was solved by optimizing the sequence of a loop far from the active site [16]. The finally designed ArM catalyzed the $\mathrm{O}_{2}$-dependent oxidation of a larger catechol derivative, 3,5-di-tert-butyl-catechol (3,5-DTBC), to the corresponding quinone (3,5-DTBQ) (Fig. 1), with a catalytic efficiency $\left(k_{\text {cat }} / K_{M}=6315 \mathrm{M}^{-1} \mathrm{~min}^{-1}\right)$ about 4.6 times higher than that observed for a smaller substrate, 4-aminophenol (4-AP) $\left(k_{\text {cat }} / K_{M}=1380 \mathrm{M}^{-1} \mathrm{~min}^{-1}\right)$.

Finally, the group of T. R. Ward developed ArMs that were active for the oxidation of secondary alcohols (phenethyl alcohol, benzyl alcohol, and cyclohexanol) in water using ${ }^{\mathrm{t}} \mathrm{BuOOH}$ as oxidizing agent. They used the above mentioned "Trojan Horse" strategy based on the non-covalent incorporation of biotinylated $\mathrm{d}_{6}$ piano stool ruthenium complexes into (strept)avidin. The best of them catalyzed the oxidation of dry phenethyl alcohol with a yield greater than $90 \%$ [19] in $90 \mathrm{~h}$ at room temperature.

\subsubsection{Amine Oxidation}

DeGrado et al.et al. also used their metalloproteins, that were originally designed for the oxidation of hydroquinones, in order to catalyze the selective $\mathrm{N} N$-hydroxylation of arylamines [17]. For this purpose, on the one hand, they reshaped the access to the substrate cavity by incorporating three mutations at different levels of the protein and, on the other hand, they introduced an additional iron-binding histidine into the active site in order to mimic the active site of the natural di-oxoxine $\ngtr p$-aminobenzoate $\mathrm{N} N$-oxygenase which is the only structurally characterized $\mathrm{NN}$-oxygenase known to contain a diiron catalytic center [20]. The resulting biohybrid proved to efficiently convert panisidine to the corresponding hydroxylamine (Fig. 1). In 2015, spectroscopic studies demonstrated that the 4-aminophenol substrate directly binds to the biferrous site in the active site of the proteins. The actual active species of the Due Ferri scaffolds were thus identified and mechanisms explaining their different reactivities were suggested [18].

\subsubsection{Sulfide Oxidation}

The oxidation of sulfides by various oxidants catalyzed by ArMs, elaborated by 
all of the strategies described in the introduction of this chapter, has been by far the most widely investigated. One of the first reports was published by Sheldon et at.et al. who constructed an ArM for the catalysis of sulfide oxidation using phytase as a protein scaffold (Fig. 2) [21]. Vanadium chloroperoxidases are nonheminic metalloenzymes that are more resistant to oxidative degradation than their heminic analogs [22]. Unfortunately, these enzymes can only accommodate small substrates in their relatively small active site, which impedes their potential use in asymmetric synthesis. Since this active site shows very high similarities with that of metal-free phytases, Sheldon et al.et al. thought about building an ArM by inserting vanadate into phytase. The new artificial metalloprotein showed a catalytic activity similar to that of natural vanadium chloroperoxidase and catalyzed the quantitative sulfoxidation of thioanisole by $\mathrm{H}_{2} \mathrm{O}_{2}$, with up to $66 \%$ ee [23]. Further experiments were performed to improve the system, both by varying the nature of the host protein (acid-phosphatase, phospholipase, sulfatase, apo-ferritin, BSA) and of the metal moiety (Mo, Re, W, Se, Os). One of the best results was obtained by Ward et al. with vanadate-loaded streptavidin (SAV), that catalyzed the enantioselective thioether sulfoxidation by ${ }^{t} \mathrm{BuOOH}$ with up to $93 \%$ ee in favor of the $(R)$ product and $96 \%$ conversion [24].

\section{Fig. 2}

New artificial metalloenzyme constructed by insertion of vanadate into phytase and that catalyzesing the quantitative and stereoselective sulfoxidation of thioanisole by $\mathrm{H}_{2} \mathrm{O}_{2}$ [21]
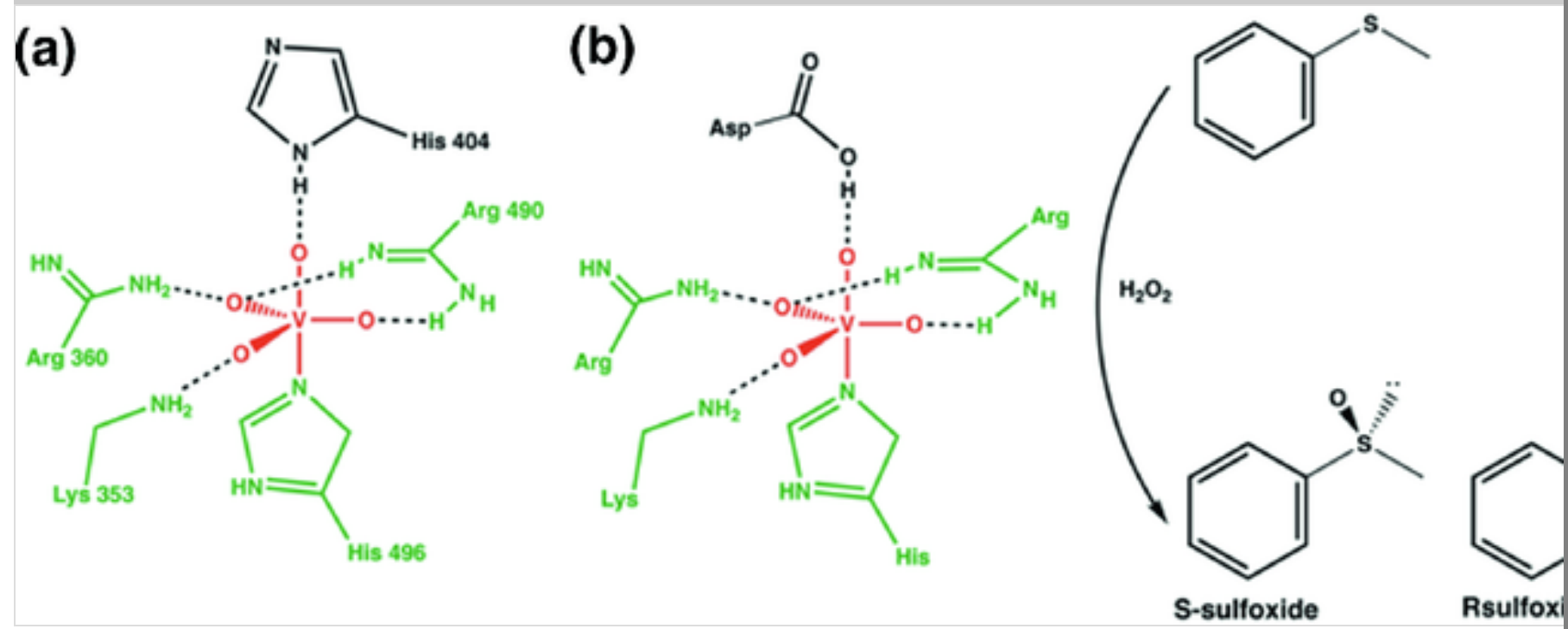
Several artificial metalloenzymes, generated using the "Trojan Horse" strategy, were also reported to catalyze the chemoselective sulfide oxidations. Not surprisingly, in 2009, the group of Ward incorporated achiral biotinylated manganese-salen complexes into WT-SAV and five mutants to obtain ArMs that were tested as enantioselective sulfoxidation catalysts. The resulting enzymes showed moderate conversions (up to 56\%) and low enantioselectivities (up to $13 \%$ ) for the sulfoxidation of thioanisole using hydrogen peroxide as an oxidant in water (Fig. 3) [25]. Later, following the same strategy, Mahy at.et al. have exploited the neocarzinostatin (NCS) variant NCS-3.24, which displays an affinity for testosterone to prepare a novel ArM. A water-soluble anionic ironporphyrin-testosterone conjugate was synthesized and subsequently associated with the NCS-3.24 variant (Fig. 3) [26]. The obtained Fe(III)-porphyrintestosterone-NCS-3.24 artificial metalloenzyme was able to catalyze the chemoand enantio-selective ( $e e=13 \%$ ) sulfoxidation of thioanisole by $\mathrm{H}_{2} \mathrm{O}_{2}$. Molecular modeling studies revealed synergy between the binding of the steroid moiety and that of the porphyrin macrocycle into the protein binding site, thus explaining both the observed better affinity for the conjugate $\left(K_{\mathrm{D}}=1.6 \mu \mathrm{M}\right)$ and the selectivity.

\section{Fig. 3}

Stereoselective and chemoselective oxidation of thioanisole by $\mathrm{H}_{2} \mathrm{O}_{2}$ catalyzed by ArMs constructed following the "Trojan Horse" strategy: insertion of a manganese-salen-biotin conjugate into SAV [25] and of an iron-porphyrintestosterone conjugate into neocarzinostatin [26] 


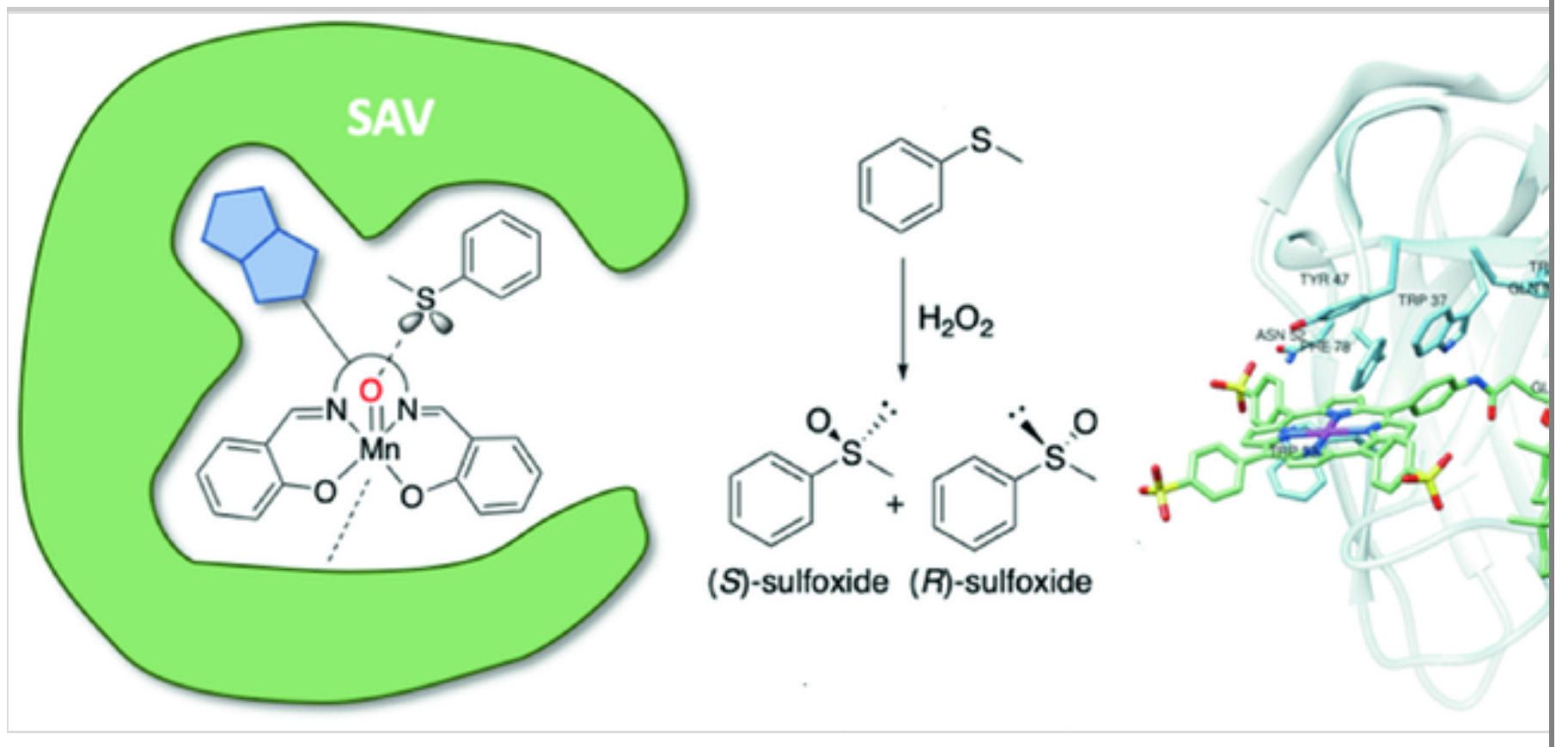

"The Host-Guest" strategy that appears to be the simplest one to incorporate metal cofactors into the cavity of proteins, has of course been the most often used to generate ArMs for sulfide oxidation catalysis. First of all, Human serum albumin (HSA) that is known to bind heme within a narrow cavity with a strong affinity $\left(K_{\mathrm{a}}=1.1 \times 10^{8} \mathrm{M}^{-1}\right)$ was widely used not only for the generation of new efficient $\mathrm{O}_{2}$ binding artificial hemoproteins but also for preparing ArMs [27, 28, 29]. Gross et al. inserted bis-sulfonated Ga- and Mn-corrole into HSA [30] as well as iron and manganese complexes of the same corrole into human, bovine (BSA), porcine (PSA), rabbit (RSA), and sheep (SSA) serum albumins to build new ArMs. These constructs were found to catalyze the sulfoxidation of thioanisole derivatives by hydrogen peroxide with conversions up to $98 \%$ and up to $74 \%$ ee [31]. Generally, better activities, selectivities as well as stabilities were obtained with albumin-Mn-corrole complexes with respect to their iron counterparts. More recently, the BSA-Mn-corrole artificial metalloenzyme was revealed to catalyze light-induced enantioselective oxidation of thioanisole into sulfoxide with $20 \%$ ee using water as the oxygen atom source in the presence of a ruthenium complex as photosensitizer (Fig. 4) [32].

\section{Fig. 4}

Metallocorroles [30, 31, 32] and Mn-salen complexes [33] inserted noncovalently in serum albumins to afford artificial metalloenzymes that catalyze the stereoselective and chemoselective oxidation of thioanisole by $\mathrm{H}_{2} \mathrm{O}_{2}$ 


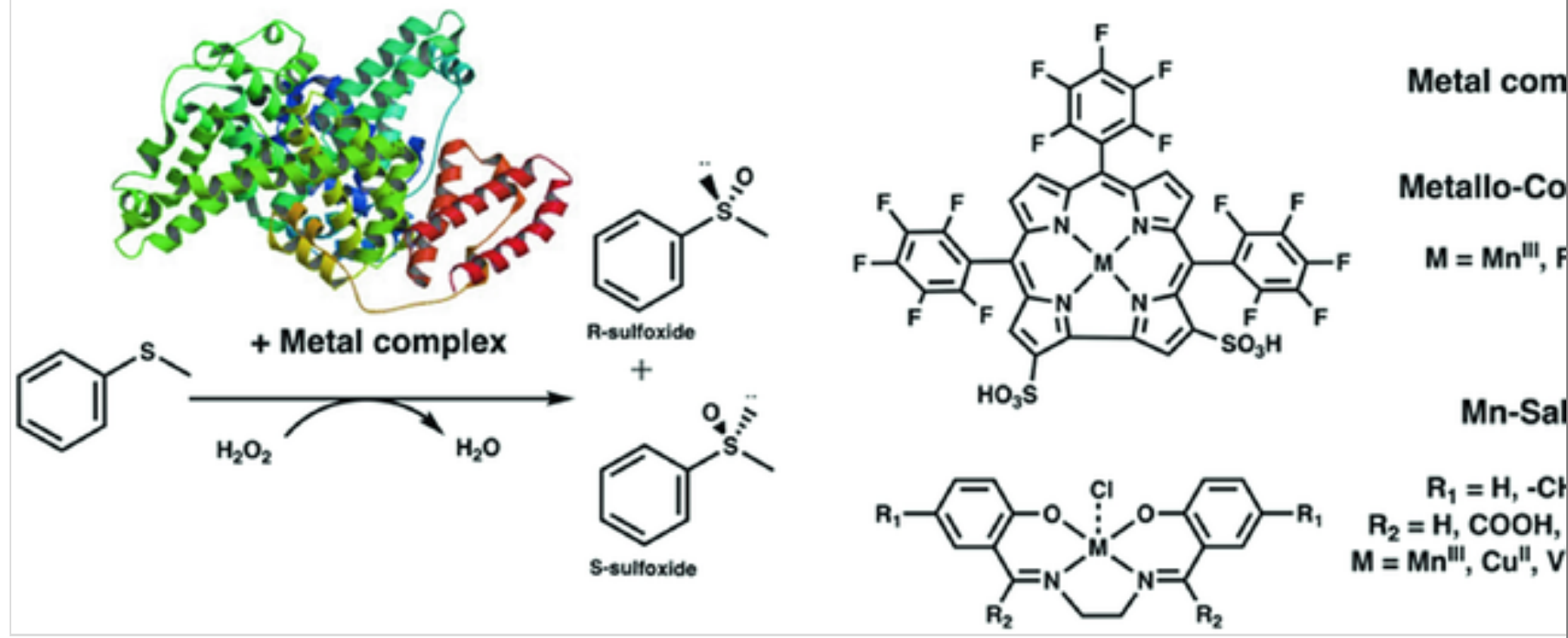

The non-covalent association of metal-salen or -salophen complexes with serum albumins to produce ArMs was also reported. First, a series of ArMs were prepared by incorporation of Mn-salen into HSA. The HSA-Mn-salen artificial metalloenzymes catalyzed the chemoselective oxidation of thioanisole by $\mathrm{NaOCl}$ with $90-100 \%$ conversion and the almost exclusive formation of methylphenylsulfoxide whereas the Mn-salen complexes alone led to an about $60 \%$ conversion with the almost exclusive formation of methylphenylsulfone (Fig. 4) [33]. Another ArM was obtained by incorporation of a cobalt(II) Schiff base complex $\left\{\mathrm{CoL}, \mathrm{H}_{2} \mathrm{~L}=2,2^{\prime}-[(1,2-\right.$

ethanediyl)bis(nitrilopropylidyne)]bisphenol\} in BSA and its catalytic activity in the enantioselective oxidation of a variety of sulfides by $\mathrm{H}_{2} \mathrm{O}_{2}$ was studied as a function of $\mathrm{pH}$, temperature, and concentration of catalyst and oxidant. Under optimal conditions, the BSA-CoL hybrid biocatalyst appeared as efficient for the enantioselective oxidation of a series of sulfides into the corresponding sulfoxides and reached excellent conversions (up to 100\%), chemoselectivity (up to $100 \%$ ), and good enantiomeric excesses (up to 87\% ee) [34].

More recently, the oxygen-binding hemoprotein, myoglobin ( $\mathrm{Mb}$ ), has also been used by several teams to build up artificial metalloenzymes. The general strategy used is based on the replacement of its iron-heme prosthetic group by other heme or non-heme metal complexes. Indeed, this heme is linked inside the hydrophobic $10 \AA$ diameter cavity of the protein by non-covalent interactions, including hydrophobic interactions, electrostatic interactions via its two 
carboxylate moieties, and coordination of its iron by the imidazole of H93 [35]. The prosthetic group of $\mathrm{Mb}$ can be easily removed without impairing its folding to yield apo-Mb, which shows a free cavity able to accommodate another metal cofactor (Fig. 5) [36].

\section{Fig. 5}

Preparation of apo-myoglobin [36] and metal complexes of salen and salophen ligands $[37,38,39,40,41]$ inserted non-covalently in apo-Mb to get artificial metalloenzymes that catalyze the stereoselective and chemoselective oxidation of thioanisole as well as iron complexes of heme derivatives bearing eight anionic carboxylate moieties and of porphycens that catalyze the hydroxylation of ethylbenzene into 1-phenylethanol by $\mathrm{H}_{2} \mathrm{O}_{2}[36,42]$

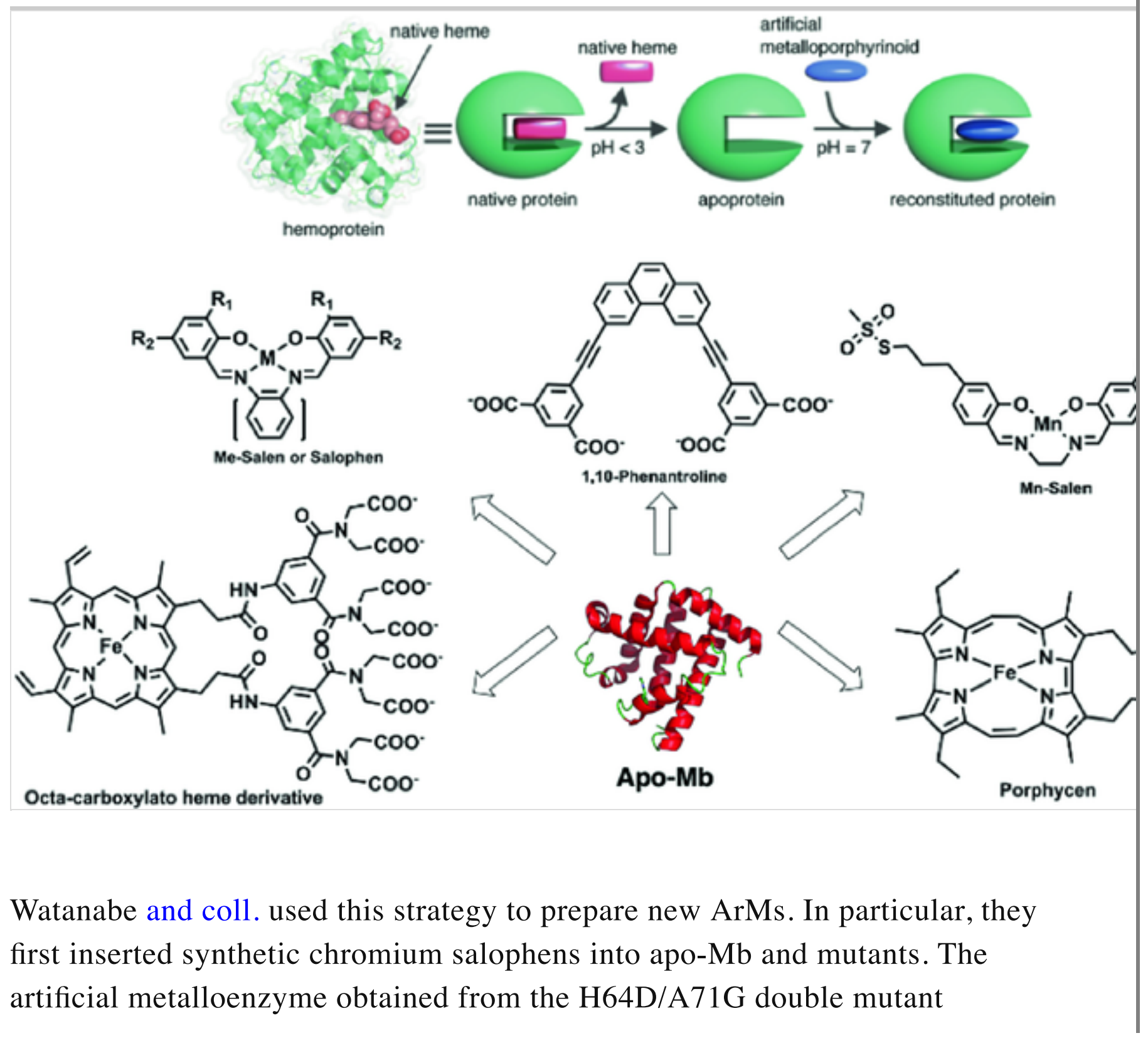


catalyzed the stereoselective sulfoxidation of thioanisole, with rather low turnover frequencies (TOF $\leq 0.13 \mathrm{~min}^{-1}$ ) and enantiomeric excesses $(e e \leq 30 \%$ in favor of the $(S)$-product) [37]. The 3D structures of two apo-Mb A71G mutant-Mn- and Cr-salophen complexes revealed that the accessibility to the active site was sterically hindered by the bulky phenylenediamine moiety of the salophen cofactors. They then used metal-salen cofactors instead, which had a rather low effect on the efficiency of the chromium cofactors $(\mathrm{TOF}=$ $0.21 \mathrm{~min}^{-1}$ ) but induced a noticeable increase in the efficiency of the manganese cofactor $\left(\mathrm{TOF}=2.7 \mathrm{~min}^{-1}\right.$ ). In addition, insertion of the later cofactor in the H64D/A71G double mutant led to a slightly increased enantiomeric excess (30\% ee in favor of the $(S)$-product) whereas its insertion in the A71G single mutant led to an enantiomeric excess very similar to that obtained with the WT protein (27\% ee in favor of the $(R)$-product) [38].

Several other teams further inserted various Fe-tetrapyrrolic compounds into apo-Mb to produce new biohybrids that catalyzed the oxidation of thioanisole by $\mathrm{H}_{2} \mathrm{O}_{2}$ and led to up to $38 \%$ ee in favor of the $(S)$-sulfoxide. The enantiomeric excess could be increased either by covalent anchoring of metal complexes into apo-Mb and mutants $[39,40,41]$ or by changing the metal such as, for example, replacing iron by manganese [41]. Accordingly, Lu et al.et al. showed that a dual-point attachment of manganese-salen complex to a double mutant of apo$\mathrm{Mb}$ (apo-Mb Y103C/L72C) led to an improved selectivity (51\% ee) in thioanisole sulfoxidation relative to the analogous single-point mutant (Y103C, 12\% ee) (Fig. 5) [40, 41].

Xylanase A from Streptomyces lividans (Xln10A), a thermostable $\beta$-1,4endoxylanase glycoside hydrolase that hydrolyzes $\beta-1,4$ bonds in the main chain of xylan [43], was also used to build up new artificial hemoproteins using the host-guest strategy. This choice was guided by an early report from Nakamura and Tsushida at.et al. that showed that xylanase possessed a wide enough active site to accommodate an $\mathrm{Fe}(\mathrm{II})-\alpha 4$-tetra-o-pivalamidophenylporphyrin. The resulting heat-resistant hemoproteins were found to bind and release $\mathrm{O}_{2}$ in aqueous medium [44]. Metal complexes of synthetic tetraaryl porphyrins bearing negatively charged substituents, such as Iron(III)tetra(4carboxyphenyl)porphyrin (Fe(TpCPP)) and iron(III)-meso-tetra(4sulfonatophenyl)porphyrin ( $\mathrm{Fe}(\mathrm{TpSPP})$ ), were then inserted into Xln10A to lead to new artificial hemoproteins that showed peroxidase activity [12]. The 
catalytic activity of these $\mathrm{Fe}(\mathrm{TpCPP})-\mathrm{X} \ln 10 \mathrm{~A}$ and $\mathrm{Fe}(\mathrm{TpSPP})-\mathrm{X} \ln 10 \mathrm{~A}$ biohybrids for the oxidation of thioanisole by $\mathrm{H}_{2} \mathrm{O}_{2}$ (Fig. 6) was then investigated and compared to that of $\mathrm{Fe}(\mathrm{TpCPP})$ and $\mathrm{Fe}(\mathrm{TpSPP})$ alone. These two Fe-porphyrin complexes led, respectively to 45 and $33 \%$ yields in sulfoxide and to respective TOFs of 0.56 and $0.41 \mathrm{~min}^{-1}$, but no enantiomeric excess could be detected. Use of the Fe(TpCPP)- and Fe(TpSPP)-Xln10A biohybrids as catalysts led to a decrease in the yields (about 24\%) and turnover frequencies (about $0.30 \mathrm{~min}^{-1}$ ), but enantiomeric excesses of up to $36 \%$ and $24 \%$ in favor of the $(S)$-sulfoxide could respectively be observed. It is noteworthy that better yield and turnover frequencies $\left(85 \%\right.$ and $\left.1.09 \mathrm{~min}^{-1}\right)$ as well as a better enantiomeric excess in favor of the $(S)$-sulfoxide $(e e=40 \%)$ could be obtained in the presence of 100 equivalents of imidazole as a co-catalyst [11,45].

\section{Fig. 6}

Stereoselective and chemoselective oxidation of thioanisole by $\mathrm{H}_{2} \mathrm{O}_{2}[11,45]$ and of 4-methoxystyrene by $\mathrm{KHSO}_{5}$ [46] catalyzed by Fe-tetrarylporphyrin-xylanase A ArM

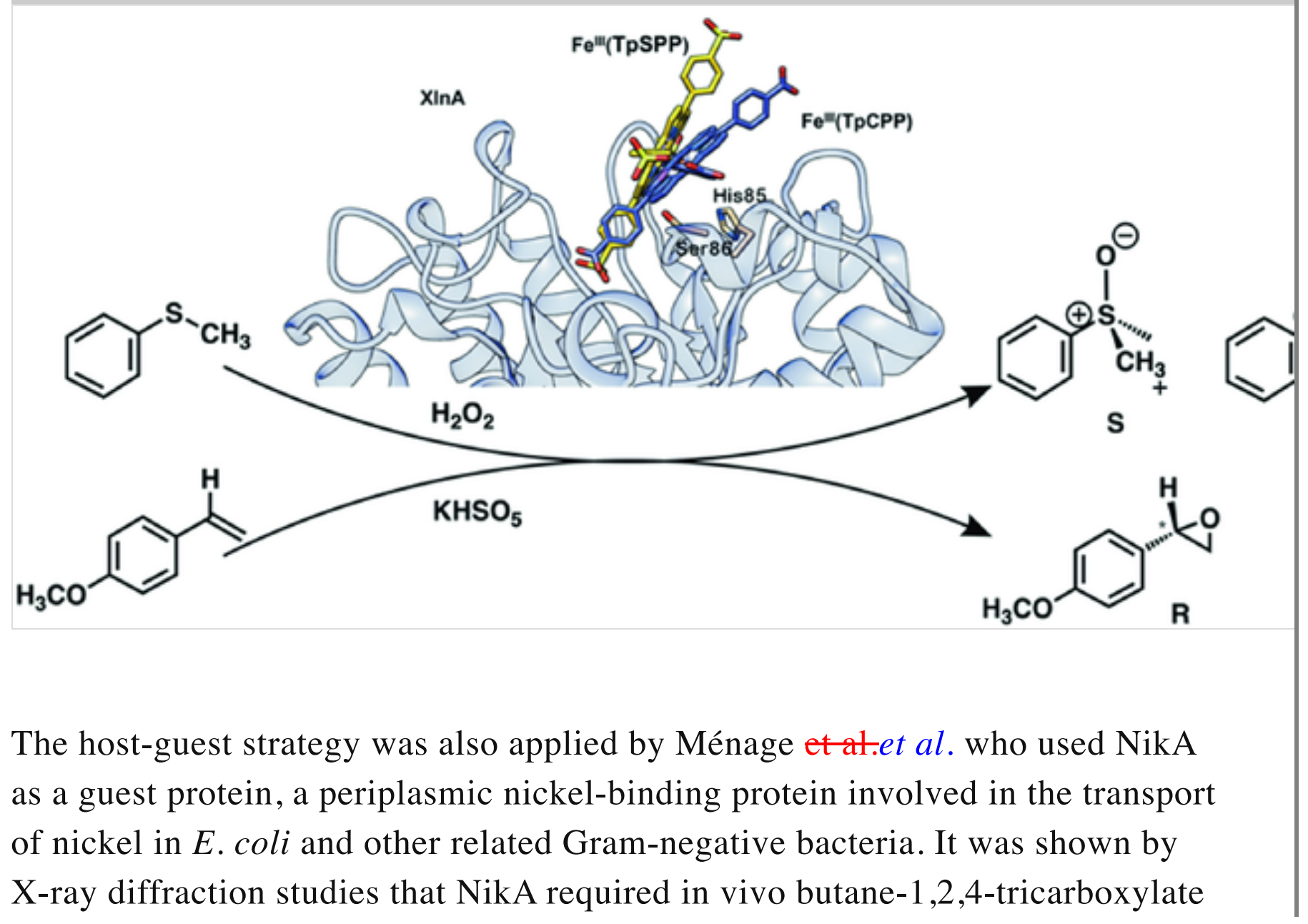


(BTC) as a specific metal-binding ligand [47]. Structural characterization of a putative endogenous metal chelator in the Periplasmic Nickel Transporter NikA showed that it was also able to bind $\mathrm{Fe}(\mathrm{EDTA})\left(\mathrm{H}_{2} \mathrm{O}\right)$ [48]. Ménage-et at. et al then took advantage of this property and inserted into NikA EDTA-like inorganic metal complexes of the $\mathrm{N}_{2} \mathrm{Py}_{2}$ type that mimic the metal environment of iron oxygenases. After the crystal structure of one of the NikA-Fe- $\mathrm{N}_{2} \mathrm{Py}_{2}$ complexes have been solved at $1.7 \AA$ resolution, they followed an original approach based on molecular docking calculations to screen sulfide substrates, of the $\mathrm{C}_{6} \mathrm{H}_{5}-\mathrm{S}-\mathrm{CH}_{2}-\mathrm{X}$ type, for catalytic oxidation by the series of iron complex NikA hybrids. A set of 374 potential sulfide substrates was identified, among which six potential substrates had a common $\mathrm{R}_{1}-\mathrm{S}-\mathrm{CH}_{2}-\mathrm{CONH}-\mathrm{R}_{2}$ motif. Interestingly, the skeleton of the defined substrate is comparable to the one of omeprazole or modafinil, which are major drugs from the pharmaceutical industry. The catalytic oxidation of those six substrates was performed in the presence of each hybrid, and the best catalytic results were obtained for the oxidation of 4- $\mathrm{CH}_{3}-\mathrm{Ph}-\mathrm{S}-\mathrm{CH}_{2}-\mathrm{CONH}-\mathrm{Ph}$ by $\mathrm{NaOCl}$, in the presence of one $\mathrm{NikA}-\mathrm{Fe}-\mathrm{N}_{2} \mathrm{Py}_{2}$ catalyst, that led to the chemoselective formation of sulfoxide in $78 \%$ yield, with a TON of 199 but a weak enantiomeric excess (5\%). This study constituted a nice proof-of-concept for the design of a substrate family, that allowed Ménage et al.et al. to define a new kind of artificial oxygenase for the catalysis of sulfoxidation reactions of pharmaceutical interest (Fig. 7) [49].

\section{Fig. 7}

Design of a new kind of artificial oxygenase for the synthesis of sulfoxides of pharmaceutical interest: molecular docking of sulfides with a $\mathrm{R}_{1}-\mathrm{S}-\mathrm{CH}_{2}-\mathrm{CONH}-$ $\mathrm{R}_{2}$ formula allowed to determine the best $4-\mathrm{CH}_{3}-\mathrm{Ph}-\mathrm{S}-\mathrm{CH}_{2}-\mathrm{CONH}-\mathrm{Ph}$ to be chemo-selectively oxidized by the NikA-Fe- $\mathrm{N}_{2} \mathrm{Py}_{2} / \mathrm{H}_{2} \mathrm{O}_{2}$ system [49] 

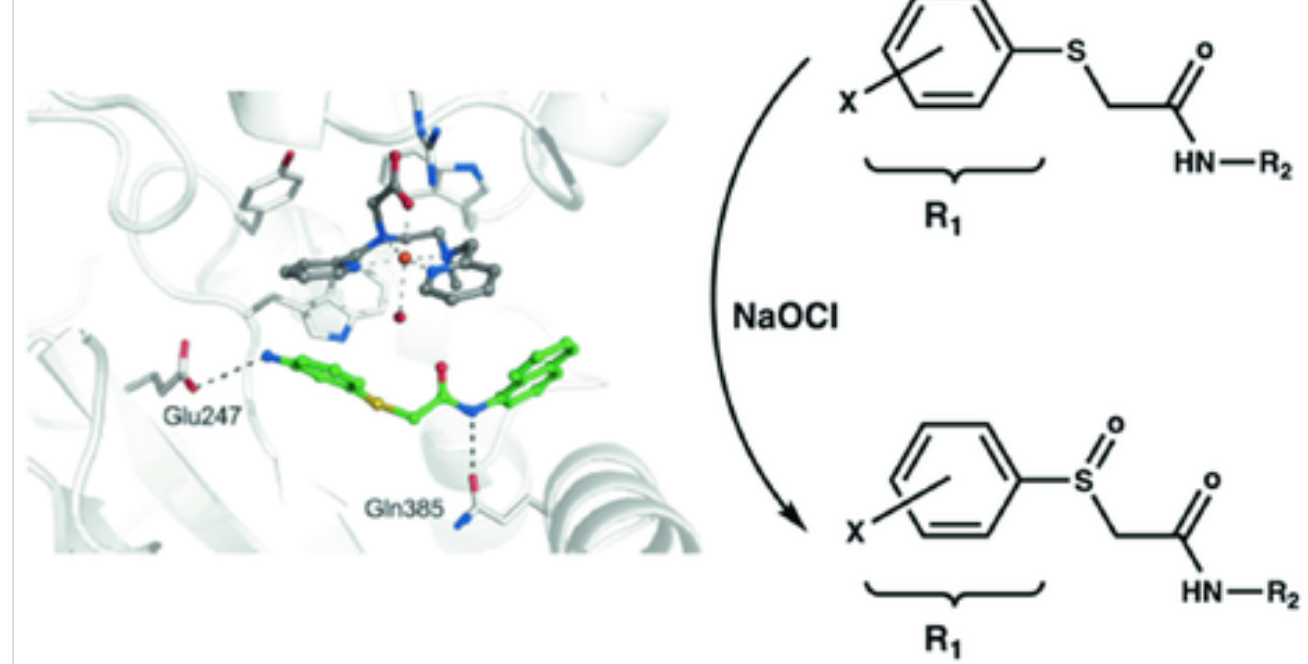

\begin{tabular}{|c|c|}
\hline R1 & \\
\hline $3-\mathrm{NH}_{2} \mathrm{C}_{6} \mathrm{H}_{4}$ & $\alpha-\mathrm{na}$ \\
\hline 4-AcNHC $6 \mathrm{H}_{4}$ & \\
\hline $4-\mathrm{CH}_{3} \mathrm{NHC}_{6} \mathrm{H}_{4}$ & \\
\hline $2,5-(\mathrm{MeO})_{2} \mathrm{C}_{6} \mathrm{H}_{4}$ & \\
\hline $3,4-(\mathrm{MeO})_{2} \mathrm{C}_{6} \mathrm{H}_{4}$ & \\
\hline $2,5-(\mathrm{MeO})_{2} \mathrm{C}_{6} \mathrm{H}_{4}$ & \\
\hline $3,4-(\mathrm{MeO})_{2} \mathrm{C}_{6} \mathrm{H}_{4}$ & \\
\hline \multicolumn{2}{|c|}{$\begin{array}{l}\text { Omeprazole : } \\
R_{1}=\beta \text {-MeO-benzimidazole } \\
\text { CONHR }=4-M e O-3,5 \text {-Dimethylp } \\
\text { Monafidil : } \\
R_{1}=(P h)_{2} C H \text { and } R_{2}=H\end{array}$} \\
\hline
\end{tabular}

Finally, Mahy et al.et al. covalently and selectively grafted a non-heme $\mathrm{Fe}$ (II) polyazadentate complex to the accessible cysteine 121 of bovine $\beta$ lactoglobulin. The biohybrid catalyzed the chemoselective oxidation of thioanisole by $\mathrm{H}_{2} \mathrm{O}_{2}$ into phenylmethylsulfoxide with an $e e$ of $20 \%$.

Mechanistic studies showed that the reaction proceeded via a high $\operatorname{spin}(S=5 / 2)$ $\mathrm{Fe}^{\mathrm{III}}\left(\eta^{2}-\mathrm{O}_{2}\right)$ intermediate that was proposed to be responsible for the catalytic sulfoxidation [50].

\subsubsection{Catechol Oxidation}

Itoh and collaborators converted a bacterial hydrolytic di-zinc $\beta$-lactamase, into a redox-active di-copper oxidase. For this, they used a mutational method based on a rational computer-assisted recasting of the metal-binding site. This analysis suggested generating a triple $\mathrm{D} 88 \mathrm{G} / \mathrm{S} 185 \mathrm{H} / \mathrm{P} 224 \mathrm{G}$ mutant of this protein, which made it possible to convert its active site into a type III dicopper reactive center. The new metalloprotein showed spectroscopic characteristics similar to those of type III copper proteins and showed high catalytic activity with an increase of two orders of magnitude in the $k_{\mathrm{cat}} / K_{M}$ value in the oxidation of catechols under aerobic conditions [51].

\subsubsection{C-H Oxidation}

Very few artificial metalloenzymes have been reported so far for the catalysis of alkane hydroxylation. However, Ricoux et al.et al. produced monoclonal antibodies raised against microperoxidase 8 (MP8), that possesses an iron(III)- 
heme c cofactor. The association of these antibodies with MP8 gave an antibody-MP8 complex that was capable of effectively catalyzing the regioselective nitration of phenol to 2- and 4-nitrophenol by $\mathrm{NO}_{2}{ }^{-}$in the presence of $\mathrm{H}_{2} \mathrm{O}_{2}$ [52]. Inhibition by cyanide and radical scavengers suggested a peroxidase-like mechanism mediated by MP8, involving the formation of highvalent iron oxo species. The successive one-electron reduction of these intermediates by $\mathrm{NO}_{2}{ }^{-}$and phenol, respectively, led to the production of nitro and phenoxy radicals, which then reacted together to give 2- and 4-nitrophenols. In this catalytic antibody, the protein thus appeared to have two main roles, it protected MP8 against oxidative degradation and induced a regioselectivity of the reaction towards the formation of 2-nitrophenol as a major product [52].

The only report to date on oxygen atom insertion into a $\mathrm{C}-\mathrm{H}$ bond catalyzed by ArMs was from the group of Hayashi and Hisaeda. They prepared apo-Mb and mutants and then inserted heme derivatives bearing up to eight anionic carboxylate moieties into the heme-binding pocket (Fig. 5). The resulting ArMs not only showed peroxidase activity but also catalyzed the oxidation of catechol with rates up to 11 -fold higher than native $\mathrm{Mb}$, as well as the regioselective hydroxylation of ethylbenzene to 1-phenylethanol by $\mathrm{H}_{2} \mathrm{O}_{2}$, when $\mathrm{Mb}$ was reconstituted with a manganese-porphycene cofactor (Fig. 5) [36, 42].

\subsubsection{Epoxidation}

Here also, only a few examples of artificial metalloenzymes catalyzing alkene epoxidation have been reported so far. In the first papers simultaneously reported by Soumillion and Kazlauskas et al et a the native $\mathrm{Zn}$ (II) ion of isoform II of human carbonic anhydrase (hCAII) was replaced by several metal cations including $\mathrm{Co}(\mathrm{II}), \mathrm{Cu}(\mathrm{II}), \mathrm{Ni}(\mathrm{II}), \mathrm{Mn}(\mathrm{II})$ and $\mathrm{Rh}(\mathrm{I})$. The $\mathrm{X}$-ray crystal structures of hCAII substituted with these metal cations revealed that the primary coordination sphere of each of these was uniquely perturbed relative to the native $\mathrm{Zn}$ (II), although the overall metal-binding motif constituted by three histidine residues remained intact [53]. In the particular case when the $\mathrm{Zn}$ (II) ion was replaced by $\mathrm{Mn}$ (II), the new hCAII-Mn(II) metalloenzyme was found to catalyze the enantioselective alkene epoxidation with up to $66.5 \%$ ee and $12.5 \%$ conversion $[54,55]$. To broaden the range of catalysts capable of catalyzing the epoxidation reaction, Reetz et at.et al. have decided to covalently modify papain with a manganese-salen complex, using Michael addition of the thiolate 
function of cysteine 25 from papain to a maleimide substituent carried by the salen ligand. The artificial enzymes appeared to catalyze epoxidation reaction with-weak enantiomeric excesses of about $10 \%[56,57]$.

Finally, the catalytic activity of Xln A-based artificial hemoproteins was also investigated for the selective oxidation of alkenes. $\mathrm{Mn}(\mathrm{III})(\mathrm{TpCPP})$ was noncovalently inserted into $\mathrm{X} \ln 10 \mathrm{~A}$ and the oxidation of various styrene derivatives by various oxidants such as hydroperoxides $\left(\mathrm{H}_{2} \mathrm{O}_{2}\right.$ and $\left.{ }^{t} \mathrm{BuOOH}\right)$, sodium hypochlorite $(\mathrm{NaOCl})$, sodium periodate $\left(\mathrm{NaIO}_{4}\right)$, and oxone ${ }^{\circledR}\left(\mathrm{KHSO}_{5}\right)$ was tested in the presence of the $\mathrm{Mn}(\mathrm{III})(\mathrm{TpCPP})-\mathrm{X} \ln 10 \mathrm{~A}$ biocatalyst. Positive results were only observed with $\mathrm{KHSO}_{5}$ as oxidant, together with the highest catalytic activity reported so far for the oxidation of styrene catalyzed by artificial metalloproteins. However, a rather low chemo- and enantioselectivities $(3 \%<e e<25 \%$ in favor of the $(S)$-product) were observed for the epoxidation of styrene and poorly activated styrenes derivatives. On the contrary, high reverse enantioselectivity ( $80 \%$ in favor of the $(R)$-isomer) was observed for the epoxidation of para-methoxystyrene by $\mathrm{KHSO}_{5}$ (Fig. 6), which constitutes the highest enantioselectivity ever reported to date for an epoxidation reaction catalyzed by an ArM [46].

\subsubsection{Dihydroxylation}

Dihydroxylation of double bonds is another oxidation reaction of synthetic interest, that is generally carried out in organic solvents using most often a high-oxidation-state transition metal such as osmium tetroxide as an oxidant [58]. In a biological medium, this reaction either requires a two-step process involving the first epoxidation by a monooxygenase followed by hydrolysis of the epoxide by an epoxide hydrolase or a one-step dihydroxylation, like for example Rieske dioxygenases that use $\mathrm{O}_{2}$ as an oxidant in a complex process that also involves electron transfer from a biological reductant (generally $\mathrm{NADH}$ ) mediated by a reductase, a ferredoxin containing [2Fe-2S] Rieske cluster [59]. There is thus a double interest to find artificial metalloenzymes that would perform such a reaction in one step under eco-compatible conditions.

The first team that tackled this challenge in 1983, was that of Okano et atet al., who used serum albumins derived ArMs for this purpose. They inserted osmium tetroxide into BSA and the formed ArM catalyzed the stereoselective cis-bis- 
hydroxylation of up to 40 equivalents of $\alpha$-methylstyrene by ${ }^{t} \mathrm{BuOOH}$ with $68 \%$ $e e$ in favor of the $(S)$-diol [60]. Later, Ward and coll. also prepared an osmium tetroxide-loaded SAV that catalyzed enantioselective olefin cis-dihydroxylation with up to $97 \%$ ee in favor of the $(R)$-product at $\sim 20$ TON in the presence of potassium ferricyanide [61].

Finally, Ménage et at.et al. also took advantage of their $\mathrm{NikAFeN}_{2} \mathrm{Py}_{2}$ artificial metalloenzyme, and, by combining model chemistry and protein X-ray crystallography, they were able to study the intramolecular dihydroxylation of one of the $N$-benzyl substituents of the [ $N$-benzyl- $N^{\prime}$-(2-hydroxybenzyl)- $N, N^{\prime}$ ethylenediaminediacetic acid] ligand. Indeed, the bound complex was able to activate dioxygen in the presence of a reductant (Dithiothreitol, DTT), leading to the formation of catechol as the sole product. The X-ray diffraction structure determination of four of the catalytic cycle intermediates and the end product showed that the hydroxylation reaction implicated an iron peroxo, which was also observed in natural iron monooxygenases (Fig. 8) [62].

\section{Fig. 8}

Intramolecular dihydroxylation of one of the $\mathbb{N}$-benzyl substituents of the [ $\mathrm{AN}$ benzyl- $\mathbb{N}^{\prime} N^{\prime}$-(2-hydroxybenzyl)- $\mathbb{N}, N^{\prime} N, N^{\prime}$-ethylenediaminediacetic acid] ligand in the reaction of the NikAFeN $\mathrm{Py}_{2}$ complex with $\mathrm{O}_{2}$ in the presence of DTT as a reductant 

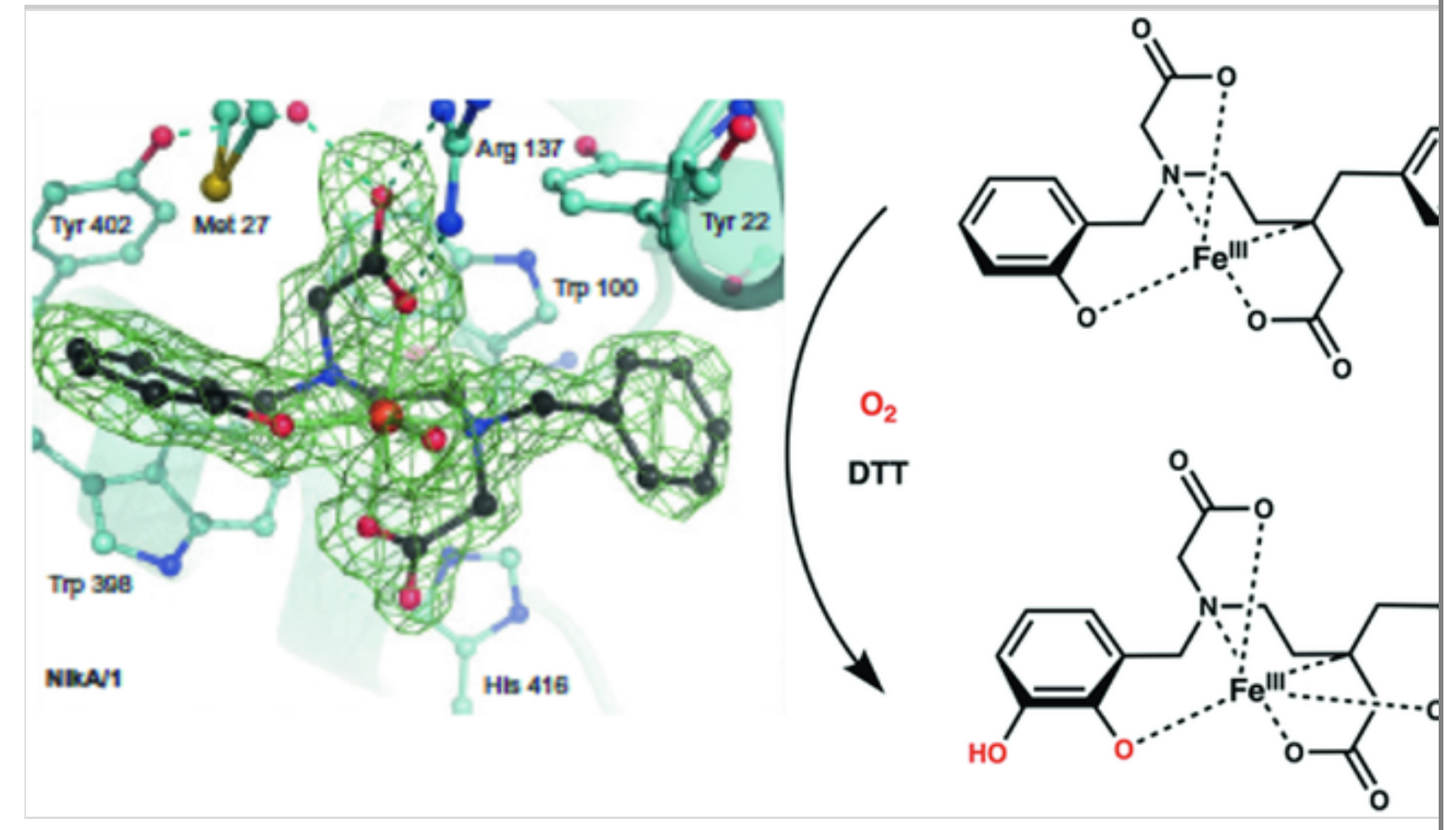

\subsection{Reductions}

\subsubsection{Hydrogen Production}

With the inevitable future shortage of fossil fuels, it becomes crucial to develop alternative energy sources and hydrogen appears to possess almost ideal features to fulfill this challenge. Moreover, hydrogen is a clean and renewable energy source. Hydrogen is still essentially produced by steam reforming of methane but other fossil fuel independent processes are actively investigated such as water splitting.

In nature hydrogen metabolism is ensured by enzymes called hydrogenases that catalyze the interconversion between protons and dihydrogen. Hydrogenases are metalloenzymes containing iron and/or nickel in their active site. One of the best-studied hydrogenases is the [FeFe]-hydrogenase. Its active site (the $\mathrm{H}$ cluster) contains a diiron cluster connected to a [4Fe4S] cluster via a cysteine bridge (Fig. 9). The latter cluster serves as an electron reservoir during the catalytic cycle while the former cluster is responsible for proton activation and reduction. 
Fig. 9

Structure of the active site of [FeFe]-hydrogenase; structures of iron cluster precursors used to build up iron-based artificial hydrogenases

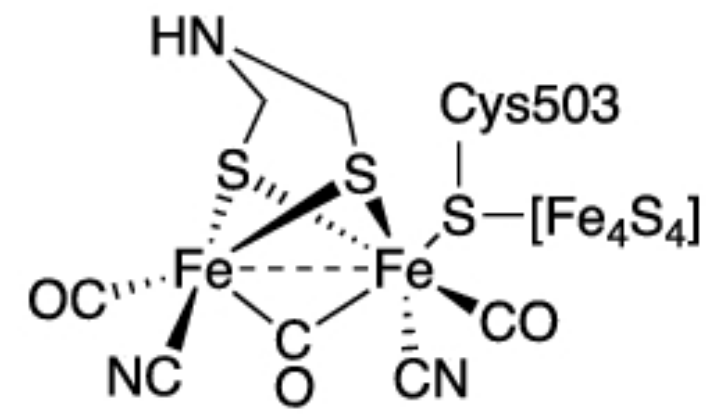

[FeFe]-hydrogenase active site

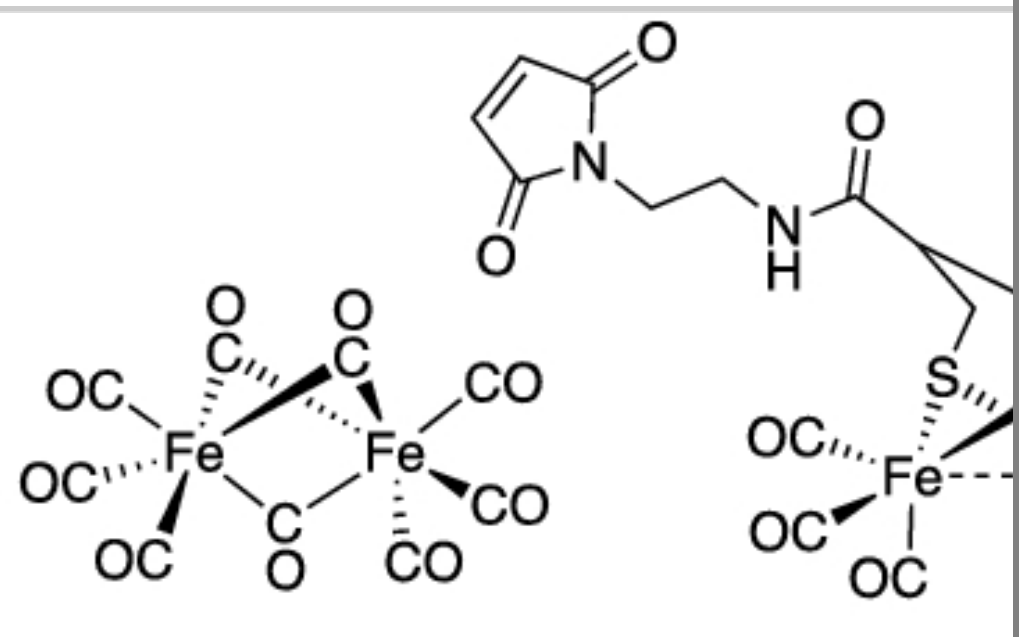

FeFe1

A lot ofMany efforts have been devoted to the design of low molecular weight mimics of hydrogenases active site (see Chap. 3 ). However, these molecules hardly mimic the second coordination sphere of the metal center, and even less the outer sphere provided by the protein environment. Embedding active site models of hydrogenase in protein scaffolds may lead to more efficient catalysts, shielding the metal center against degradation and enabling electron/proton tunneling to the active site [63].

The first strategy to design a functional artificial hydrogenase consisted of incorporating a simplified diiron carbonyl dithiolate cluster into an appropriate protein scaffold to mimic [ $\left.\mathrm{FeFe}_{j}^{+}\right]$-hydrogenase. In the seminal work published by Hayashi and coworkers, apo-cytochrome c (Cyt c) was chosen as a protein scaffold [64]. When devoid of its natural prosthetic group, heme c, Cyt c displays a CXXC motif that can mimic the bridging dithiolate ligand of the diiron subcluster (Fig. 10).

Fig. 10

Apo-proteins displaying a CXXC motif for bridging a diiron hexacarbonyl cluster. Left: apo-cytochrome c; right: C-terminal peptide fragment of cytochrome c556 


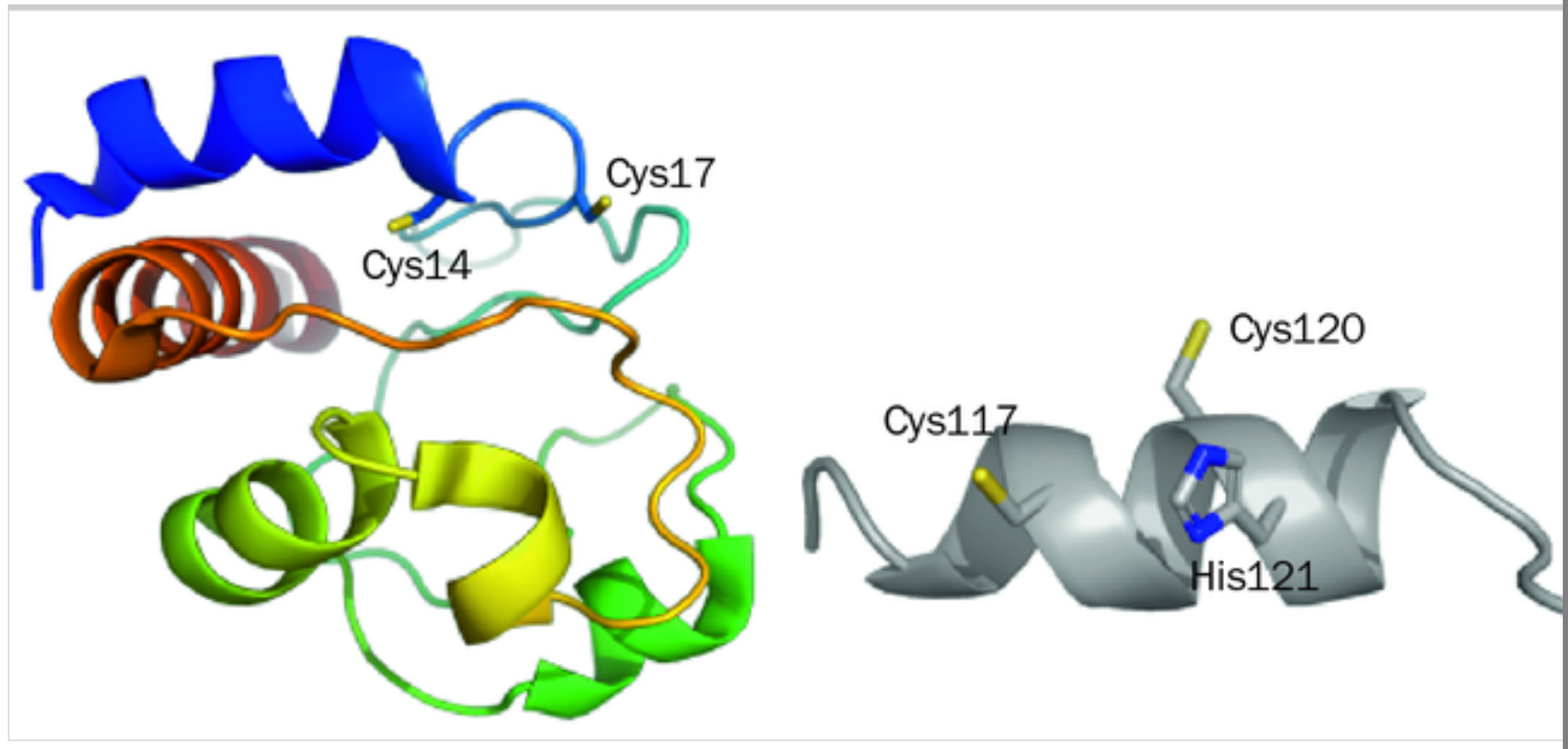

Indeed, the reaction of $\mathrm{Fe}_{2}(\mathrm{CO})_{9}$ with apo-Cyt $\mathrm{c}$ afforded a metalloprotein where the diiron hexacarbonyl cluster is bridged by two sulfur atoms provided by the cysteine side chains. The hydrogenase activity of the biohybrid was tested under photochemical conditions using ascorbate as a sacrificial electron donor and $\left[\mathrm{Ru}(\mathrm{bpy})_{3}\right]^{2+}$ as photosensitizer (Fig. 11). A TON of 80 was measured after $2 \mathrm{~h}$ at $\mathrm{pH} 4.7$.

\section{Fig. 11}

Photocatalytic reduction of $\mathrm{H}^{+}$or $\mathrm{CO}_{2}$ using $\left[\mathrm{Ru}(\mathrm{bpy})_{3}\right]^{2+}$ as photosensitizer and ascorbate as sacrificial electron donor

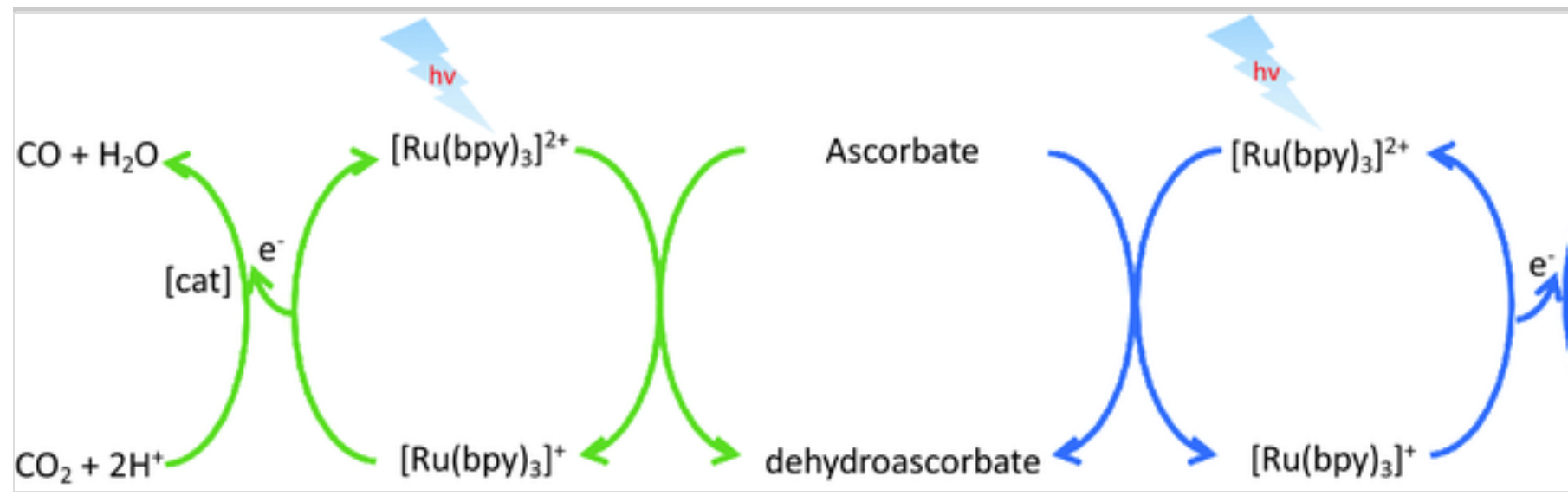

Along the same line, the same team reported the use of a hexadecapeptide 
located at the $\mathrm{C}$-terminus of cytochrome $\mathrm{c}_{556}$ presenting a $\mathrm{CXXC}$ motif assorted by a neighboring histidine that was used to coordinate a ruthenium-based photosensitizer (Fig. 10) [65]. Photocatalytic reduction of $\mathrm{H}^{+}$was effective at $\mathrm{pH} 8.5$ with a TON of 9 after $2 \mathrm{~h}$.

The Q96C mutant of heme-free nitrobindin (NB) was also employed as protein scaffold to covalently anchor the model FeFe1 of the $\left[\mathrm{Fe}_{2}\right]$-subsite of [FeFe]hydrogenase via reaction between its maleimide group and the thiol of C96 [66]. Photocatalytic reduction of $\mathrm{H}^{+}$was effective at $\mathrm{pH} 4.0$ with a TON of 130 after $6 \mathrm{~h}$.

Apo-ferritin (Fr) was also used to host diiron hexacarbonyl dithiolate clusters inside its cavity that naturally presents numerous metal-binding sites [67]. Loading of $\mathbf{F e F e} 2$ within the cavity of apo-Fr was readily achieved at neutral $\mathrm{pH}$ without alteration of its structure. Light-driven reduction of $\mathrm{H}^{+}$afforded $\mathrm{H}_{2}$ with a TON of 31 after $3 \mathrm{~h}$ at pH 5 to be compared with free $\mathbf{F e F e} 2$ that gave a TON of 3.6 in the same conditions. It was shown that, since the photosensitizer remained outside the cavity, electron tunneling through the Fr shell necessarily followed a multistep pathway.

The N-hydroxysuccinimidyle ester derivative of FeFe3 was conjugated to calf thymus histone $\mathrm{H} 1$ whose $\mathrm{C}$-terminal domain contains numerous lysine residues and is intrinsically disordered [68]. Conjugation induced a significant conformational change with formation of $\alpha$-helices. A change in the size and density of the nanoparticles was also observed. This biohybrid was able to catalyze the light-driven production of $\mathrm{H}_{2}$ with a TON of 359 after $6 \mathrm{~h}$ at $\mathrm{pH} 5.0$ to be compared with a TON of 54 for the precursor.

Nevertheless, all the artificial hydrogenases containing a diiron hexacarbonyl dithiolate active site suffer from progressive degradation upon illumination even if the protein scaffold provides some kind of protection resulting in increased catalyst lifetime. This is why Ghirlanda's team proposed to exploit the hydrogen reduction ability of cobalt protoporphyrin IX (CoPPIX, Fig. 12) to build up artificial hydrogenases. Considering the high similitude between heme $\mathrm{b}(=\mathrm{Fe}-$ protoporphyrin IX) and CoPPIX, Ghirlanda and coworkers selected two hemoproteins, namely $\mathrm{Mb}[69]$ and cytochrome $\mathrm{b}_{562}\left(\mathrm{Cyt}_{562}\right)$ [70] to build up Co-based artificial hydrogenases. 


\section{Fig. 12}

Left: Structure of Co-PPIX; Đown, leftmiddle: X-ray structure of Cyt C-CoPPIX;; right: X-ray structure of $\mathrm{Cyt} \mathrm{b}_{562}$

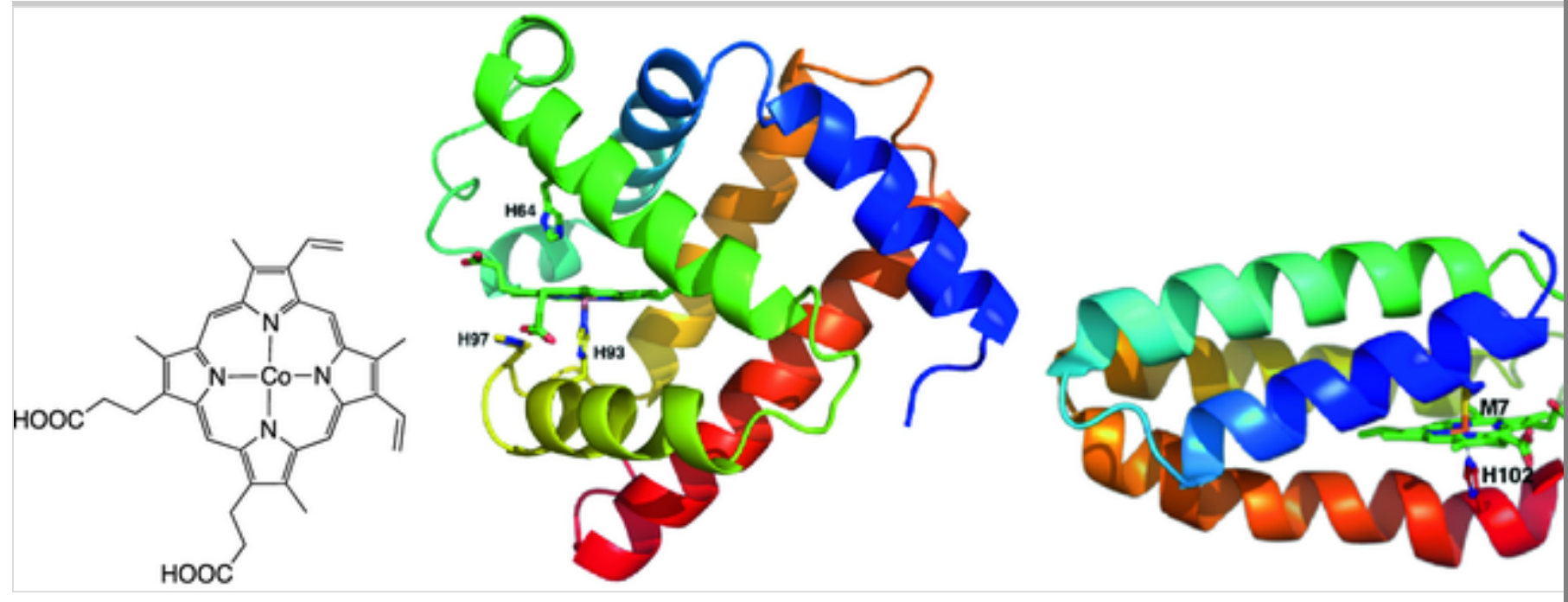

In $\mathrm{Mb}$, the iron of heme $\mathrm{b}$ is pentacoordinated, with $\mathrm{H} 93$ occupying one of the axial positions (Fig. 12). In Cyt $\mathrm{b}_{562}$, the iron ion is hexacoordinated, the two axial positions being occupied by H102 and M7 (Fig. 12). Mb-CoPPIX catalyzed the light-driven production of $\mathrm{H}_{2}$ with a TON of 243 after $12 \mathrm{~h}$ at $\mathrm{pH}$ 6.5 and 518 at pH 7.0, which is 3 times higher than that CoPPIX alone. The double mutant H64A/H97A was even more active with a TON of 512 at pH 6.5. Embedding of CoPPIX into WT apo-Cyt $\mathrm{b}_{562}$ did not increase the catalytic performance of the metal complex in light-driven $\mathrm{H}_{2}$ production $(\mathrm{TON}=120$ after $8 \mathrm{~h}$ at $\mathrm{pH} 7$ ). However, mutation of the coordinating M7 by alanine or aspartate led to more efficient hybrid catalysts with TONs of 310 and 270, respectively. Photocatalytic production of $\mathrm{H}_{2}$ was also effective under aerobic conditions, which opens attractive avenues in the future development of environmentally benign artificial hydrogenases.

\subsubsection{Carbon Dioxide Hydrogenation and Reduction}

Carbon dioxide emissions owing to fossil fuel consumption are a real environmental threat because of the associated greenhouse effect. On the other hand, conversion of $\mathrm{CO}_{2}$ into added-value chemicals such as $\mathrm{CO}$ or $\mathrm{HCOOH}$ may contribute to counteract this threat [71]. 
$\mathrm{CO}_{2}$ Reduction

In nature, the interconversion between $\mathrm{CO}_{2}$ and $\mathrm{CO}$ is catalyzed by [NiFe] carbon monoxide dehydrogenase $(\mathrm{CODH})$ via a two-electron, proton-coupled process [72]. An ArM catalyzing the selective two-electron $\mathrm{CO}_{2}$ reduction to $\mathrm{CO}$ in water was assembled by dative anchoring of $[\mathrm{Ni}(\text { cyclam })]^{2+}$ to the single histidine residue at position 83 of WT azurin (WT-CuAz) or to the double mutant H83Q/Q107H (Fig. 13) [73].

Fig. 13

Structure of $\left[\mathrm{Ni}(\text { cyclam) }]^{2+}\right.$; X-ray structures of WT-CuAz and H83Q/Q107H mutant
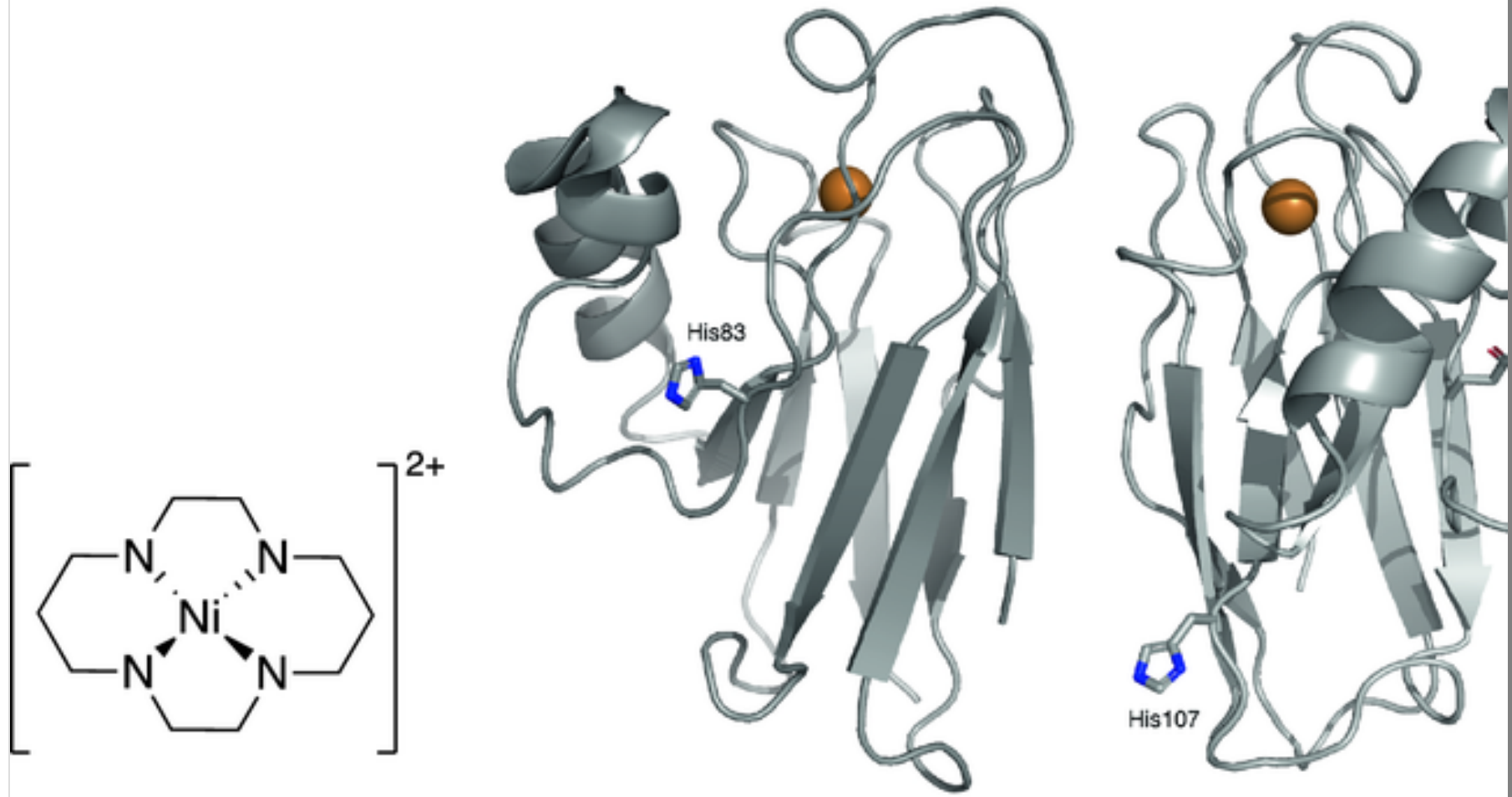

Electrocatalytic reduction of $\mathrm{CO}_{2}$ was observed at a slightly more positive potential for $\mathrm{H} 83 \mathrm{Q} / \mathrm{Q} 107 \mathrm{H} \mathrm{CuAz}-[\mathrm{Ni}($ cyclam)] compared to free $[\mathrm{Ni}(\text { cyclam })]^{2+}$. Moreover, the redox-active copper ion in the ArM appeared to serve as electron relay/storage during catalysis. Photocatalytic reduction of $\mathrm{CO}_{2}$ catalyzed by $\mathrm{CuAz}-[\mathrm{Ni}(\mathrm{cyclam})]$ was also achieved in solution in the presence of $\left[\mathrm{Ru}(\mathrm{bpy})_{3}\right]^{2+}$ as photoinitiator and ascorbate as sacrificial electron donor (Fig. 11). Most interestingly, ArMs were much more selective for $\mathrm{CO}_{2}$ reduction 
vs. $\mathrm{H}^{+}$reduction as the produced $\mathrm{CO} / \mathrm{H}_{2}$ molar ratios were significantly larger than those obtained with the free nickel complex. Also, the ArM built up from WT Az was more selective than the double mutant, likely owing to the partially buried position of $\mathrm{H} 83$.

A light-driven ArM to catalyze $\mathrm{CO}_{2}$ reduction was further built up by simultaneous anchoring of $\left[\mathrm{Ru}(\mathrm{bpy})_{3}\right]^{2+}$ and $[\mathrm{Ni}(\mathrm{cyclam})]^{2+}$ to $\mathrm{Az}[74]$.

The delete empty line above former one was covalently attached by reaction of the epoxide derivative (Fig. 14) to Az variants carrying a surface-exposed cysteine at three different positions to study the dependence of the distance between $\mathrm{Ru}$ and $\mathrm{Ni}$ on the photocatalytic activity. The most active ArM was built up from the S78C Az mutant (Fig. 14) that exclusively reduced $\mathrm{CO}_{2}$ and not $\mathrm{H}^{+}$under photoirradiation. The mechanism of reduction was elucidated thanks to photophysical studies.

Fig. 14

Photosensitizer precursor and X-ray structure of S78C CuAz 

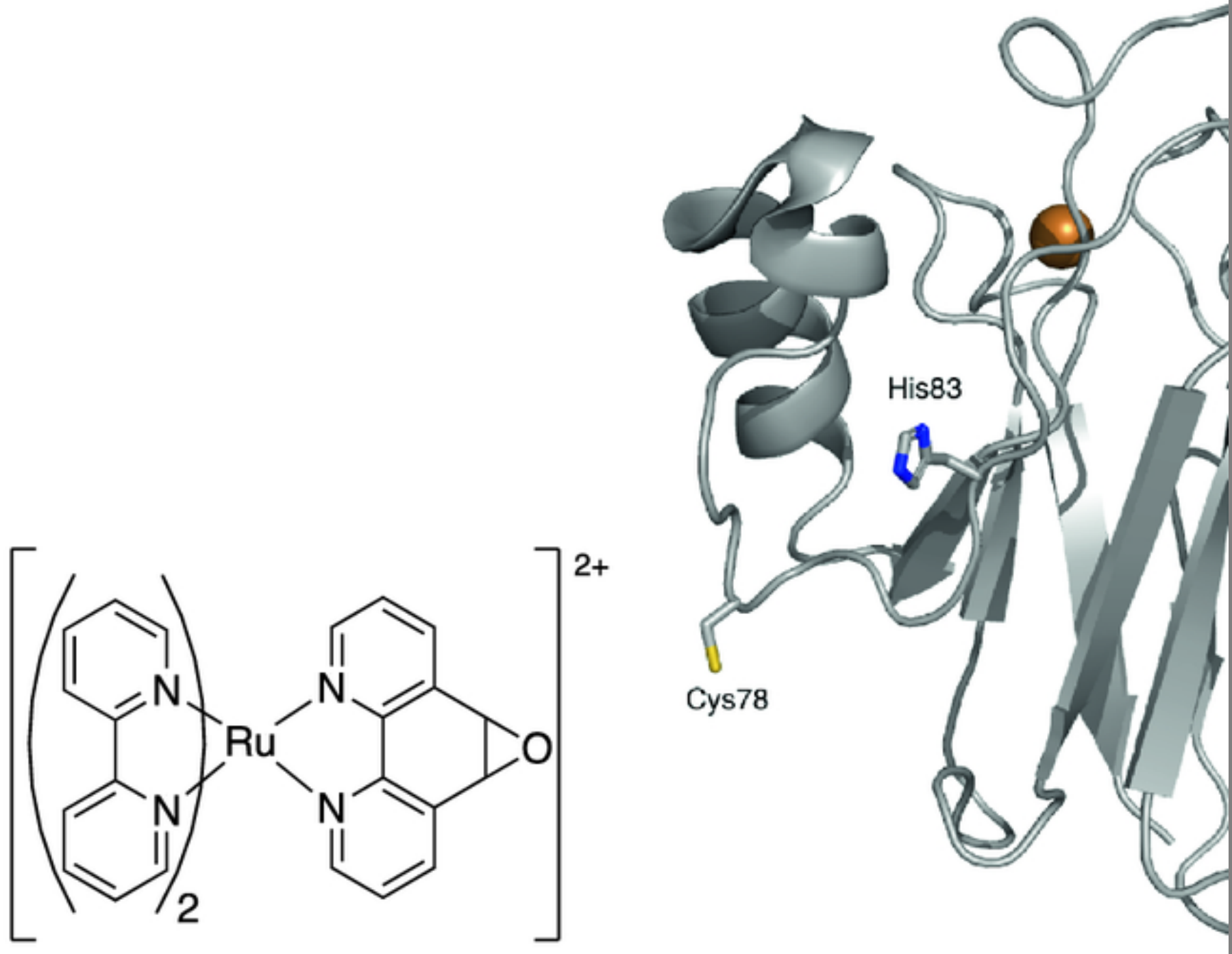

\section{$\mathrm{CO}_{2}$ Hydrogenation}

Formate dehydrogenases (FDHs) catalyze the reduction of $\mathrm{CO}_{2}$ to formate and the reverse oxidation of formic acid to $\mathrm{CO}_{2}$. The mechanism of NADHdependent FDHs involves hydride transfer from NADH to $\mathrm{CO}_{2}$ [75]. An ArM catalyzing the hydrogenation of $\mathrm{CO}_{2}$ to formic acid was built up by covalent anchoring of the bis(diphosphine)Rh(I) complex to lactococcal multidrugresistant regulator (LmrR, Fig. 15) [76].

\section{Fig. 15}

Left: structure of bis(diphosphine)Rh(I) complex; Right: X-ray crystal structure of LmrR-[Rh] showing covalent linkage between C89 of one of the monomers and one of the maleimide groups of the complex (disorder is observed for the other linkage) 

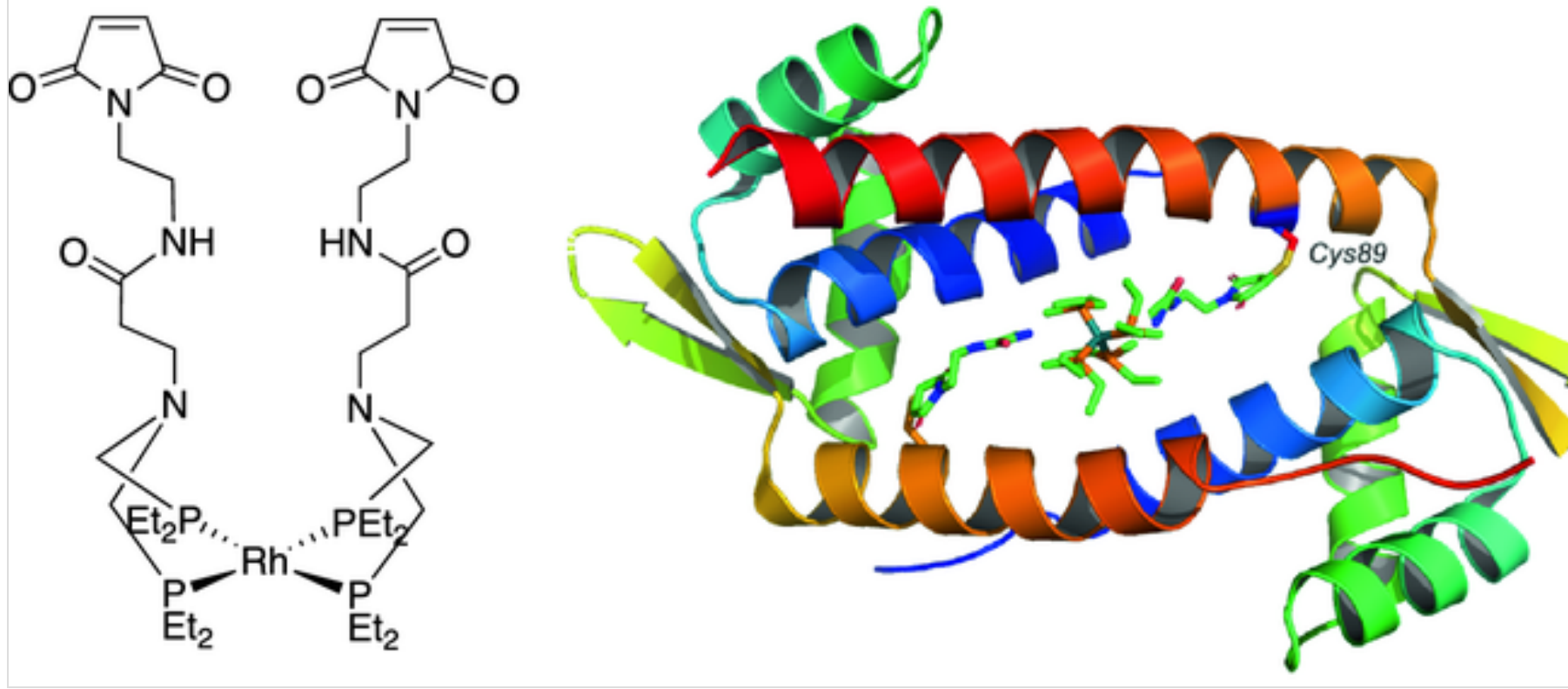

This protein scaffold has a homodimeric structure creating a cavity to host the metal center. A cysteine residue was engineered at position 89 of LmrR. This position was chosen so that, in the dimer, the cysteines were located at a distance compatible with the double anchoring of the rhodium complex by reaction of its two maleimides. Indeed, under appropriate reactional conditions, a protein conjugate with a 2:1 monomer:rhodium ratio was formed with the complex almost fully occupying the cavity of LmrR (Fig. 15). While the bis(diphosphine) $\mathrm{Rh}(\mathrm{I})$ complex was unable to catalyze the hydrogenation of $\mathrm{CO}_{2}$ on its own, LmrR-[Rh] catalyzed the formation of formic acid upon exposure to stoichiometric mixtures of $\mathrm{CO}_{2}$ and $\mathrm{H}_{2}$ in bicarbonate solution. A catalytic cycle involving the successive formation of $\mathrm{Rh}$ (III)-dihydride and $\mathrm{Rh}(\mathrm{I})$-monohydride intermediates was proposed. The difference of catalytic activity between the free complex and LmrR-[Rh] was tentatively explained by the assumption that only LmrR-[Rh] was able to transfer a hydride to $\mathrm{CO}_{2}$ likely due to favorable second and outer-sphere interactions with the substrate.

\subsubsection{Enantioselective Cyclic Imine Reduction}

Enantiopure amines are key compounds, found in numerous pharmaceuticals and agrochemicals to name a few applications. A strategy to access these compounds relies on enantioselective reduction of imines catalyzed by imine reductases [77]. However, natural imine reductases are still scarce, leaving room 
for the development of artificial imine reductases.

Nearly all the examples reported in the literature so far deal with the production of salsolidine by asymmetric transfer hydrogenation (ATH) of its imine precursor (Scheme 1). Salsolidine is a tetrahydroisoquinoline alkaloid produced by plants of the genus Salsola. The $(R)$-enantiomer of salsolidine has been found as a potent inhibitor of monoamine oxidase A [78]. Plant extracts were also shown to display significant choline esterase inhibition [79].

\section{Scheme 1}

Transfer hydrogenation of salsolidine precursor

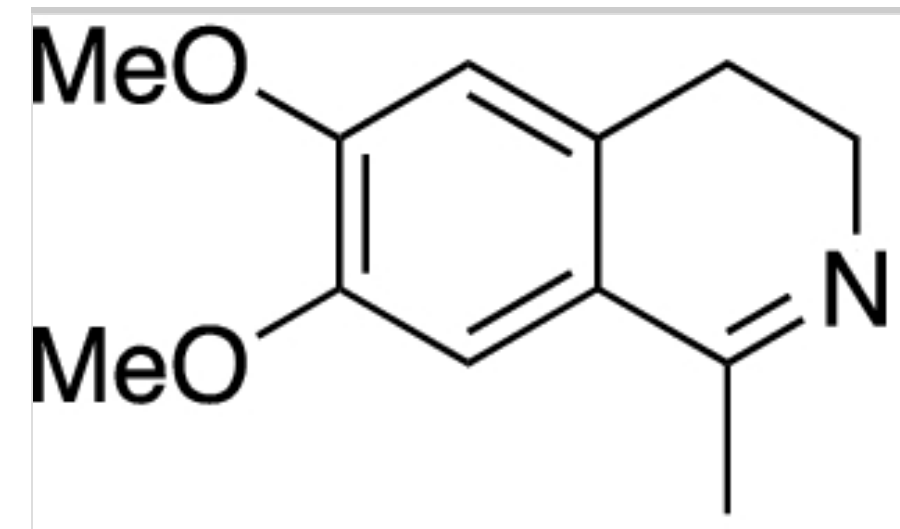

\section{[Red]}

$\mathrm{MeO}$

$\mathrm{MeO}$

\section{Streptavidin as Protein Scaffold}

The first ArM catalyzing the ATH of the salsolidine precursor was designed from the biotin - SAV system [80]. The biotin derivative BTN-[Ir] (Fig. 16) carrying half-sandwich iridium(III) complex comprising a chelating beta-amino sulfonamide ligand was synthesized and assembled by supramolecular anchoring to WT-SAV. WT-SAV $\subset$ BTN-[Ir] catalyzed the quantitative conversion to salsolidine with an enantiomeric excess (ee) of $57 \%$ for the (RR)isomer using formate as hydrogen donor. Subsequently, an array of mutants was prepared by saturation mutagenesis at position S112. The crystal structure of the S112A-SAV $\subset$ BTN-[Ir] biohybrid showed that the biotin derivative occupied the biotin-binding site and that A112 was located at a short distance from the metal center (Fig. 16). Moreover, the absolute configuration of iridium in the 
biohybrid was shown to be $\mathrm{S}$. The ee reached $96 \%$ for the (RR)-isomer with the S112A mutant while the enantioselectivity was nearly fully reversed with the S112K-SAV mutant ( $e e=78 \%$ for the (SS)-isomer). Furthermore, it was found that K121 from an adjacent monomer might act as an external proton donor during the catalytic cycle.

Fig. 16

Left: structure of BTN-[Ir]; right: X-ray structure of S112A-SAV $\subset$ BTN-[Ir]
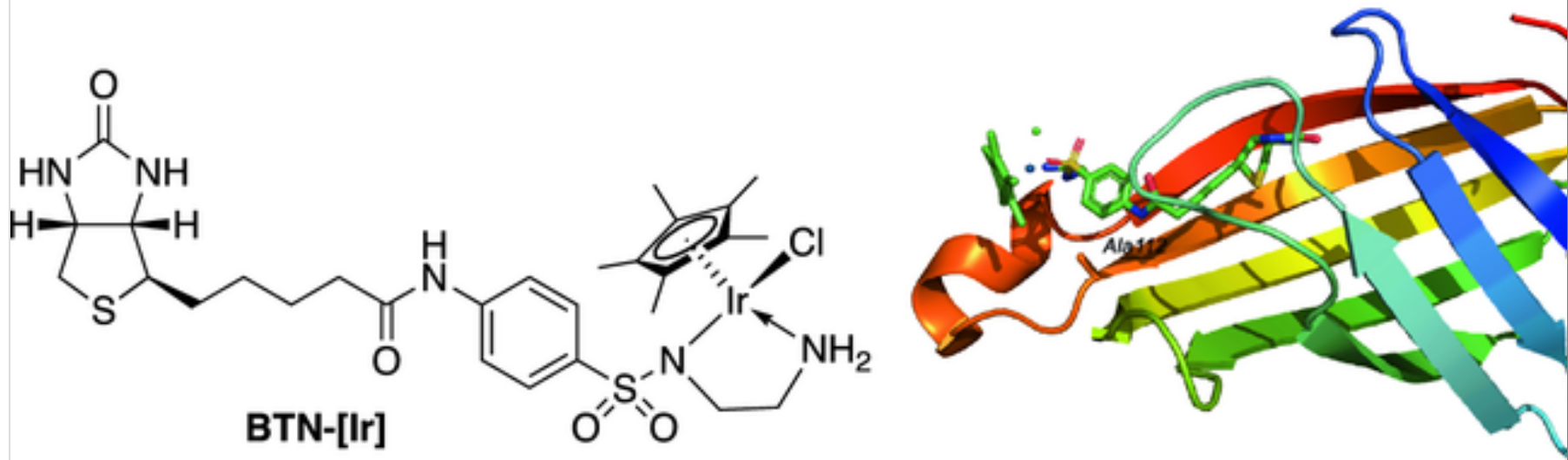

Computational and saturation kinetics studies were further performed to understand the opposite enantioselectivities afforded by both mutants [81]. It appeared that the final absolute configuration of the salsolidine product was dictated by the configuration of the metal center which was initially imposed by the protein environment.

Still, the ArM resulting from supramolecular anchoring of BTN-[Ir] to WTSAV catalyzed the ATH at a much slower rate than the free complex [82]. To circumvent this issue, aminoacids K121, R84, and D67 located at the vicinity of the metal center were systematically mutated. The best mutant in terms of $k_{\text {cat }}$ and $K_{m}$ measured on 1-methyl-3,4-dihydroisoquinoline was

R84A/S112A/K121A where the positively charged K and R aminoacids were replaced by the small and neutral alanine.

Other artificial imine reductases were built up by combining supramolecular and dative anchoring of half-sandwich rhodium(III) or iridium(III) to SAV [83]. This time, the biotin entity was linked to the ancillary cyclopentadienyl ligand rather than to the $\mathrm{N}^{\wedge} \mathrm{N}$ chelating ligand (Fig. 17). A histidine was introduced at 
positions S112 or K121 of SAV to provide a coordination site for rhodium or iridium once in the binding pocket of the protein host and to activate it. The Xray structure of the resulting ArMs showed that the rhodium ion was indeed coordinated to the imidazole of $\mathrm{H} 112$ of the same monomer while it was coordinated to the imidazole side chain of a neighboring monomer in $\mathrm{K} 121 \mathrm{H}$ SAV (Fig. 17).

\section{Fig. 17}

Up: iridium precursor for double anchoring to SAV. Down: left: X-ray structure of $\mathrm{K} 121 \mathrm{H}-\mathrm{SAV} \subset[\mathrm{Rh}]$ (Two symmetry-related monomers); right: X-ray structure of $\mathrm{S} 112 \mathrm{H}-\mathrm{SAV} \subset[\mathrm{Rh}]$

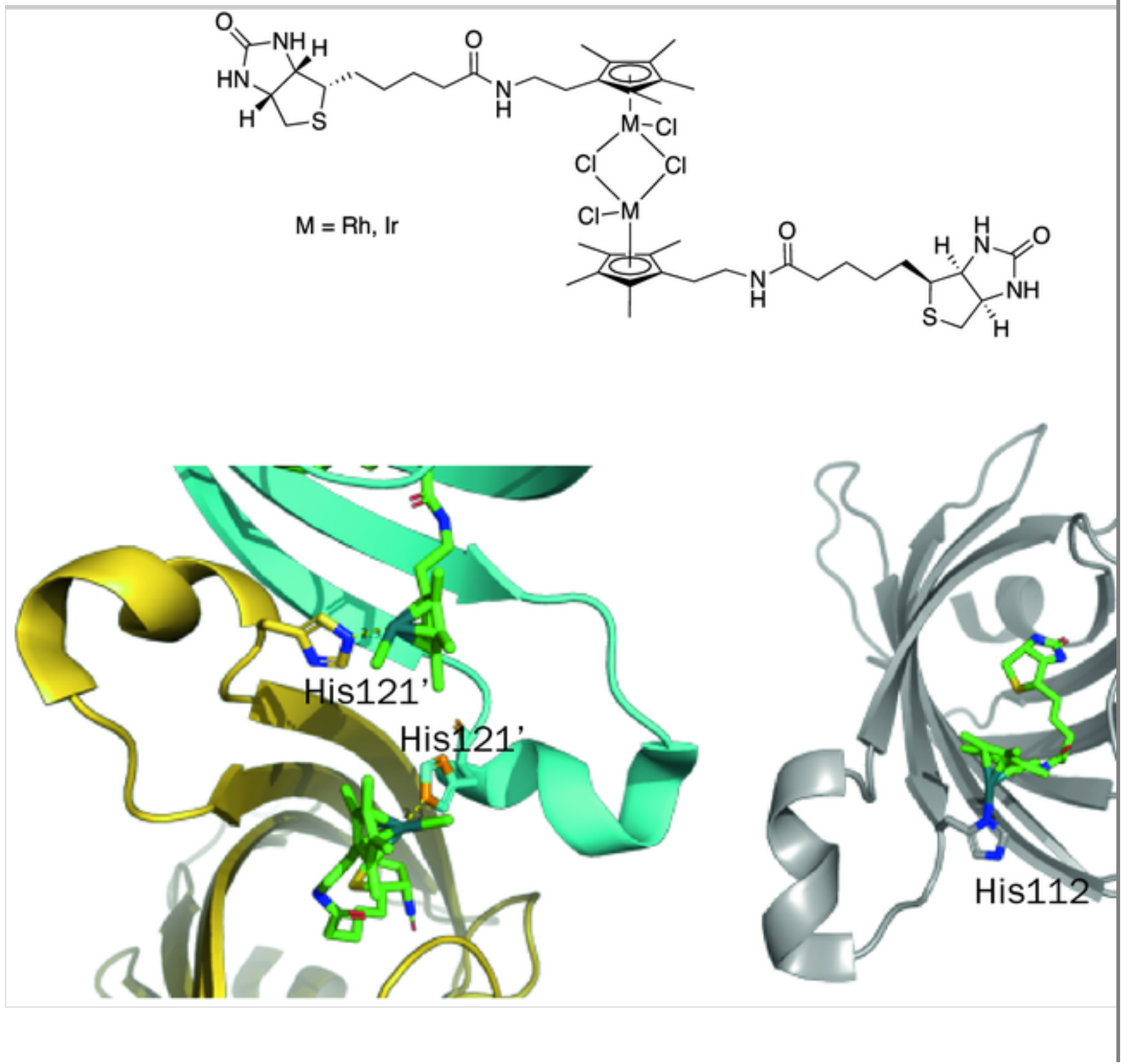


Embedding the rhodium and iridium complexes into WT-SAV, S112H-SAV and K121H-SAV afforded artificial imine reductases whose efficacy in the ATH of the salsolidine precursor differed markedly from the complexes alone. The most enantioselective ArM resulted from the embedding of the rhodium cofactor into $\mathrm{K} 121 \mathrm{H}-\mathrm{SAV}$ yielding mainly (RR)-salsolidine with $79 \%$ ee. Interestingly, inversion of selectivity was again observed with S112H-SAV since (SS)salsolidine was preferentially produced with an $e e$ of $55 \%$.

Directed evolution was applied to the ArM resulting infrom the supramolecular anchoring of the iridium complex BTN-[Ir] to SAV [84]. Aminoacids located at close range to the metal cofactor were subjected to iterative saturation mutagenesis. Catalysis tests were directly run on cell-free extracts supplemented with a diamide to prevent catalyst poisoning by glutathione [85]. This strategy allowed to identify a mutant affording an ee of $50 \%$ for (SS)salsolidine with $75 \%$ conversion. Another mutant displayed an 8 -fold increase in $k_{\text {cat }}$ compared to the cofactor alone.

Recently, to overcome the previously noticed dependence of SAV-to-Ir ratio on the enantioselectivity owing to the tetrameric nature of SAV, a single chain dimeric streptavidin (scdSAV) was engineered followed by genetic optimization of positions 112 and 121 [86]. Two monovalent scdSAVs (scdSAVmv1 and scdSAVmv2) were also produced to study the influence of the second cofactor on the catalytic properties of the ArM. X-ray structural analysis showed that the iridium cofactor adopts two different conformations in scdSAV, one being more solvent-exposed than the other. Conversely, the Ir cofactor adopts only one conformation once bound to its binding pocket. Under optimized conditions, an ArM affording a high TON and high eeee were identified. Most importantly, ATH experiment could be extended to the preparative scale without detrimental effects on the conversion and $e e$. This breakthrough lets us anticipate biotechnological developments of artificial imine hydrogenases in the near future.

\section{Carbonic Anhydrase as Protein Scaffold}

The half-sandwich iridium complex CA-[Ir] bearing an arylsulfonamide entity (Fig. 18) was synthesized and assembled to hCAII [87]. Binding of the metal cofactor by coordination to the catalytic zinc ion was assessed by X-ray 
structural analysis (Fig. 18) that also highlighted the low occupation of the metal cofactor in the binding site. WT-hCAII $\subset \mathbf{C A}$-[Ir] catalyzed the transfer hydrogenation of the salsolidine precursor with $82 \%$ conversion $(\mathrm{TON}=9)$ and $70 \%$ ee in (SS)-salsolidine. The catalytic performances of the ArM were further improved by mutating positions 91 and 170 to alanines.

\section{Fig. 18}

Left: structure of the iridium catalyst to be anchored to hCA II; right: X-ray structure of WT-hCAII $\subset$ CA-[Ir]
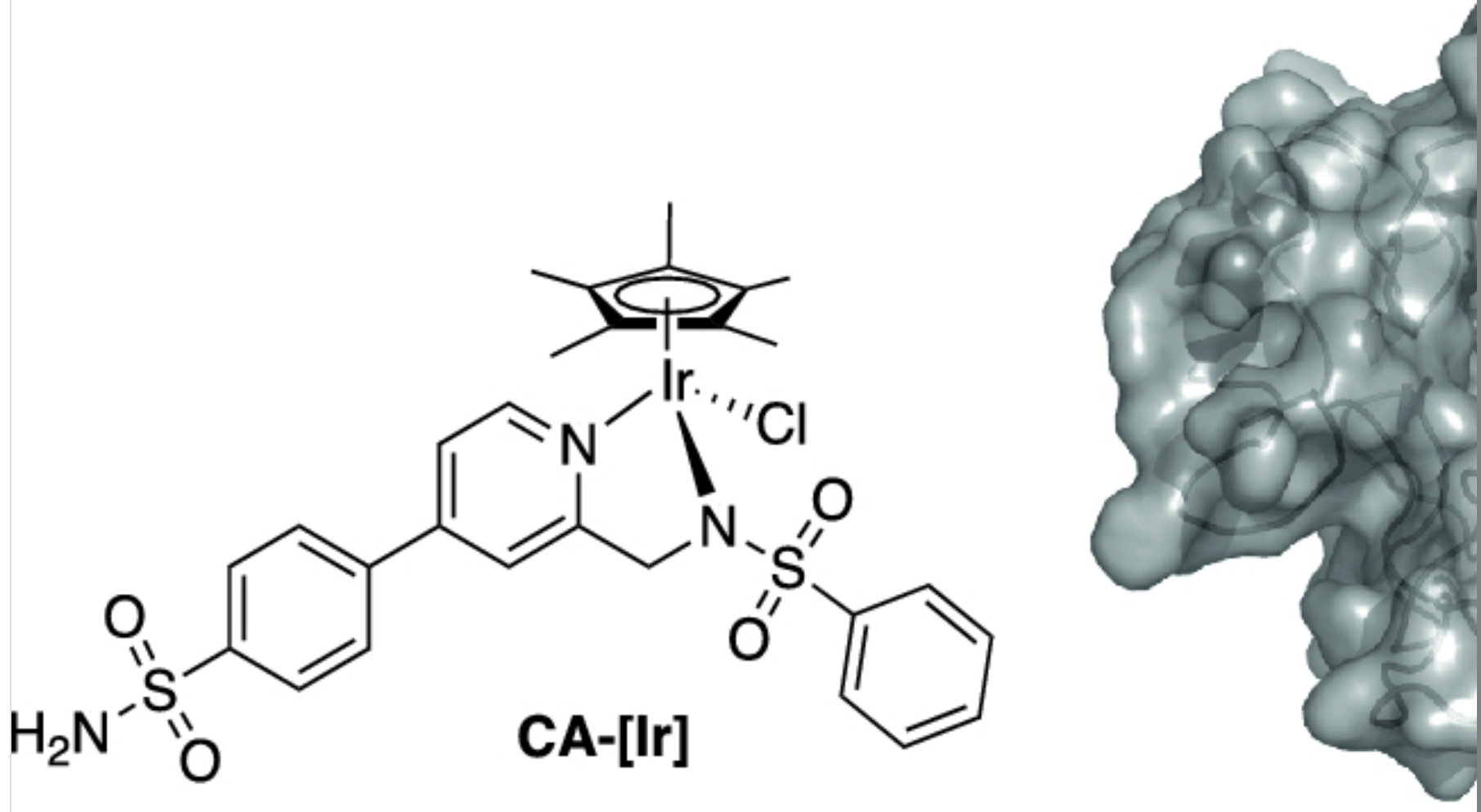

Rosetta protein design software was further applied to increase the affinity of the iridium cofactor for CA II and in turn to increase the catalytic performances of the ArM [88]. Up to eight combinations of mutations were produced and assembled to CA-[Ir]. The best mutant afforded (SS)-salsolidine with $94 \%$ ee and a TON of 98. Slight improvement of the selectivity was observed by replacing one of the methyl substituents of the cyclopentadienyl ligand by a bulkier propyl group. 


\subsection{Artificial Metalloenzymes for Polymerization Catalysis}

\subsubsection{Polymerization of Phenylacetylene}

Polyacetylenes are a group of conjugated polymers with unique electrical, (nonlinear) optical, optoelectronic, magnetic, chiroptical, (enantio)permselective, and photolithographic properties. Prior to the design of ArMs catalyzing the polymerization of phenylacetylene (PA), it had been shown that PA could be polymerized in water in the presence of various rhodium complexes, for instance $[\mathrm{Rh}(\mathrm{L}) \mathrm{Cl}]_{2}$ (with $\mathrm{L}=\mathrm{nbd}$; cod) and that the resulting polymers displayed up to $100 \%$ cis configuration depending on the rhodium catalyst [89].

The first ArM to catalyze a polymerization reaction was built up by dative anchoring of $\mathrm{Rh}(\mathrm{nbd})$ entities to horse apo-Fr as protein scaffold [90]. Apoferritin is a multimeric protein made of 24 identical subunits forming spherical nanoparticles of $8 \mathrm{~nm}$ inner diameter. Metallation of apo-Fr by $[\mathrm{Rh}(\mathrm{nbd}) \mathrm{Cl}]_{2}$ (Fig. 19) afforded the metalloprotein Fr-[Rh $]_{\mathrm{n}}$ containing $57.5 \pm 3.5 \mathrm{Rh}$ per Fr in average. The $3 \mathrm{D}$ structure of $\mathrm{Fr}-[\mathrm{Rh}]_{\mathrm{n}}$ was solved by X-ray crystallography. Each subunit was shown to contain three Rh ions, two of them being coordinated by the imidazole of His residues while the last one was coordinated by $\mathrm{C} 48$ and E45 residues. Furthermore, a change of hapticity from $\eta^{4}$ to $\eta^{2}$ was observed for the nbd ligand since the other double bond underwent nucleophilic addition of the thiol function of Cys (Fig. 20). All the rhodium ions arewere located inside the cavity of Fr.

\section{Fig. 19}

Rhodium precursors used to build up artificial enzymes catalyzing the polymerization of PA 

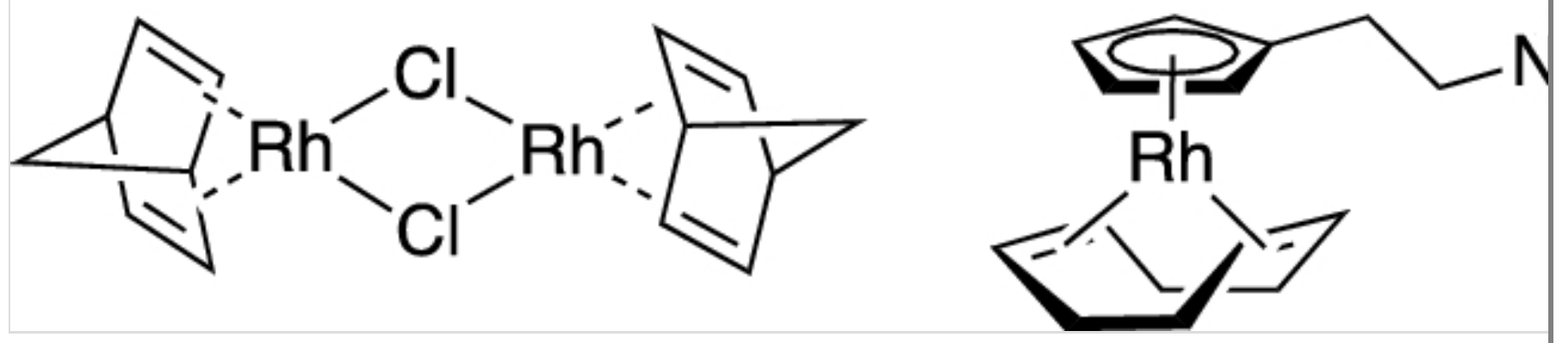

Fig. 20

Left: X-ray structure of a $\mathrm{Fr}-[\mathrm{Rh}]_{\mathrm{n}}$ subunit showing the three coordination sites of rhodium; right: Hypothetical active site of Fr-[Rh]n
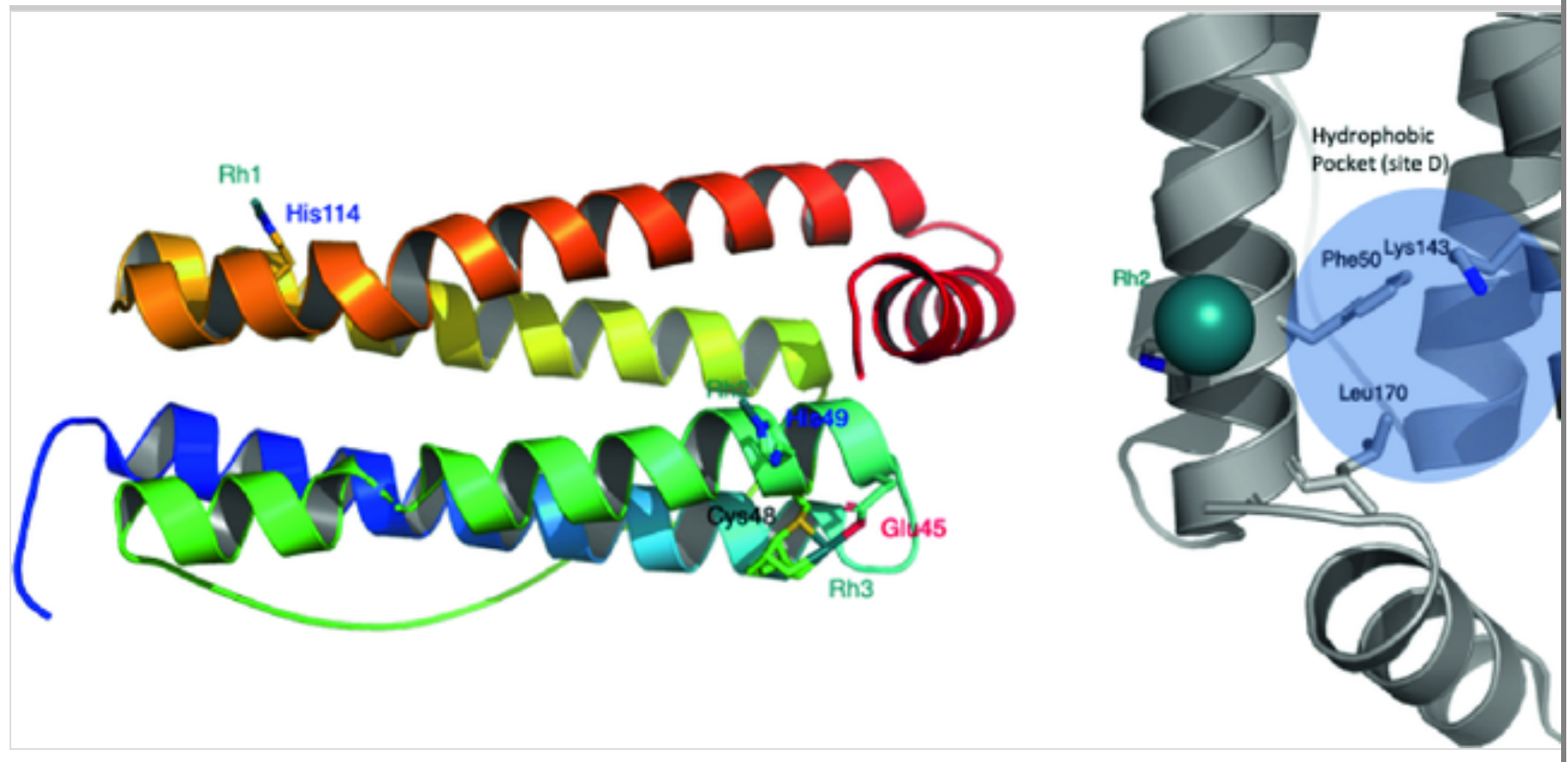

Polymerization of PA occurred in the cavity of Fr- $[\mathrm{Rh}]_{\mathrm{n}}$. Subsequent extraction from the cage afforded a polymer with a eiscis-transoidal configuration (Scheme 2) as determined by NMR, an $\mathrm{M}_{\mathrm{n}}$ of $(13.1 \pm 1.5) \times 10^{3}$ (i.e. 130 monomers per polymer chain in average) and dispersity of $2.6 \pm 0.3$. The average size of the polymer as well as the dispersity appear to be governed by the size of the Fr cavity while its eiscis configuration is identical to that obtained with the rhodium precursor. 


\section{Scheme 2}

Polymerization of phenylacetylene
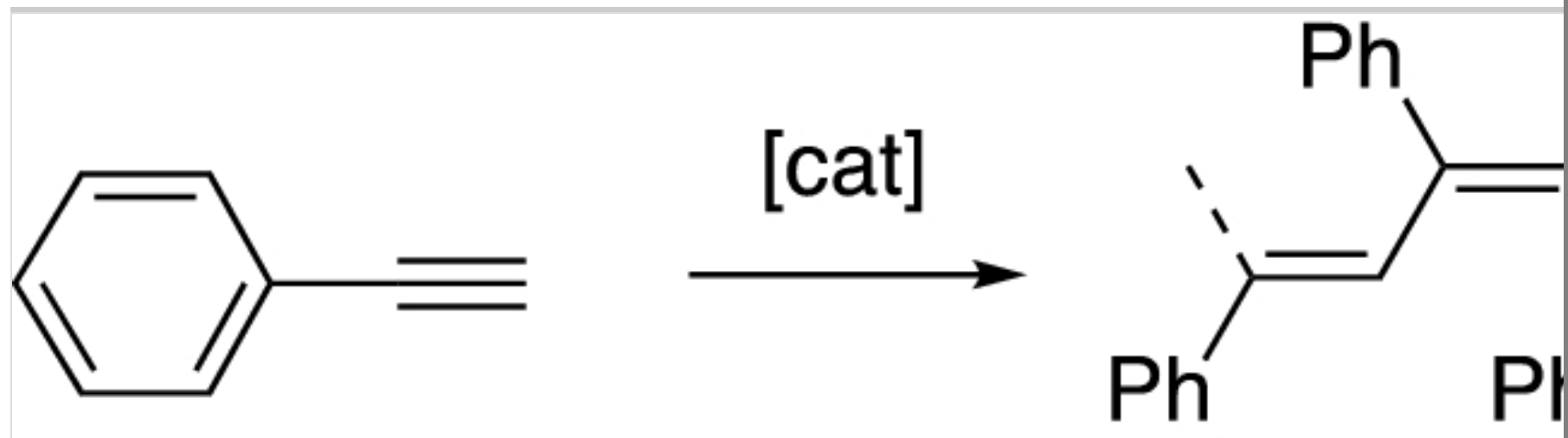

Insight into the actual active site of $\mathrm{Fr}-[\mathrm{Rh}]_{\mathrm{n}}$ and the mechanism of polymerization was provided by computational studies using QM/MM approach [91]. The rhodium ion coordinated to H49 was suggested to extrude from its binding site upon insertion of PA to move to site D comprising an ensemble of three hydrophobic residues where propagation occurred (Fig. 20).

Later on, a new biohybrid construct was designed to catalyze the polymerization of PA. This time, heme-free NB was selected as a protein scaffold owing to its $\beta$-barrel structure made of 10 twisted $\beta$-strands creating a well-defined rigid cavity for hosting the metal-binding site and the substrate [92]. The halfsandwich $\mathrm{Rh}$ (cod) complex carrying a maleimide group (Fig. 19) was synthesized and conjugated to the Q96C mutant of NB. The anchoring point was chosen so as to be located at the entrance of the cavity. Polymerization of PA proceeded under mild conditions to afford a polymer with an $M_{n}$ of $42.6 \times 10^{3}$ and dispersity of 2.6. The most interesting finding was the stereochemistry of the generated polymer since the trans: cis ratio equaled 53:47, to be compared to the precursor complex that gave almost exclusively the cis configuration as previously reported for other $\mathrm{Rh}(\mathrm{I})$ catalysts [89]. The trans:cis ratio even increased to $30: 70$ when the reaction was performed at $2{ }^{\circ} \mathrm{C}$. NB was further engineered to enlarge the cavity by mutating positions distant by $6 \AA$ from the 
Rh center. Mutant NB4 (H76L/Q96C/H158L) afforded the highest trans:cis ratio (82:12). X-ray crystallography of NB4-[Rh] assorted by molecular dynamics simulation suggested that the metal center in NB4-[Rh] displays a defined orientation probably explaining the high stereoselectivity of the reaction (Fig. 21).

Fig. 21

$\mathrm{X}$-ray structure of NB4-[Rh]

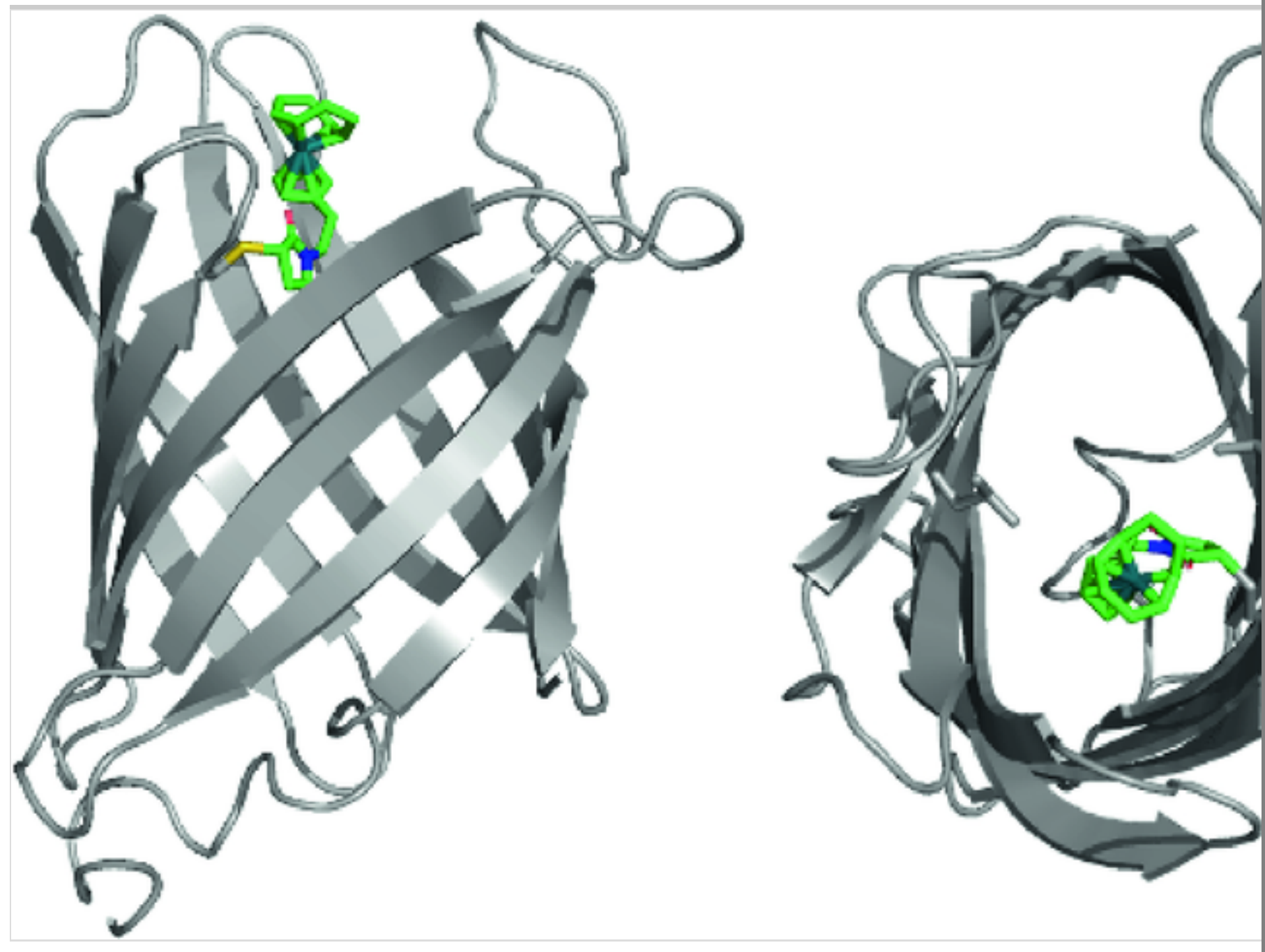

Another ArM was built up by covalent anchoring of the same rhodium(cod) complex to an engineered form of Fhu A [93]. [Note: Description of FhuA and its engineered form $\triangle \mathrm{CVF}^{\mathrm{TEV}}$ will be given below]. The amphipathic solvent MPD was shown to efficiently stabilize the resulting biohybrid in its fully folded form. FhuA-[Rh] was able to catalyze the polymerization of PA in 52\% yield to afford a polymer with an $M_{n}$ of 5,500 and dispersity of 2.9. Most 
interestingly, the trans: cis ratio equaled 75:25, meaning that embedding of the rhodium complex within the protein environment provided by FhuA reversed the stereoselectivity of the reaction.

\subsubsection{Ring-Opening Metathesis Polymerization (ROMP) of Olefins}

The first biohybrid to catalyze a ROMP reaction was introduced by Schwaneberg and Okuda in 2013 [94]. The synthesis of this ArM is based on the covalent anchoring of a Hoveyda-Grubbs metathesis catalyst $[95,96]$ to a variant of the E. coli transmembrane protein FhuA (ferric hydroxamate uptake protein component $A$ ). This protein conveniently displays a $\beta$-barrel folding made of 22 anti-parallel $\beta$-sheets creating a wide cavity suitable for hosting the metal catalyst and the substrate. Prior to ArM assembling, FhuA was engineered to create an anchoring point for the metal complex via a cysteine at position 545 and optimize its accessibility; TEV cleavage sites were also introduced in two loops to facilitate mass analysis of the ArM. The ruthenium benzylidene complex HG3 (Fig. 22) designed from a previously published water-soluble Grubbs catalyst [96] was conjugated to FhuA in its unfolded form by Michael addition of the single cysteine to the maleimide group of HG3. Refolding of FhuA-HG3 was then achieved by dialysis in the presence of polyethylene polyethyleneglycol (PE-PEG).

\section{Fig. 22}

ROMP catalyst precursors 


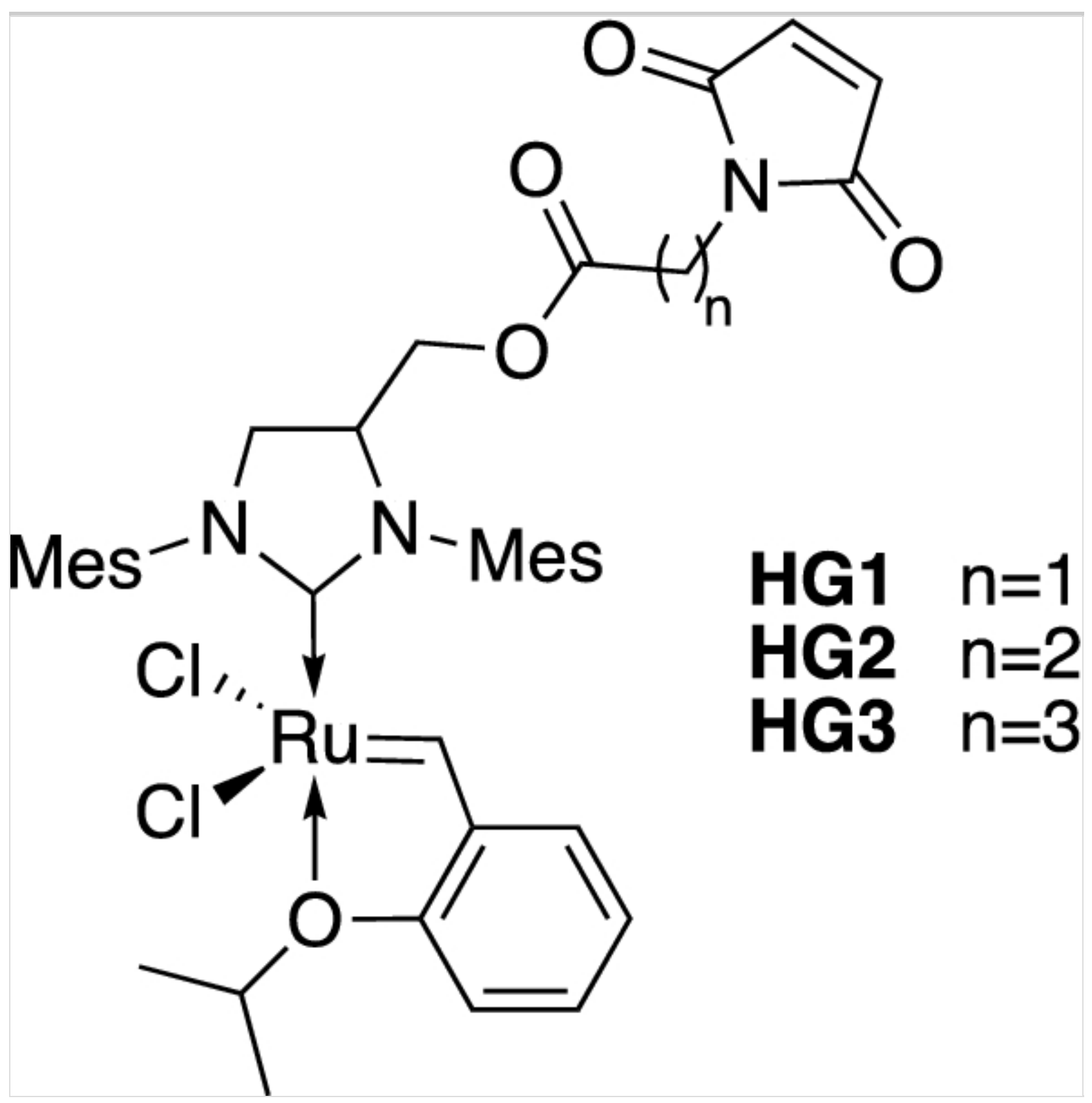

The catalytic activity of the ArM was tested in the ROMP reaction of a watersoluble 7-oxanorbornene derivative (Scheme 3). The partially folded ArM FhuA-HG3 afforded a polymer with 77\% yield and a cis:trans ratio of 60:40 while the fully folded FhuA-HG3 gave rise to a lower conversion (37\%).

\section{Scheme 3}

Ring-opening metathesis polymerization (ROMP) of 7-oxanorbornene derivative 

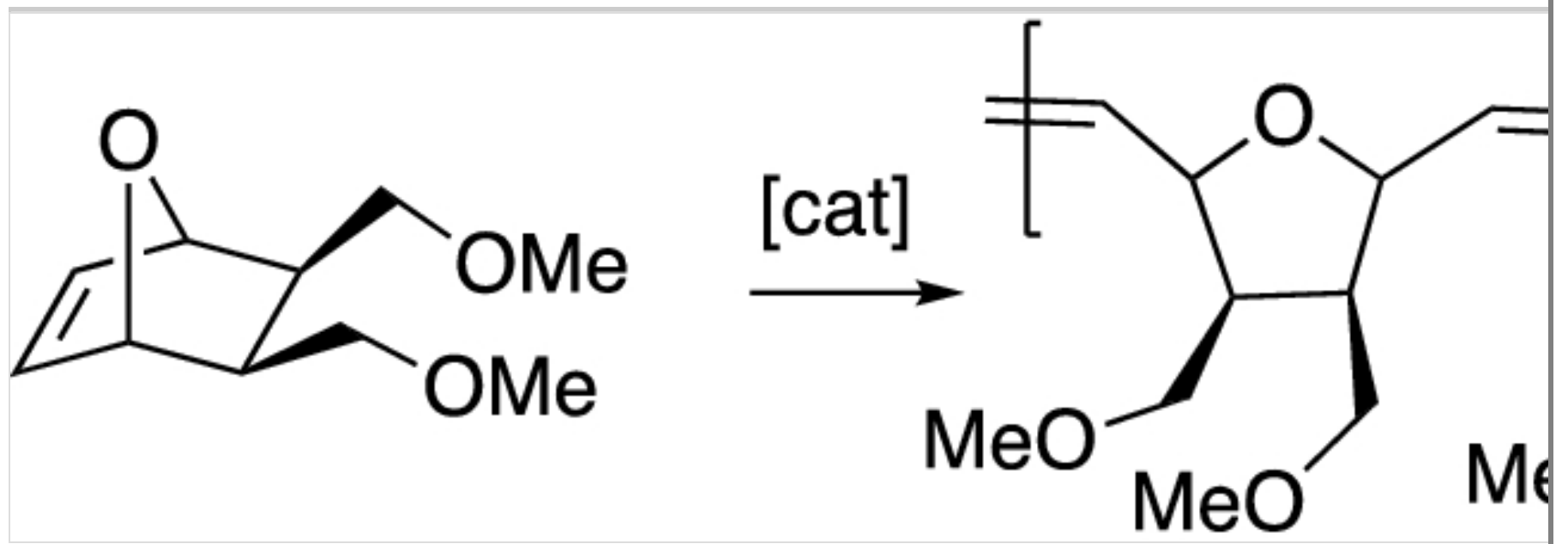

The same team next investigated the influence of the linker arm length on the activity of ArMs derived from FhuA [97]. They synthesized complexes HG1 and HG2 and assembled them to FhuA. Under conditions where the biohybrid is folded, the highest conversion was obtained with FhuA-HG1. Conjugation of the same series of ruthenium benzylidene complexes HG1-3 to NB variants carrying a single cysteine was further investigated [98]. Only HG3 was successfully conjugated to NB4 most probably owing to steric constraints. This prompted the research team to engineer a new NB variant (L75A/H76L/Q96C/M184L/H158L; NB11) displaying a larger cavity. Indeed, all three complexes afforded the expected conjugates with high yield this time. The best combination in terms of catalytic activity in ROMP was provided by NB11-HG3 at pH 6 with a conversion of $78 \%$ and of TON of 9900. The resulting polymer had an $M_{n}$ of $180 \Theta \times 10^{3}$ and a narrow dispersity of 1.05 .

A new NB variant called NB4exp was recently engineered in an attempt to increase the size of the protein cavity [99]. Two additional $\beta$-strands were incorporated to form an extended $\beta$-barrel structure with a calculated cavity size of $1389 \AA^{3}$. Complexes HG1-3 were successfully coupled to NB4exp and their activity tested in the ROMP of the 7-oxanorbornene derivative. The best catalyst appeared to be NB4exp-HG2 that afforded a polymer with an $\mathrm{M}_{\mathrm{n}}$ of $750 \times 10^{3}$, a dispersity of 1.21 , and a conversion of $81 \%$. Interestingly NB4expHG2 outperformed the water-soluble metathesis catalyst Aquamet in terms of initial rate of reaction and conversion.

\section{Advanced Developments of Artificial}




\section{Metalloenzymes}

\subsection{Cascade Reactions}

Enzymes function in vivin vivo in the presence of other biomacromolecules including other enzymes and small molecules other than their substrates. In vitrIn vitro, combinations of enzymes are routinely employed, to catalyze cascades of reactions, including at the industrial scale [100, 101]. The combination of transition metal catalysts with enzymes has however often led to mutual inhibition $[102,103,104,105]$. To overcome this issue, scientists rely mainly on compartmentalization strategies [106, 107] but ArMs offer another strategy as they may operate in harmony with other enzymes to achieve a synthetic goal. After all, the protein shell constitutes a protective environment for the metal of the active site of an ArM.

\subsubsection{Cascade Reactions Employing Artificial Transfer Hydrogenase}

By incorporating a $\mathrm{d}^{6}$-piano stool iridium complex bound to biotin within SAV, Hollmannet et at.al. [108] generated an artificial transfer hydrogenase (ATHase) that catalyzed the racemic reduction of imines by formate. They subsequently combined this ATHase with the natural monoaminooxidase-N-9 (MAO-N-9) that uses dioxygen to selectively oxidize the $(S)$-stereoisomer of a variety of amine substrates and provide the corresponding imines along with hydrogen peroxide. While the ATHase reduced imines into racemic $(R S)$-amine, only the $(S)$-isomer was reoxidized by MAO-N-9 into imine leading to the accumulation of the $(R)$-amine isomer. The reaction did not proceed unless either catalase or peroxidase was also added to the combination as hydrogen peroxide produced by MAO-N-9 was found to be detrimental to the ATHase activity. The combination of the three enzymes was efficient in the dynamic kinetic resolution of various chiral amines. It is noteworthy that inactivation was observed when the free iridium complex was used instead of the ATHase emphasizing the protective role of the protein shell and thus of artificial enzymes. HRP was also used as a catalase alternative that consumed hydrogen peroxide to bleach scopoletin and thus allowed to follow the ATHase activity (Scheme 4, left). In a similar approach, Ward et at.et al. prepared another ATHase that was able to reduce imines using NADPH instead of formate as it relied on 4,7-dihydroxy-1,10-phenanthroline $\mathrm{d}^{6}$-piano stool iridium complex. 
Glucose dehydrogenase (GDH) uses glucose to reduce $\mathrm{NADP}^{+}$to NADPH and the combination of the ATHase/MAO/catalase and GDH proved to be efficient in the dynamic kinetic resolution of various amines using simply glucose and dioxygen in the presence of catalytic amount of NADPH (Scheme 4, left) [109].

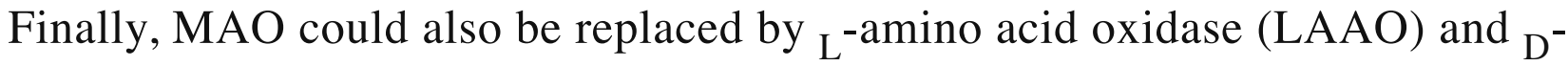
amino acid oxidase (DAAO) that resulted in the accumulation of ${ }_{\mathrm{L}}$-pipecolic acid starting from ${ }_{L}$-lysine (Scheme 4 , right).

\section{Scheme 4}

Left, the artificial metalloenzyme ATHase and the natural MAO catalyzing a cascade of two reactions leading to the production of ( $R R$ )-amines, starting from either racemic amines or imines and using oxygen and formate. Either catalase or HRP could be used to catalyze $\mathrm{H}_{2} \mathrm{O}_{2}$ to $\mathrm{H}_{2} \mathrm{O}$ dismutation thus protecting the ATHase but the later could additionally bleach scopoletin enabling kinetic monitoring of ATHase activity. Right, ATHase in a cascade of reaction with LAAO and DAAO to form L-pipecolic acid

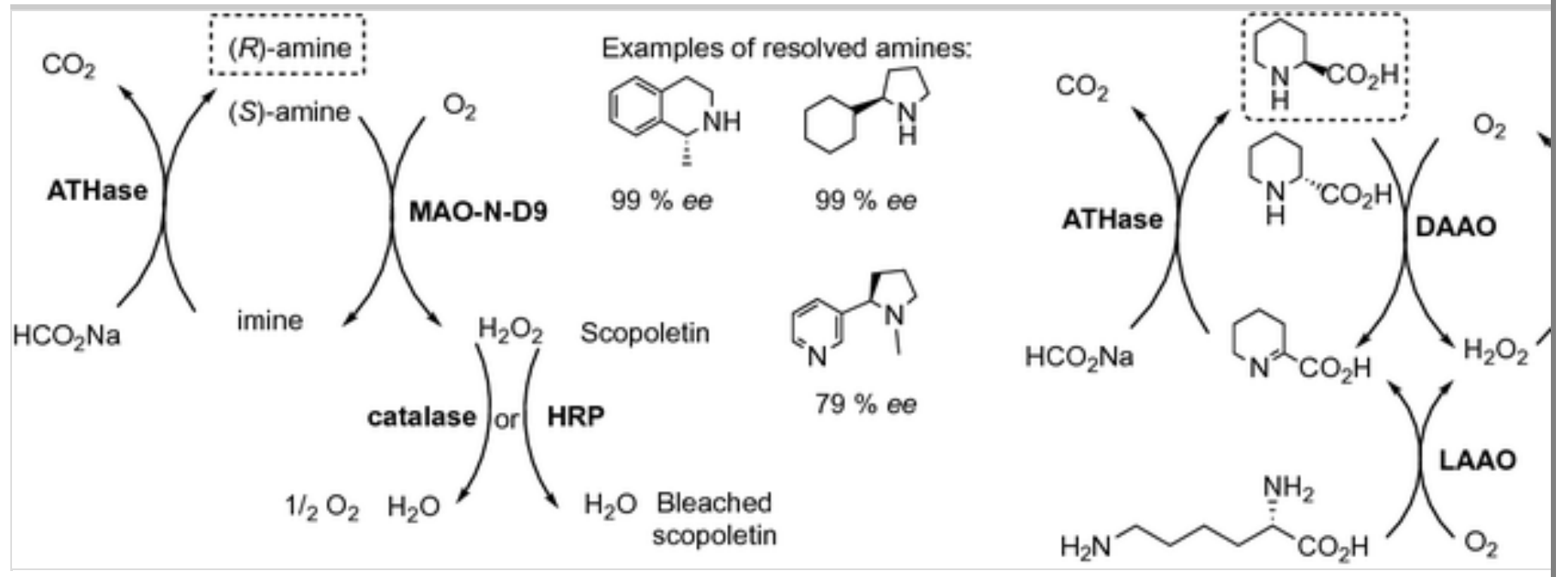

Additionally, the ATHase was used in combination with ene reductase-catalyzed asymmetric reduction of $\alpha, \beta$-unsaturated compounds. NADH mimics (mNADHs) have been shown to accelerate the ene reductase-catalyzed reaction but existing regeneration methods of NADPH fail for mNADHs. Nonetheless, the ATHase regenerated mNADH by using formate therefore only catalytic amount of mNADH was needed for ene reductase to catalyze the reduction with TON reaching 2000 (Scheme 5). 


\section{Scheme 5}

Artificial ATHase for recycling NADH from formate, which was used in cascade with ene reductase to reduce various alkenes

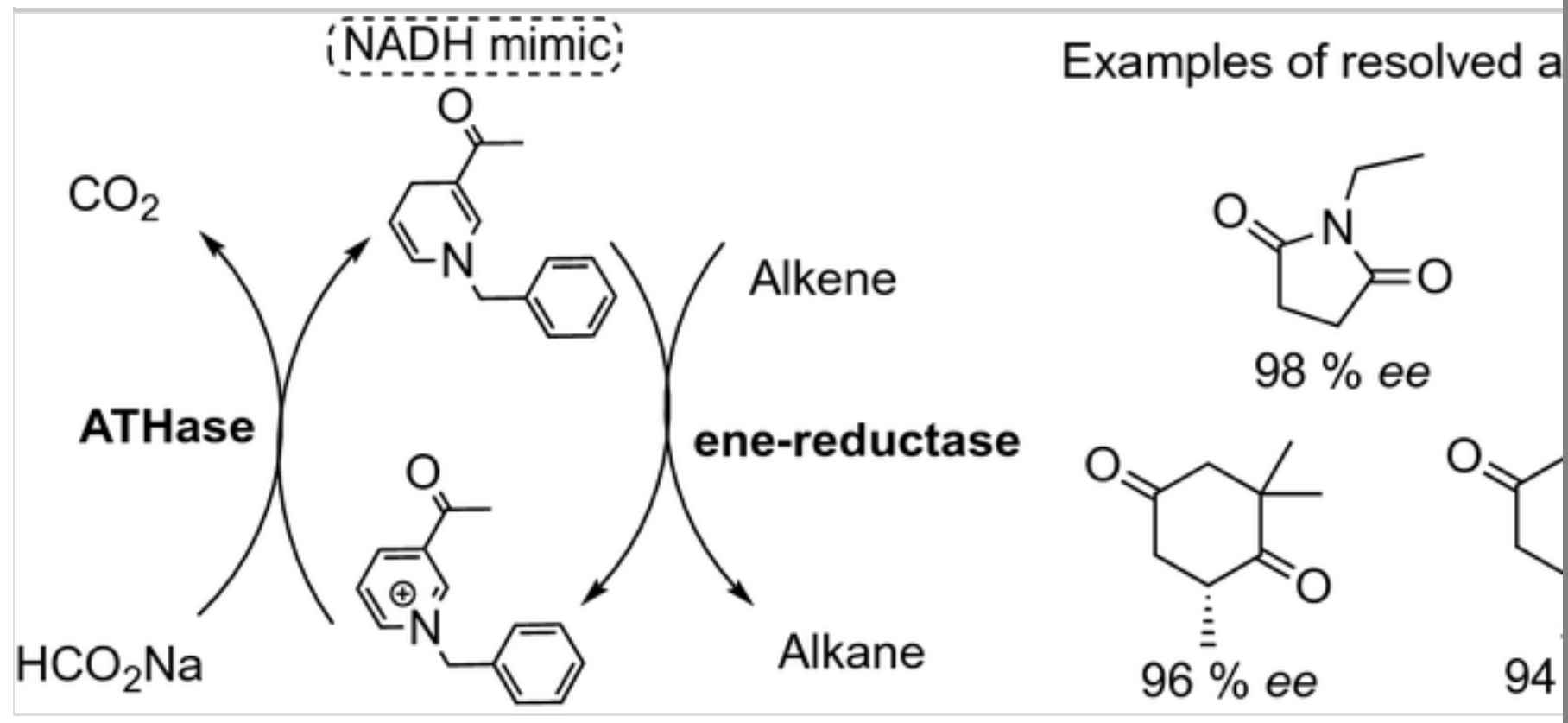

\subsubsection{Cascade Reactions Employing Other Artificial Reductases}

An artificial reductase using formate to regenerate $\mathrm{NADPH}$ from $\mathrm{NADP}^{+}$was prepared by covalently grafting a $\mathrm{Cp} * \mathrm{Rh}$ (III) 1,10-phenathroline or 1,1 'bipyridine complex $\left(\mathrm{Cp}^{*}=\right.$ pentamethylcyclopentadienyl $)$ in the active site of alcohol dehydrogenase (ADH) [110]. The natural ADH uses NADPH to reduce ketones into alcohol. The combination of ADH with the artificial reductase enabled the recycling of NADPH by formate thus requiring only a catalytic amount of NADPH (Scheme 6).

\section{Scheme 6}

Artificial reductase (in red) and natural alcohol dehydrogenase (in green) catalyzing a cascade of two reactions leading to the production of alcohol from ketone and formate using catalytic amounts of NADPH 


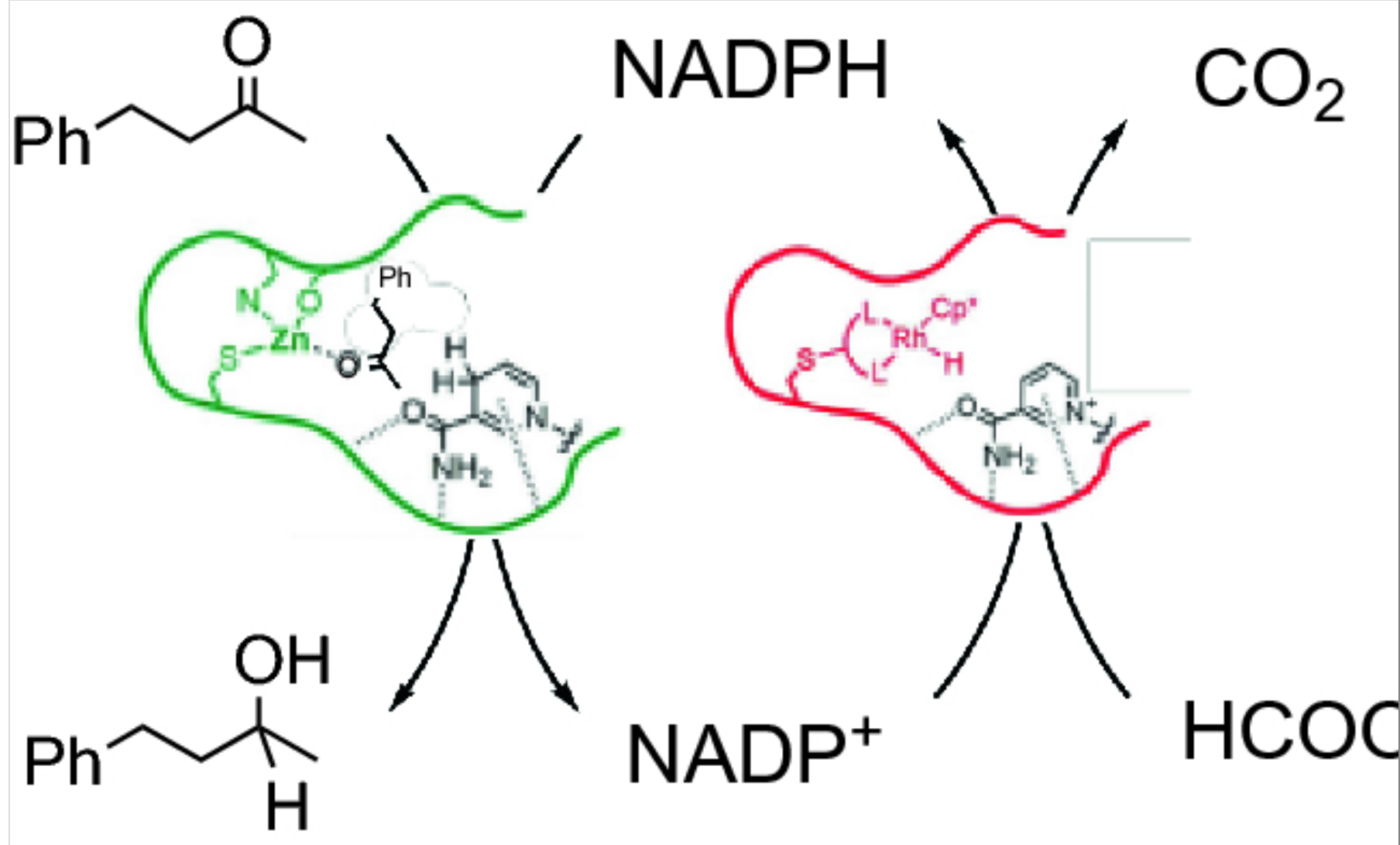

\subsection{In Vivo Catalysis}

The main problem faced by in vivein vivo catalysis by transition metal complexes is the potential deactivation of the catalyst in the living cell medium, which is quite different from simple vitro aqueous media. Living cells are indeed complex entities containing very large amounts of potential inhibitors for unprotected catalysts such as glutathione that has clearly been identified as a major inhibitor for precious metal catalysts in aqueous media [85]. One way to protect catalysts for in vivoin vivo applications is their incorporation into a protein scaffold. This does not only protect the catalysts from the living cell environment but also helps their solubilization in aqueous media.

\subsubsection{Olefin Metathesis}

With this issue in mind, Ward and coworkers developed the in cellulo production of SAV and its exportation to the periplasm of bacteria thanks to its fusion with the OmpA signal peptide. The choice of the periplasm as a compartment was mainly to take advantage of its low content in glutathione 
compared to that of the cytoplasm. Once in this compartment, SAV was also easily accessible to exogeneous molecules such as a synthetic biotinylated Hoveyda-Grubbs ruthenium complex to form the artificial metathase directly in the bacterial periplasm. The artificial metathase was shown to catalyze ringclosing metathesis. This was demonstrated in vivo by the transformation of a non-fluorescent substrate into the fluorescent umbelliferone 2 (Fig. 23). The scope of the reaction was then extended to the water-soluble benchmark substrate $\mathbf{3}$ which provided a poor yield. Interestingly, the authors took advantage of this low activity to perform directed evolution of the artificial metalloenzyme in cellulo and managed to get a 5-fold yield improvement from a quintuple mutant (Fig. 23) [111].

\section{Fig. 23}

Expression of SAV in the periplasm of E. coliE. coli by relying on the OmpA signal peptide and formation an artificial metathase upon the incorporation of a biotinylated ruthenium complex. Metathase activity detected via the formation of fluorescent umbelliferone $\mathbf{2}$ and directed evolution facilitated the reaction with benchmark substrate $3 \mathbf{3}$ [111]

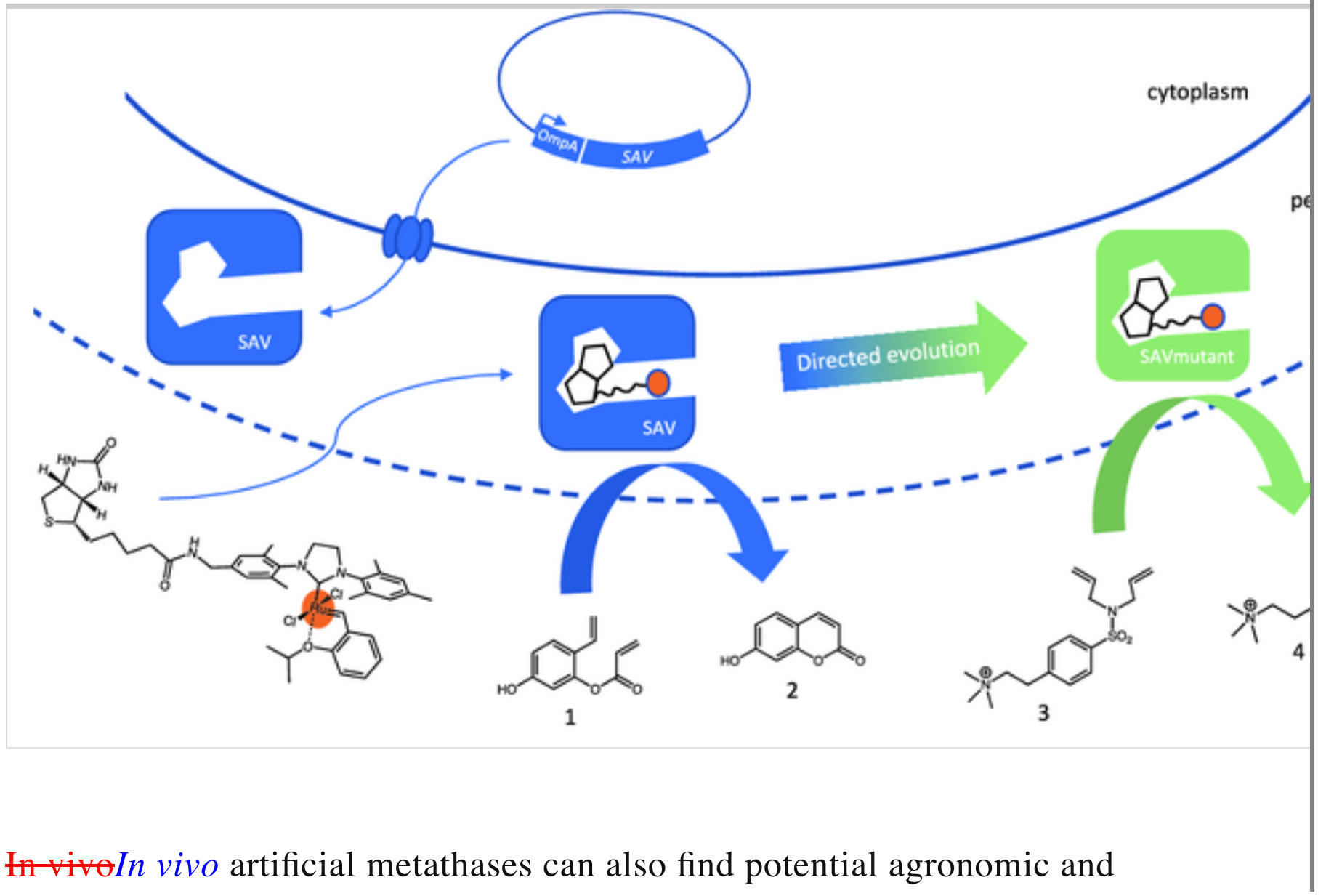


therapeutic applications. A fluorescent 7-diethylaminocoumarin (DEAC) and a $N$-[4-(4-dimethylamino)phenylazo]benzoate (DABCYL) based quencher were grafted to an Hoveyda-Grubbs ruthenium complex and incorporated in the hydrophobic pocket of HSA to afford an ArM-based ethylene biosensor [112]. Ethylene competitively displaced the DABCYL entity from coordination to ruthenium thus restoring the fluorescence of DEAC (Fig. 24, left). The reaction occurred in fruit flesh as demonstrated by the imaging of a thin slice of kiwifruit incubated with the artificial enzyme. In this case, although the macroscopic analysis does not demonstrate the activity within living cells, it clearly shows that the artificial metalloenzyme is active within the tissue of a living organism and could be used to quantify ethylene which is directly linked to ripening of fruits (Fig. 24, right).

\section{Fig. 24}

Left, reaction of ethylene, and the artificial methatase. Right, fluorescence imaging of a kiwifruit slice incubated with the metalloenzyme reflecting ethylene distribution within the slice [112]
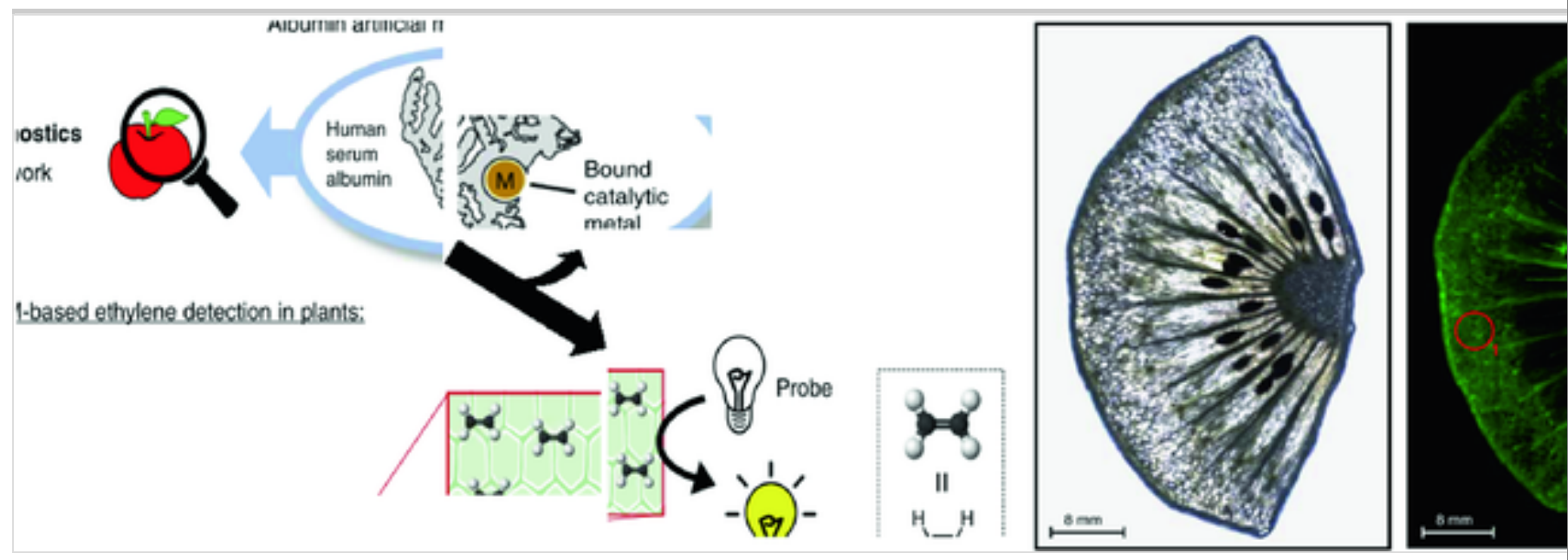

In a similar strategy, a fluorescent Hoveyda-Grubbs ruthenium complex was incorporated in the hydrophobic pocket of HSA functionalized with $\mathrm{N}$-glycan targeting moieties for selective accumulation in cancer cells. The resulting artificial methatase was then used to catalyze the invin vivo activation of cytotoxic umbelliprenin by ring-closing metathesis. Results indicated that the enzyme accumulated in different cancer cell lines (SW620, HeLa, A549) leading to cell death [113]. 


\subsubsection{Polymerization of Phenylacetylene}

As described earlier, rhodium-based ArMs were developed for the catalysis of the polymerization of PA. Grimm et al. have transposed this reaction into whole-cell catalytic systems [114]. The authors constructed a variant of NB fused with an autotransporter of esterase (EstA). Expression in E. Coli resulted in displaying NB on the outer membrane of the bacterial cells. The covalent anchoring of the half-sandwich Rh(cod) (Fig. 19) to NB4 at the surface of the cells formed an artificial enzyme. The generated biohybrid bugs were evaluated for the catalysis of the polymerization of PA. This cellular system provided poly(phenylacetylene) with $80 \%$ of trans content and with $39 \times 10^{6}$ TON per cell.

\subsubsection{Deallylation}

Bioorthogonal uncaging of amines by cleavage of allyl carbamate protecting group catalyzed by organometallic ruthenium complexes has been shown to function under biologically relevant conditions and even inside living cells. Several organometallic ruthenium complexes were assayed and $\left[(\mathrm{Cp})\left(\mathrm{Me}_{2} \mathrm{NQ}\right)\right.$ (allyl)Ru $\mathrm{PF}_{6}\left(\mathrm{Cp}=? \eta^{5}\right.$-cyclopentadienyl, $\mathrm{Me}_{2} \mathrm{NQ}=4-(\mathrm{N}, \mathrm{N} N, N-$ dimethylamino)-2-quinolinecarboxyl) showed the highest TON in the deprotection of $\mathrm{N} N$-(allyloxycarbonyl)aminocoumarin of bis[ $\mathrm{AN}$ (allyloxycarbonyl)]rhodamine 110 and of $\mathrm{N} N$-(allyloxycarbonyl)doxorubicin (Scheme 7) [115].

\section{Scheme 7}

Catalysis of the uncaging of a coumarin derivative, a rhodamine derivative and of doxorubicin by the ruthenium complex employed as a cofactor at the active site of allylic deallylase 


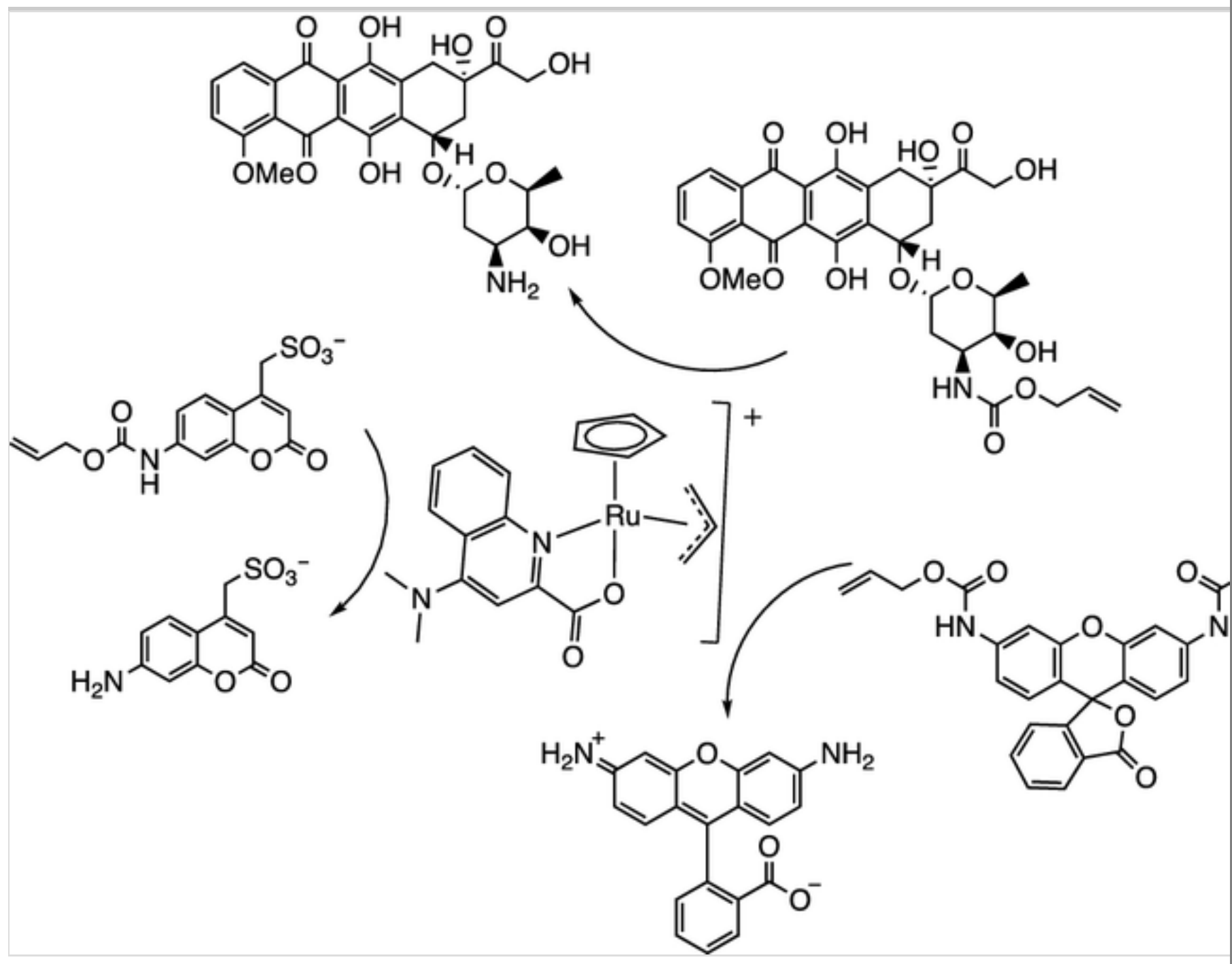

The ruthenium complex was thereafter covalently bound to biotin and assembled to SAV to form an artificial allylic deallylase. Cell-penetrating benzopentasulfides (B5S) were bound to biotin and the four streptavidin binding pockets of the artificial enzyme were shared between biotin bound ruthenium complex and biotin bound B5S. Such artificial enzymes could accumulate in the cytoplasm of HeLa Kyoto cells, wherein they catalyzed the uncaging of rhodamine 110 from bis[ $N$-(allyloxycarbonyl)] rhodamine 110 . In another approach that allowed the artificial enzyme to cross the cellular membrane, B5S were covalently bound to streptavidin leaving its four binding pockets available for biotin bound ruthenium complex. The artificial enzyme also accumulated in the cytoplasm and it could be fully exploited as its four binding pockets were available for catalysis [116].

Bacterial cells were also used as a platform for allylic deallylase activity. SAV 
was expressed at the surface of cells as described earlier relying on OmpA then incubated with the biotin bound ruthenium complex to form the artificial allylic deallylase. Directed evolution was used to further improve the activity in the uncaging of aminocoumarin, which was measured in 96-well plates and the most efficient mutants were identified as double mutants S112Y-K121S and S112M-K121A [117]. In addition to bacterial cells and human cells, algae cells, i.e., Chlamydomonas reinhardtii cells, were also exploited. The $\mathrm{N}$ hydroxysuccinimide 7 ester derivative of biotin was reacted with available amines and thiols at the cell membrane resulting in algae cells displaying biotin entities at their surface. These cells were incubated with SAV, which could then bind one of the displayed biotins at one of its four binding pockets. The remaining three binding pockets were then used to bind the biotin bound ruthenium complex. The formed artificial allylic deallylase displayed at the surface of algae cells wasere used for in vivoin vivo catalysis (Fig. 25) [118].

\section{Fig. 25}

Artificial allylic deallylase displayed at the surface of $C$.reinhardtii $C$. reinhardtii 


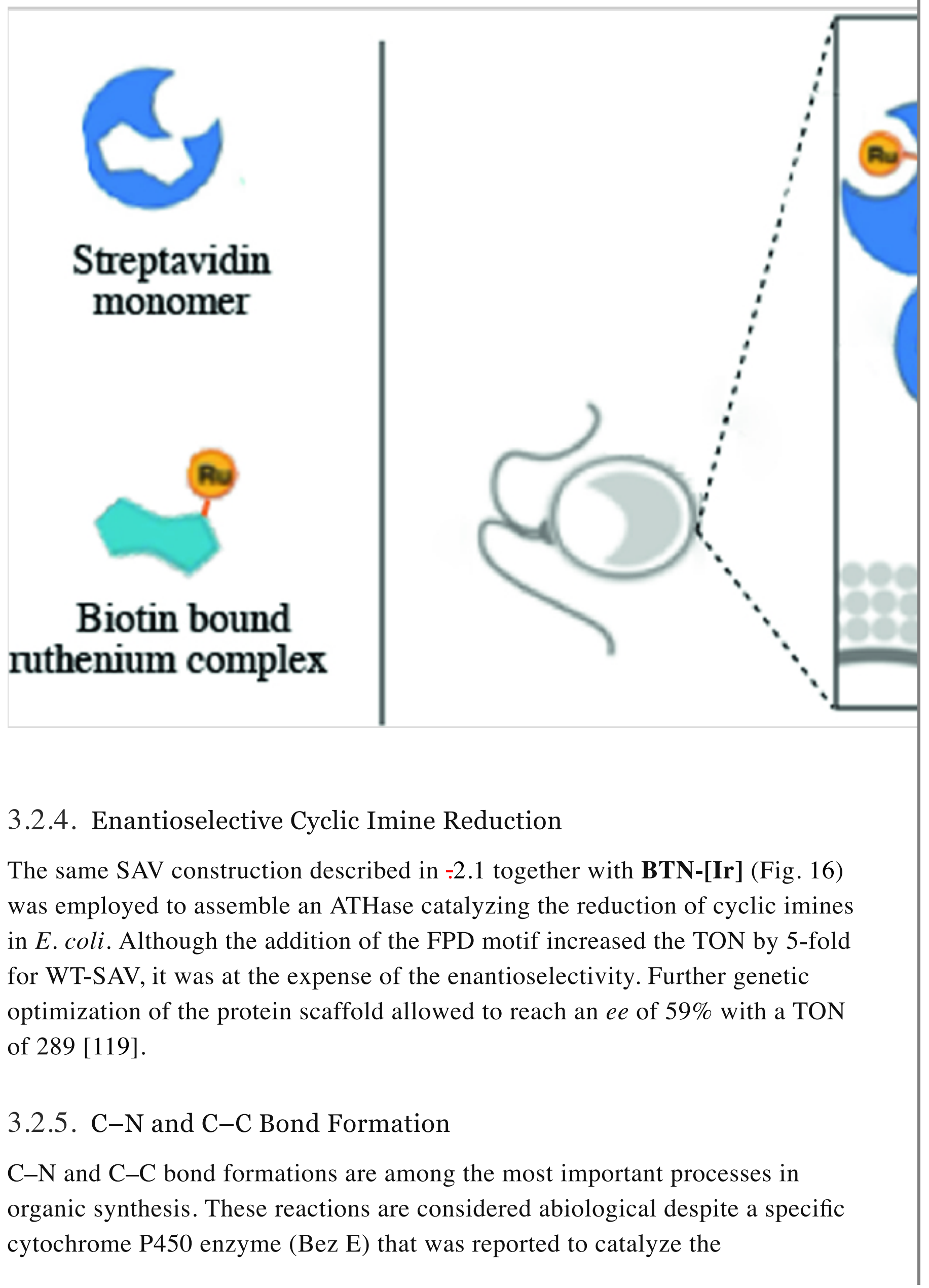


intramolecular transfer of natural nitrene to a $\mathrm{C}=\mathrm{C}$ bond leading to an aziridine intermediate in the biosynthesis of benzastatin [120]. Inspired by Bez E, efforts were dedicated to the development of artificial enzymes capable of catalyzing nitrene and carbene transfer reactions in water and particularly in vivo.

Nitrene transfer reactions were initiated with iron porphyrins and then Cyt P450 by Breslow and Gellman [121, 122, 123] and Mansuy [124] in the early 1980s. 25 years later, Fasan and coworkers showed that cytochrome $\mathrm{P}_{450} \mathrm{BM}_{3}$ and some of its variants were able to catalyze intramolecular $\mathrm{C}-\mathrm{H}$ amination $[125,126]$. Hartwig and coworkers replaced the iron of the heme of a Cyt P450 from a thermophilic organism, CYP119, by iridium and obtained the most active and the most chemoselective artificial enzyme for intramolecular $\mathrm{C}-\mathrm{H}$ aminations, which they further improved the yield and selectivity by mutation [127]. 2018 Nobel Prize laureate F. Arnold [128] and coworkers showed that Cyt P450 engineered into a cytochrome P411 that contained a serine axial ligand to the heme iron in place of the WT cysteine ligand was able to catalyze, in the presence of NADPH as reductant, the intermolecular transfer of nitrene moieties into benzylic $\mathrm{C}-\mathrm{H}$ bonds under anaerobic conditions (Scheme 8) [129]. Application of directed evolution to the protein afforded mutant $\mathrm{P}^{4} 11_{\mathrm{CHA}}$ that catalyzed the benzylic tosylamidation of 4-ethylanisole by tosyl azide $\left(\mathrm{TsN}_{3}\right)$ to form the benzylic N-tosylamide with up to 1,300 turnovers, $66 \%$ yield, and excellent enantioselectivity $(99 \%$ ee) even at the preparative scale and invivein vivo in whole E. coli cells. Further investigations in whole E. coli cells led to other variants that catalyzed the to sylamidation of indoles, such as 1methylindole [130]. The most efficient variant, namely P411-IA, provided the desired indole amidation products with up to 8400 turnovers and $90 \%$ yield, with a chemoselectivity of 110:12:1 in favor of nitrene transfer over reduction or triazole formation. Finally, the variant of P411BM3-CIS-T438S having a single active site mutation, $\mathrm{I} 263 \mathrm{~F}$, was the most active in the aziridination of a series of styrene derivatives, including less electron-rich substrates with up to 600 TTN, 70\% yield, and 99\% ee (Scheme 8) [131].

\section{Scheme 8}

Intermolecular nitrene transfer reactions catalyzed by cytochrome P411 variants 


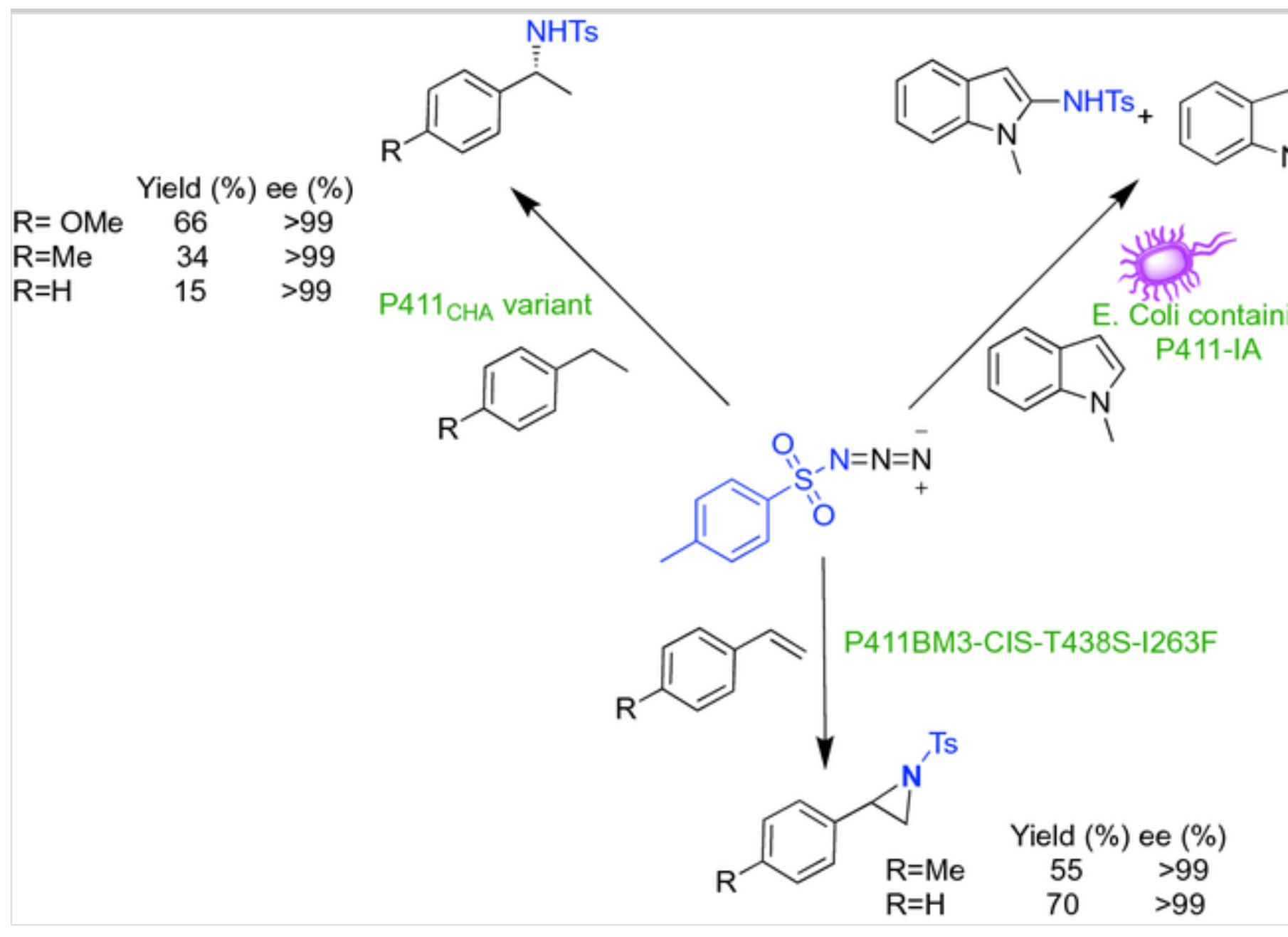

Roelfes and coworkers prepared an ArM by incorporation of heme into LmrR and showed that this enzyme as well as its mutants were able to catalyze carbene transfer reactions by ethyl diazoacetate 2 (EDA) into the double bond of styrene derivatives $[132,133,134]$. Ward and coworkers brought this activity to whole cells by incorporation of a biotinylated dirhodium complex within engineered streptavidin variants and using EDA as a transfer agent, the resulting biohybrids were found to catalyze the carbene insertion into styrene, leading to the corresponding cyclopropane as well as the insertion of the carbene moiety of trifluoroethylphenyl diazoacetate into allylic $\mathrm{C}-\mathrm{H}$ bonds of cyclohexadiene. Chemical and genetic optimizations allowed to modulate the catalytic activity of the ArMs which could be expressed in the periplasm of E. Coli cells. The most efficient artificial enzyme invivin vivo was obtained by assembling the dirhodium complex with the SAV K121C mutant expressed in the periplasm of E. coli and catalyzed the cyclopropanation of styrene with up to 20 turnovers (Fig. 26) [135]. 
Fig. 26

Carbene transfer reactions catalyzed by ArMs derived from LmrR or SAV

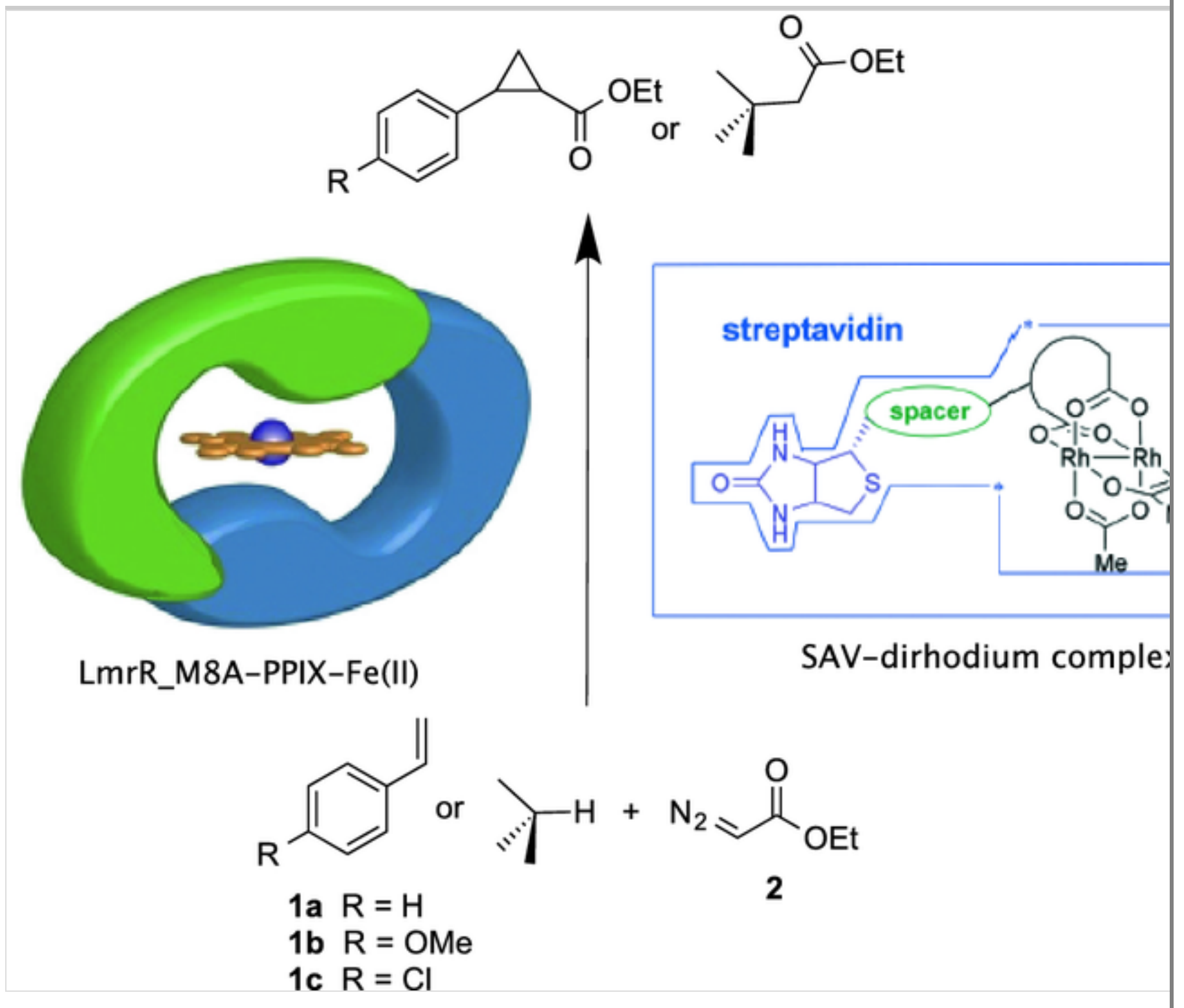

The directed evolution of Cyt $\mathrm{P} 450_{\mathrm{BM} 3}$ was also employed by several groups including Arnold's who was the first to enhance the activity and the selectivity of cytochrome $\mathrm{P} 450_{\mathrm{BM} 3}$ for the catalysis of cyclopropanation reactions [136]. Directed evolution was also applied to Mb by Fasan et at.et al. to produce artificial hemoproteins that could catalyze cyclopropanation reactions. The H64V-V68A double mutant catalyzed the benchmark reaction with $99 \%$ yield and $99.9 \%$ ee. Additionally, this mutant was found to catalyze the functionalization of the $\mathrm{C}-\mathrm{H}$ of indoles by $\mathrm{EDA}$, with $85 \%$ conversion and a 
TON of 106 [137]. It is noteworthy that this reaction could even be performed in whole cells, with $99 \%$ conversion and a TON of 82 [138, 139]. Brustad and coworkers used orthogonal expression techniques of hemoproteins to introduce mutations in the heme-binding pocket to allow the direct "in cellulo" incorporation of metal complexes of Deuteroporphyrin IX as cofactors into the apoprotein. Incorporation of $\mathrm{Fe}(\mathrm{Me})$-Deuteroporphyrin IX and $\operatorname{Ir}(\mathrm{Me})$ Deuteroporphyrin IX in the WIVS-FM*T268A variant, derived Cyt $\mathrm{P}^{4} 50_{\mathrm{BM}}$, led to artificial hemoproteins that catalyzed the cyclopropanation of styrene by EDA [140, 141]. Hayashi and coworkers found out that Mb reconstituted (rMb) with iron(II)-porphycene was able to catalyze the cyclopropanation of styrene by EDA, and was 26-fold more efficient than native Mb [142, 143]. Substituting the native $\mathrm{Fe}$ ion of $\mathrm{Mb}$ by either $\mathrm{Co}, \mathrm{Cu}, \mathrm{Mn}, \mathrm{Ru}, \mathrm{Rh}, \mathrm{Pd}, \mathrm{Ag}$, or Ir allowed Hartwig and coworkers to generate new hemoproteins that catalyzed the intramolecular carbene insertion of a diazoester into a $\mathrm{C}-\mathrm{H}$ bond to form a dihydrobenzofuran product as well as the enantio- and diastereoselective cyclopropanation of unactivated olefins [144]. CYP119 mutants containing iridium methyl unit were found able to catalyze intramolecular carbene insertion $[145,146]$ and directed evolution, focusing on amino acids close to the active site, allowed to select four mutants, C317G, T213G, L69V, V254L, that were able to catalyze the reaction with $94 \%$ ee and a TOF of $43 \mathrm{~min}^{-1}$ at best. Arnold and coworkers showed that engineered cytochrome P450s, catalyzed the insertion of fluoroalkyl carbene intermediates into $\alpha$-amino $\mathrm{C}\left(\mathrm{sp}^{3}\right)-\mathrm{H}$ bonds [147] and the reaction be performed on a preparative scale, but in vivo catalysis was not documented.

\subsubsection{Diels-Alder Reaction}

Because natural Diels-Alderases are rare and the Diels-Alder cycloaddition reaction is of major importance for chemical syntheses, many research teams have been tackling the elaboration of new artificial metalloenzymes that would catalyze the Diels-Alder reaction under ecofriendly conditions. $\mathrm{Cu}^{\mathrm{II}}$ was shown to be the most efficient water-compatible transition metal for the Lewis acid catalysis of this cycloaddition $[148,149,150]$ and therefore most artificial metallo-Diels-Alderases have been prepared by incorporating $\mathrm{Cu}^{\mathrm{II}}$ complexes into biomacromolecules covalently or non-covalently.

Reetz and coworkers inserted $\mathrm{Cu}^{\mathrm{II}-}$ phtalocyanine into serum albumins including 
BSA and HSA [151, 152]. Palomo et al. generated an heterogeneous artificial Diels-Alderase by assembling $\mathrm{Cu}^{\mathrm{II}}$-phenanthroline-lipase at the surface of Sepabeads $^{\mathrm{TM}}[153,154] . \mathrm{Cu}^{\mathrm{II}}-1,10-$ phenanthroline was also coupled to a testosterone anchor and inserted into the neo-carzinostatin variant NCS-3.24, thanks to its affinity for the testosterone moiety [155]. ( $\eta^{6}$-arene)-Ru ${ }^{\mathrm{II}}$ complexes were covalently anchored into papain [156] whereas $\mathrm{Cu}^{\mathrm{II}}$ phenanthroline and terpyridine complexes were covalently anchored into F119C and Y26C mutants of dimeric double chain $\left(\mathrm{A}_{3}\right)$ [157] and dimeric single chain (A3_A3') [158] synthetic alpha-repeat proteins. $\mathrm{Cu}^{\mathrm{II}}$-pyrenyl and -terpyridine complexes were also anchored, respectively, into $\mathrm{Nb}$ and FhuA [159]. Deuss et at.et al. also covalently bound $\mathrm{Cu}^{\mathrm{II}}$-phenanthroline (Phen) and -dipicolylamine complexes in two sterol carrier protein type 2 like domain (SCP-2L) mutants [160]. Finally, the $\mathrm{Cu}^{\mathrm{II}}-1,10$-phenanthroline complex was also bound to the LmrR M89C mutant [161]. All of the prepared ArMs catalyzed the Diels-Alder cycloaddition using benchmark substrates 2-azachalcone and cyclopentadiene, providing up to four isomer products. Yields ranging between 11 and $98 \%$ could be obtained, whereas the endeendo isomer was always the major isomer with endo/exeendo/exo ratios ranging from $66 / 34$ to $96 / 4$. The enantiomeric excesses varied greatly with values between 0 and $97 \%$. The most efficient of these enzymes were the $\mathrm{Cu}^{\mathrm{II}}$-Phen-SB-Lys-GTL*/196 catalyst [154] and the $\mathrm{Cu}^{\mathrm{II}}$ Phen-LmrR-M89C [161] that provided 98 and 93\% yield and 97\% ee with an ende/exeendo/exo ratio of about 95:5, respectively. Directed evolution was used by Reetz et al.et al. to design a $\mathrm{Cu}$ (II)-specific binding site in the thermostable protein tHisF. The introduction of a His-His-Asp coordinating triad for the $\mathrm{Cu}^{\mathrm{II}}$ ion into this $\mathrm{F}$ affording a copper enzyme catalyzing the Diels-Alder reaction of the benchmark substrates with $73 \%$ yield, $93 / 7$ endendo/exo ratio and $46 \%$ $e e$ [152], [162]. The substitution of the native Fe(II) of the His-His-Asp coordinating triad of 1-aminocyclopropane carboxylic acid oxidase by $\mathrm{Cu}^{\mathrm{II}}$ afforded the most efficient artificial Diels-Alderase ever reported with a quantitative yield and $>99 \%$ ee [163].

Finally, Ghattas et at.et al. used the $\mathrm{A}_{2 \mathrm{~A}}$ adenosine receptor embedded in the cytoplasmic membrane of living human cells as a platform to build artificial metallo-Diels Alderases. The metalloenzymes were assembled by inserting in the WT receptor conjugates of a strong antagonist covalently bound to $\mathrm{Cu}$ (II) catalysts. The resulting cells enantio selectively catalyzed the abiotic Diels- 
Alder cycloaddition reaction with up to $42 \%$ yield, an 82/18 endeendo/exo ratio, and a $14 \% e e$ (Fig. 27) [164]. The prospects of this strategy lie in the in vivein vivo preparation of organ-confined receptor-based artificial metalloenzymes for the catalysis of reactions exogenous to the human metabolism. This strategy could be used for the targeted synthesis of either drugs or deficient metabolites and for the activation of prodrugs, leading to therapeutic tools with unforeseen applications.

\section{Fig. 27}

Diels-Alder cycloaddition catalyzed by an artificial metalloenzyme assembled at the surface of a living HEK cell via the insertion of a $\mathrm{Cu}^{\mathrm{II}}$-phenanthroline- $\mathrm{A}_{2 \mathrm{~A}}$ agonist conjugate in the $\mathrm{A}_{2 \mathrm{~A}}$ adenosine receptor

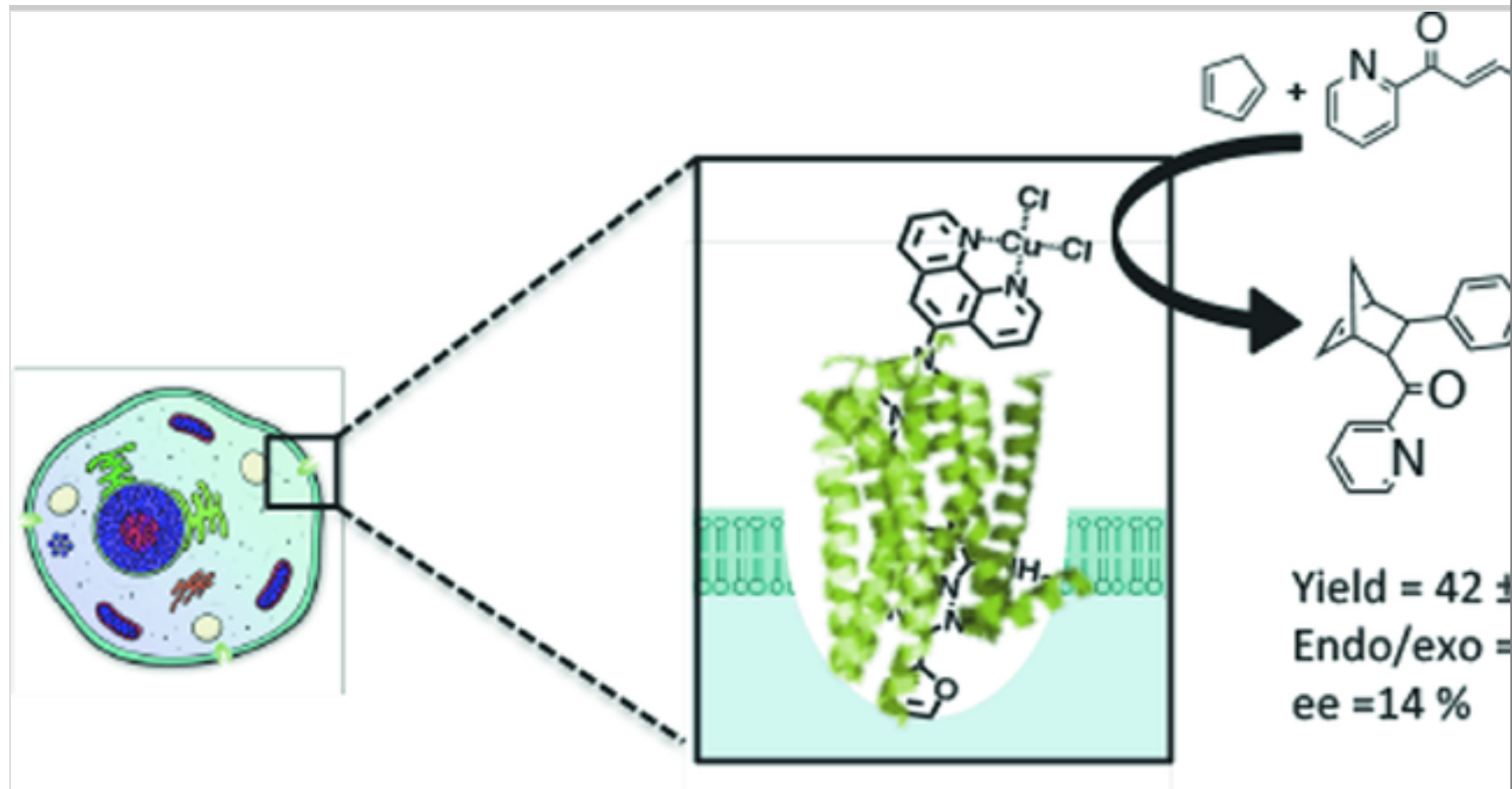

\section{Conclusions}

To sum up, ArMs are powerful biohybrids capable of catalyzing a wide range of reactions under eco-compatible conditions. The construction of such catalysts is typically designed through different strategies including the host/guest interaction, the "Trojan horse" strategy, the covalent binding of the metallic complex into the protein scaffold, or de novode novo design of metal-binding peptides. In terms of oxidation reactions, sulfide oxidation has been the most 
studied reaction and one of the best results was obtained by Ward et al. with vanadate-loaded streptavidin, which catalyzed the enantioselective thioether sulfoxidation with up to $93 \%$ ee and $96 \%$ conversion [24]. Other oxidation reactions were successfully catalyzed by ArMs, including alcohol oxidation, amine oxidation, catechol oxidation, epoxidation, and dihydroxylation.

However, $\mathrm{C}-\mathrm{H}$ activation remains one of the biggest challenges to tackle, with only one example of oxygen insertion into a $\mathrm{C}-\mathrm{H}$ bond described so far [36, 42]. Concerning reduction reactions, a lot of efforts have been devoted to mimic the activity of [ $\mathrm{FeFe}]$-hydrogenases by taking advantage of the second coordination sphere surrounding handmade metallic complexes in ArMs. Yet, the stability of the systems still needs to be improved to reach the high activity required for future hydrogen production applications. Another active field for ArMs is the $\mathrm{CO}_{2}$ reduction catalysis, but the most successful reduction reaction catalyzed by ArMs is the enantioselective reduction of cyclic imines catalyzed by Ir or Ru complexes incorporated in various protein scaffolds with up to $94 \%$ eeee and a TON of 98. ArMs have also been designed for the catalysis of polymerization reactions such as phenylacetylene polymerization, as well as ring-opening Metathesis Polymerization which have both been performed with good conversion rates and high TON. Apart from the simple applications described above, ArMs have also been used for the development of cascade reactions by association with natural enzymes for dynamic kinetic resolution of amines or for the stereoselective synthesis of L-pipecolic acid. Finally, the capacity of ArMs to catalyze abiotic reactions in biological medium opens new opportunities to improve the toolbox of bioorthogonal chemistry applications. This prompted the scientific community to develop catalytic hybrid systems operating in vivo and some exciting constructs have been obtained for olefin metathesis, polymerization of phenylacetylene, uncaging by deallylation, $\mathrm{C}-\mathrm{N}$ and $\mathrm{C}-\mathrm{C}$ bond formation, as well as Diels-Alder reactions. There is no doubt that artificial metalloenzymes have a bright future ahead as sustainable and environmentally friendly catalysts.

\section{References}

1. Degtyarenko K (2005) Metalloproteins. Encycl Genet Genom Prot Bioinf g306204. https://doi.org/10.1002/047001153X.g306204 
2. Valdez CE, Smith QA, Nechay MR, Alexandrova AN (2014) Mysteries of metals in metalloenzymes. Acc Chem Res 47:3110-3117. https://doi.org/10.1 $021 / \operatorname{ar} 500227 \mathrm{u}$

3. Que L, Tolman WB (2008) Biologically inspired oxidation catalysis. Nature 455:333-340. https://doi.org/10.1038/nature07371

4. Liu J-Y, Li X-F, Li Y-Z, Chang W-B, Huang A-J (2002) Oxidation of styrene by various oxidants with different kinds of metalloporphyrins. J Mol Catal Chem 187:163-167. https://doi.org/10.1016/S1381-1169(02)00137-1

5. Meunier B (1992) Metalloporphyrins as versatile catalysts for oxidation reactions and oxidative DNA cleavage. Chem Rev 92:1411-1456. https://doi. org/10.1021/cr00014a008

6. de Araujo Tôrres MG, da Silva VS, Idemori YM, DeFreitas-Silva G (2017) Manganese porphyrins as efficient catalysts in solvent-free cyclohexane oxidation. Arab J Chem S1878535217302423. https://doi.org/10.1016/j.arabjc .2017 .12 .007

7. Barona-Castaño J, Carmona-Vargas C, Brocksom T, de Oliveira K (2016) Porphyrins as catalysts in scalable organic reactions. Molecules 21:310. https: //doi.org/10.3390/molecules21030310

8. Schwizer F, Okamoto Y, Heinisch T, Gu Y, Pellizzoni MM, Lebrun V, Reuter R, Köhler V, Lewis JC, Ward TR (2018) Artificial metalloenzymes: reaction scope and optimization strategies. Chem Rev 118:142-231. https://doi.org/10. 1021/acs.chemrev.7b00014

9. Mahy J-P, Ghattas W, Di Méo T, Ricoux R (2018) Artificial metalloenzymes (Chap. 3). In: Williams G, Hall M (eds) Catalysis Series. Royal Society of Chemistry, Cambridge, pp 53-87

10. Mahy J-P, Raffy Q, Allard M, Ricoux R (2009) Various strategies for obtaining artificial hemoproteins: From "hemoabzymes" to "hemozymes". Biochimie 91:1321-1323. https://doi.org/10.1016/j.biochi.2009.03.002 
11. Mahy J-P, Maréchal J-D, Ricoux R (2014) Various strategies for obtaining oxidative artificial hemoproteins with a catalytic oxidative activity: from "Hemoabzymes" to "Hemozymes"? J Porphyr Phthalocyanines 18:10631092. https://doi.org/10.1142/S1088424614500813

12. Ricoux R, Dubuc R, Dupont C, Marechal J-D, Martin A, Sellier M, Mahy JP (2008) Hemozymes peroxidase activity of artificial hemoproteins constructed from the streptomyces lividans Xylanase A and Iron(III)carboxy-substituted porphyrins. Bioconjug Chem 19:899-910. https://doi.or $\mathrm{g} / 10.1021 / \mathrm{bc} 700435 \mathrm{a}$

13. Mahy J-P, Ricoux R (2016) Design, synthesis and reactivity for a new kind of eco-compatible hybrid biocatalyst: artificial hemoproteins. Handb Porphyr Sci Appl Chem Phys Mater Sci Eng Biol Med, 38 Green Chem

14. Kaplan J, DeGrado WF (2004) De novo design of catalytic proteins. Proc Natl Acad Sci 101:11566-11570. https://doi.org/10.1073/pnas.0404387101

15. Summa CM, Rosenblatt MM, Hong J-K, Lear JD, DeGrado WF (2002) Computational de novo design, and characterization of an A2B2 Diiron protein. J Mol Biol 321:923-938. https://doi.org/10.1016/S0022-2836(02)00 $589-2$

16. Faiella M, Andreozzi C, de Rosales RTM, Pavone V, Maglio O, Nastri F, DeGrado WF, Lombardi A (2009) An artificial di-iron oxo-protein with phenol oxidase activity. Nat Chem Biol 5:882-884. https://doi.org/10.1038/n chembio. 257

17. Reig AJ, Pires MM, Snyder RA, Wu Y, Jo H, Kulp DW, Butch SE, Calhoun JR, Szyperski T, Solomon EI, DeGrado WF (2012) Alteration of the oxygen-dependent reactivity of de novo Due Ferri proteins. Nat Chem 4:900-906. https://doi.org/10.1038/nchem.1454

18. Snyder RA, Butch AJ, Reig AJ, DeGrado WF, Solomon EI (2012) Molecular-level insight into the differential oxidase and oxygenase reactivities of De Novo Due Ferri proteins. J Am Chem Soc 137:9302-9314. https://doi.org/10.1021/jacs.5b03524 
19. Thomas CM, Letondor C, Humbert N, Ward TR (2005) Aqueous oxidation of alcohols catalyzed by artificial metalloenzymes based on the biotinavidin technology. J Organomet Chem 690:4488-4491. https://doi.org/10.10 16/j.jorganchem.2005.02.001

20. Choi YS, Zhang H, Brunzelle JS, Nair SK, Zhao H (2008) In vitro reconstitution and crystal structure of p-aminobenzoate N-oxygenase (AurF) involved in aureothin biosynthesis. Proc Natl Acad Sci 105:6858-6863. http s://doi.org/10.1073/pnas.0712073105

21. van de Velde F, Arends IWCE, Sheldon RA (2000) Vanadium-catalysed enantioselective sulfoxidations: rational design of biocatalytic and biomimetic systems. Top Catal 13:259-265. https://doi.org/10.1023/A:1009 094619249

22. van de Velde F, Arends IWCE, Sheldon RA (2000) Biocatalytic and biomimetic oxidations with vanadium. J Inorg Biochem 80:81-89. https://do i.org/10.1016/S0162-0134(00)00043-X

23. van de Velde F, Könemann L (1998) Enantioselective sulfoxidation mediated by vanadium-incorporated phytase: a hydrolase acting as a peroxidase. Chem Commun 1891-1892. https://doi.org/10.1039/a804702b

24. Pordea A, Creus M, Panek J, Duboc C, Mathis D, Novic M, Ward TR (2008) Artificial metalloenzyme for enantioselective sulfoxidation based on vanadyl-loaded streptavidin. J Am Chem Soc 130:8085-8088. https://doi.or $\mathrm{g} / 10.1021 / \mathrm{ja} 8017219$

25. Pordea A, Mathis D, Ward TR (2009) Incorporation of biotinylated manganese-salen complexes into streptavidin: new artificial metalloenzymes for enantioselective sulfoxidation. J Organomet Chem 694:930-936. https:// doi.org/10.1016/j.jorganchem.2008.11.023

26. Sansiaume-Dagousset E, Urvoas A, Chelly K, Ghattas W, Maréchal J-D, Mahy J-P, Ricoux R (2014) Neocarzinostatin-based hybrid biocatalysts for oxidation reactions. Dalton Trans 43:8344-8354. https://doi.org/10.1039/c4 dt00151f 
27. Nakagawa A, Komatsu T, Iizuka M, Tsuchida $\mathrm{E}$ (2008) $\mathrm{O}_{2}$ binding to human serum albumin incorporating iron porphyrin with a covalently linked methyl- L -histidine isomer. Bioconjug Chem 19:581-584. https://doi.org/10. 1021/bc700400n

28. Komatsu T, Nakagawa A, Qu X (2009) Structural and mutagenic approach to create human serum albumin-based oxygen carrier and photosensitizer. Drug Metab Pharmacokinet 24:287-299. https://doi.org/10.2133/dmpk.24.2 87

29. Zunszain PA, Ghuman J, Komatsu T, Tsuchida E, Curry S (2003) Crystal structural analysis of human serum albumin complexed with hemin and fatty acid. BMC Struct Biol 3:6. https://doi.org/10.1186/1472-6807-3-6

30. Mahammed A, Gray HB, Weaver JJ, Sorasaenee K, Gross Z (2004) Amphiphilic corroles bind tightly to human serum albumin. Bioconjug Chem 15:738-746. https://doi.org/10.1021/bc034179p

31. Mahammed A, Gross Z (2005) Albumin-conjugated corrole metal complexes: extremely simple yet very efficient biomimetic oxidation systems. J Am Chem Soc 127:2883-2887. https://doi.org/10.1021/ja045372 $\mathrm{c}$

32. Herrero C, Quaranta A, Ricoux R, Trehoux A, Mahammed A, Gross Z, Banse F, Mahy J-P (2016) Oxidation catalysis via visible-light water activation of a $\left[\mathrm{Ru}(\mathrm{bpy})_{3}\right]^{2+}$ chromophore BSA-metallocorrole couple. Dalton Trans 45:706-710. https://doi.org/10.1039/C5DT04158A

33. Rousselot-Pailley P, Bochot C, Marchi-Delapierre C, Jorge-Robin A, Martin L, Fontecilla-Camps JC, Cavazza C, Ménage S (2009) The protein environment drives selectivity for sulfide oxidation by an artificial metalloenzyme. ChemBioChem 10:545-552. https://doi.org/10.1002/cbic.20 0800595

34. Tang J, Huang F, Wei Y, Bian H, Zhang W, Liang H (2016) Bovine serum albumin-cobalt(II) Schiff base complex hybrid: an efficient artificial 
metalloenzyme for enantioselective sulfoxidation using hydrogen peroxide. Dalton Trans 45:8061-8072. https://doi.org/10.1039/C5DT04507J

35. Hunter CL, Lloyd E, Eltis LD, Rafferty SP, Lee H, Smith M, Mauk AG (1997) Role of the heme propionates in the interaction of heme with apomyoglobin and apocytochrome $b_{5}$. Biochemistry 36:1010-1017. https://d oi.org/10.1021/bi961385u

36. Hayashi T, Hisaeda Y (2002) New functionalization of myoglobin by chemical modification of heme-propionates. Acc Chem Res 35:35-43. https: //doi.org/10.1021/ar000087t

37. Ueno T, Koshiyama T, Abe S, Yokoi N, Ohashi M, Nakajima H, Watanabe Y (2007) Design of artificial metalloenzymes using non-covalent insertion of a metal complex into a protein scaffold. J Organomet Chem 692:142-147. htt ps://doi.org/10.1016/j.jorganchem.2006.08.043

38. Ueno T, Koshiyama T, Ohashi M, Kondo K, Kono M, Suzuki A, Yamane T, Watanabe Y (2005) Coordinated design of cofactor and active site structures in development of new protein catalysts. J Am Chem Soc 127:6556-6562. h ttps://doi.org/10.1021/ja045995q

39. Ohashi M, Koshiyama T, Ueno T, Yanase M, Fujii H, Watanabe Y (2003) Preparation of artificial metalloenzymes by insertion of chromium(III) Schiff base complexes into apomyoglobin Mutants. Angew Chem Int Ed 42:1005-1008. https://doi.org/10.1002/anie.200390256

40. Carey JR, Ma SK, Pfister TD, Garner DK, Kim HK, Abramite JA, Wang Z, Guo Z, Lu Y (2004) A site-selective dual anchoring strategy for artificial metalloprotein design. J Am Chem Soc 126:10812-10813. https://doi.org/10 $.1021 / \mathrm{ja} 046908 \mathrm{x}$

41. Zhang J-L, Garner DK, Liang L, Chen Q, Lu Y (2008) Protein scaffold of a designed metalloenzyme enhances the chemoselectivity in sulfoxidation of thioanisole. Chem Commun 1665. https://doi.org/10.1039/b718915j

42. Hayashi T, Murata D, Makino M, Sugimoto H, Matsuo T, Sato H, Shiro Y, 
Hisaeda Y (2006) Crystal structure and peroxidase activity of myoglobin reconstituted with iron porphycene. Inorg Chem 45:10530-10536. https://do i.org/10.1021/ic061130x

43. Ducros V, Charnock SJ, Derewenda U, Derewenda ZS, Dauter Z, Dupont C, Shareck F, Morosoli R, Kluepfel D, Davies GJ (2000) Substrate specificity in glycoside hydrolase family 10: structural and kinetic analysis of the Streptomyces Lividans Xylanase 10A. J Biol Chem 275:23020-23026. https: //doi.org/10.1074/jbc.275.30.23020

44. Komatsu T, Ishihara S, Tsuchida E, Nishide H, Morokuma C, Nakamura S (2005) Heat-resistant oxygen-carrying hemoproteins consist of recombinant xylanases and synthetic iron(II) porphyrin. Biomacromol 6:1489-1494. http s://doi.org/10.1021/bm0492551

45. Ricoux R, Allard M, Dubuc R, Dupont C, Maréchal J-D, Mahy J-P (2009) Selective oxidation of aromatic sulfide catalyzed by an artificial metalloenzyme: new activity of hemozymes. Org Biomol Chem 7:32083211. https://doi.org/10.1039/b907534h

46. Allard M, Dupont C, Muñoz Robles V, Doucet N, Lledós A, Maréchal J-D, Urvoas A, Mahy J-P, Ricoux R (2012) Incorporation of manganese complexes into xylanase: new artificial metalloenzymes for enantioselective epoxidation. ChemBioChem 13:240-251. https://doi.org/10.1002/cbic.20110 0659

47. Cherrier MV, Cavazza C, Bochot C, Lemaire D, Fontecilla-Camps JC (2008) Structural characterization of a putative endogenous metal chelator in the periplasmic nickel transporter NikA. Biochemistry 47:9937-9943. https://do i.org/10.1021/bi801051y

48. Cherrier MV, Martin L, Cavazza C, Jacquamet L, Lemaire D, Gaillard J, Fontecilla-Camps JC (2005) Crystallographic and spectroscopic evidence for high affinity binding of $\operatorname{FeEDTA}\left(\mathrm{H}_{2} \mathrm{O}\right)^{-}$to the periplasmic nickel transporter NikA. J Am Chem Soc 127:10075-10082. https://doi.org/10.102 $1 / \mathrm{ja} 0518530$ 
49. Esmieu C, Cherrier MV, Amara P, Girgenti E, Marchi-Delapierre C, Oddon F, Iannello M, Jorge-Robin A, Cavazza C, Ménage S (2013) An artificial oxygenase built from scratch: substrate binding site identified using a docking approach. Angew Chem Int Ed 52:3922-3925. https://doi.org/10.10 02/anie.201209021

50. Buron C, Sénéchal-David K, Ricoux R, Le Caër J-P, Guérineau V, Méjanelle P, Guillot R, Herrero C, Mahy J-P, Banse F (2015) An artificial enzyme made by covalent grafting of an $\mathrm{Fe}^{\mathrm{II}}$ complex into $\beta$-lactoglobulin: molecular chemistry, oxidation catalysis, and reaction-intermediate monitoring in a protein. Chem Eur J 21:12188-12193. https://doi.org/10.100 2/chem.201501755

51. Fujieda N, Hasegawa A, Ishihama K, Itoh S (2012) Artificial dicopper oxidase: rational reprogramming of bacterial metallo- $\beta$-lactamase into a catechol oxidase. Chem Asian J 7:1203-1207. https://doi.org/10.1002/asia.2 01101014

52. Ricoux R, Girgenti E, Sauriat-Dorizon H, Blanchard D, Mahy J-P (2002) Regioselective nitration of phenol induced by catalytic antibodies. J Protein Chem 21:473-477. https://doi.org/10.1023/A:1021351120772

53. Håkansson K, Wehnert A, Liljas A (1994) X-ray analysis of metalsubstituted human carbonic anhydrase II derivatives. Acta Crystallogr D Biol Crystallogr 50:93-100. https://doi.org/10.1107/S0907444993008790

54. Okrasa K, Kazlauskas RJ (2006) Manganese-substituted carbonic anhydrase as a new peroxidase. Chem Eur J 12:1587-1596. https://doi.org/10.1002/che $\mathrm{m} .200501413$

55. Fernández-Gacio A, Codina A, Fastrez J, Riant O, Soumillion P (2006) Transforming carbonic anhydrase into epoxide synthase by metal exchange. Chem Bio Chem 7:1013-1016. https://doi.org/10.1002/cbic.200600127

56. Reetz MT (2002) Directed evolution of selective enzymes and hybrid catalysts. Tetrahedron 58:6595-6602. https://doi.org/10.1016/S0040-4020(0 2)00668-3 
57. Reetz MT, Rentzsch M, Pletsch A, Maywald M, Maiwald P, Peyralans JJ-P, Maichele A, Fu Y, Jiao N, Hollmann F, Mondière R, Taglieber A (2007) Directed evolution of enantioselective hybrid catalysts: a novel concept in asymmetric catalysis. Tetrahedron 63:6404-6414. https://doi.org/10.1016/j.t et.2007.03.177

58. Kolb HC, VanNieuwenhze MS, Sharpless KB (1994) Catalytic asymmetric dihydroxylation. Chem Rev 94:2483-2547. https://doi.org/10.1021/cr00032 a009

59. Abu-Omar MM, Loaiza A, Hontzeas N (2005) Reaction mechanisms of mononuclear non-heme iron oxygenases. Chem Rev 105:2227-2252. https:// doi.org/10.1021/cr040653o

60. Kokubo T, Sugimoto T, Uchida T, Tanimoto S, Okano M (1983) The bovine serum albumin-2-phenylpropane-1,2-diolatodioxo-osmium(VI) complex as an enantioselective catalyst for cis-hydroxylation of alkenes. J Chem Soc Chem Commun 769-770. https://doi.org/10.1039/C39830000769

61. Köhler V, Mao J, Heinisch T, Pordea A, Sardo A, Wilson YM, Knörr L, Creus M, Prost J-C, Schirmer T, Ward TR (2011) OsO4·Streptavidin: a tunable hybrid catalyst for the enantioselective cis-dihydroxylation of olefins. Angew Chem Int Ed 50:10863-10866. https://doi.org/10.1002/anie.2 01103632

62. Cavazza C, Bochot C, Rousselot-Pailley P, Carpentier P, Cherrier MV, Martin L, Marchi-Delapierre C, Fontecilla-Camps JC, Ménage S (2010) Crystallographic snapshots of the reaction of aromatic C-H with $\mathrm{O}_{2}$ catalysed by a protein-bound iron complex. Nat Chem 2:1069-1076. https:// doi.org/10.1038/nchem.841

63. Alcala-Torano R, Sommer DJ, Bahrami Dizicheh Z, Ghirlanda G (2016) Chapter seventeen - design strategies for redox active metalloenzymes: applications in hydrogen production. In: Pecoraro VL (ed) Methods in enzymology. Academic Press, pp 389-416 
64. Sano Y, Onoda A, Hayashi T (2011) A hydrogenase model system based on the sequence of cytochrome c: photochemical hydrogen evolution in aqueous media. Chem Commun 47:8229. https://doi.org/10.1039/c1cc11157 d

65. Sano Y, Onoda A, Hayashi T (2012) Photocatalytic hydrogen evolution by a diiron hydrogenase model based on a peptide fragment of cytochrome c556 with an attached diiron carbonyl cluster and an attached ruthenium photosensitizer. J Inorg Chem 108:159-162. https://doi.org/10.1016/j.jinorg bio.2011.07.010

66. Onoda A, Kihara Y, Fukumoto K, Sano Y, Hayashi T (2014) Photoinduced hydrogen evolution catalyzed by a synthetic diiron dithiolate complex embedded within a protein matrix. ACS Catal 4:2645-2648. https://doi.org/ $10.1021 / \operatorname{cs} 500392 \mathrm{e}$

67. Chen W, Li S, Li X, Zhang C, Hu X, Zhu F, Shen G, Feng F (2019) Iron sulfur clusters in protein nanocages for photocatalytic hydrogen generation in acidic aqueous solutions. Chem Sci 10:2179-2185. https://doi.org/10.103 9/C8SC05293J

68. Hu X, Chen W, Li S, Sun J, Du K, Xia Q, Feng F (2019) Diiron dithiolate complex induced helical structure of histone and application in photochemical hydrogen generation. ACS Appl Mater Interfaces 11:1969119699. https://doi.org/10.1021/acsami.9b01866

69. Sommer DJ, Vaughn MD, Ghirlanda G (2014) Protein secondary-shell interactions enhance the photoinduced hydrogen production of cobalt protoporphyrin IX. Chem Commun 50:15852-15855. https://doi.org/10.103 9/C4CC06700B

70. Sommer DJ, Vaughn MD, Clark BC, Tomlin J, Roy A, Ghirlanda G (2016) Reengineering cyt b562 for hydrogen production: a facile route to artificial hydrogenases. Biochim Biophys Acta BBA-Bioenerg 1857:598-603. https: //doi.org/10.1016/j.bbabio.2015.09.001

71. Artz J, Müller TE, Thenert K, Kleinekorte J, Meys R, Sternberg A, Bardow 
A, Leitner W (2018) Sustainable conversion of carbon dioxide: an integrated review of catalysis and life cycle assessment. Chem Rev 118:434-504. https ://doi.org/10.1021/acs.chemrev.7b00435

72. Shi J, Jiang Y, Jiang Z, Wang X, Wang X, Zhang S, Han P, Yang C (2015) Enzymatic conversion of carbon dioxide. Chem Soc Rev 44:5981-6000. http s://doi.org/10.1039/C5CS00182J

73. Schneider CR, Shafaat HS (2016) An internal electron reservoir enhances catalytic $\mathrm{CO}_{2}$ reduction by a semisynthetic enzyme. Chem Commun 52:9889-9892. https://doi.org/10.1039/C6CC03901D

74. Schneider CR, Manesis AC, Stevenson MJ, Shafaat HS (2018) A photoactive semisynthetic metalloenzyme exhibits complete selectivity for $\mathrm{CO}_{2}$ reduction in water. Chem Commun 54:4681-4684. https://doi.org/10.10 39/C8CC01297K

75. Amao Y (2018) Formate dehydrogenase for $\mathrm{CO}_{2}$ utilization and its application. J CO2 Util 26:623-641. https://doi.org/10.1016/j.jcou.2018.06. 022

76. Laureanti JA, Buchko GW, Katipamula S, Su Q, Linehan JC, Zadvornyy OA, Peters JW, O'Hagan M (2019) Protein scaffold activates catalytic $\mathrm{co}_{2}$ hydrogenation by a rhodium bis(diphosphine) complex. ACS Catal 9:620625. https://doi.org/10.1021/acscatal.8b02615

77. Gamenara D, Domínguez de María P (2014) Enantioselective imine reduction catalyzed by imine reductases and artificial metalloenzymes. Org Biomol Chem 12:2989-2992. https://doi.org/10.1039/C3OB42205D

78. Bembenek ME, Abell CW, Chrisey LA, Rozwadowska MD, Gessner W, Brossi A (1990) Inhibition of monoamine oxidases A and B by simple isoquinoline alkaloids: racemic and optically active 1,2,3,4-tetrahydro-, 3,4dihydro-, and fully aromatic isoquinolines. J Med Chem 33:147-152. https:/ /doi.org/10.1021/jm00163a025 
79. Tundis R, Menichini F, Conforti F, Loizzo MR, Bonesi M, Statti G, Menichini F (2009) A potential role of alkaloid extracts from Salsola species (Chenopodiaceae) in the treatment of Alzheimer's disease. J Enzyme Inhib Med Chem 24:818-824. https://doi.org/10.1080/14756360802399662

80. Duerrenberger M, Heinisch T, Wilson YM, Rossel T, Nogueira E, Knoerr L, Mutschler A, Kersten K, Zimbron MJ, Pierron J, Schirmer T, Ward TR (2011) Artificial transfer hydrogenases for the enantioselective reduction of cyclic imines. Angew Chem-Int Ed 50:3026-3029. https://doi.org/10.1002/a nie. 201007820

81. Muñoz Robles V, Dürrenberger M, Heinisch T, Lledós A, Schirmer T, Ward TR, Maréchal J-D (2014) Structural, kinetic, and docking studies of artificial imine reductases based on biotin-streptavidin technology: an induced lockand-key hypothesis. J Am Chem Soc 136:15676-15683. https://doi.org/10.1 $021 / \mathrm{ja} 508258 \mathrm{t}$

82. Schwizer F, Koehler V, Duerrenberger M, Knoerr L, Ward TR (2013) Genetic optimization of the catalytic efficiency of artificial imine reductases based on biotin-streptavidin technology. ACS Catal 3:1752-1755. https://doi .org/10.1021/cs400428r

83. Zimbron JM, Heinisch T, Schmid M, Hamels D, Nogueira ES, Schirmer T, Ward TR (2013) A dual anchoring strategy for the localization and activation of artificial metalloenzymes based on the biotin-streptavidin technology. J Am Chem Soc 135:5384-5388. https://doi.org/10.1021/ja3099 $74 \mathrm{~s}$

84. Hestericova M, Heinisch T, Alonso-Cotchico L, Marechal J-D, Vidossich P, Ward TR (2018) Directed evolution of an artificial imine reductase. Angew Chem-Int Ed 57:1863-1868. https://doi.org/10.1002/anie.201711016

85. Wilson YM, Duerrenberger M, Nogueira ES, Ward TR (2014) Neutralizing the detrimental effect of glutathione on precious metal catalysts. J Am Chem Soc 136:8928-8932. https://doi.org/10.1021/ja500613n

86. Wu S, Zhou Y, Rebelein JG, Kuhn M, Mallin H, Zhao J, Igareta NV, Ward 
TR (2019) Breaking symmetry: engineering single-chain dimeric streptavidin as host for artificial metalloenzymes. J Am Chem Soc 141:15869-15878. https://doi.org/10.1021/jacs.9b06923

87. Monnard FW, Nogueira ES, Heinisch T, Schirmer T, Ward TR (2013) Human carbonic anhydrase II as host protein for the creation of artificial metalloenzymes: the asymmetric transfer hydrogenation of imines. Chem Sci 4:3269-3274. https://doi.org/10.1039/c3sc51065d

88. Heinisch T, Pellizzoni M, Duerrenberger M, Tinberg CE, Koehler V, Klehr J, Haeussinger D, Baker D, Wardt TR (2015) Improving the catalytic performance of an artificial metalloenzyme by computational design. J Am Chem Soc 137:10414-10419. https://doi.org/10.1021/jacs.5b06622

89. Tang BZ, Poon WH, Leung SM, Leung WH, Peng H (1997) Synthesis of stereoregular poly(phenylacetylene)s by organorhodium complexes in aqueous media. Macromolecules 30:2209-2212. https://doi.org/10.1021/ma9 $61573 \mathrm{~s}$

90. Abe S, Hirata K, Ueno T, Morino K, Shimizu N, Yamamoto M, Takata M, Yashima E, Watanabe Y (2009) Polymerization of phenylacetylene by rhodium complexes within a discrete space of apo-ferritin. J Am Chem Soc 131:6958-6960. https://doi.org/10.1021/ja901234j

91. Ke Z, Abe S, Ueno T, Morokuma K (2012) Catalytic mechanism in artificial metalloenzyme: QM/mm study of phenylacetylene polymerization by rhodium complex encapsulated in apo-ferritin. J Am Chem Soc 134:1541815429. https://doi.org/10.1021/ja305453w

92. Onoda A, Fukumoto K, Arlt M, Bocola M, Schwaneberg U, Hayashi T (2012) A rhodium complex-linked beta-barrel protein as a hybrid biocatalyst for phenylacetylene polymerization. Chem Commun 48:9756-9758. https:// doi.org/10.1039/c2cc35165j

93. Kinzel J, Sauer DF, Bocola M, Arlt M, Garakani TM, Thiel A, Beckerle K, Polen T, Okuda J, Schwaneberg U (2017) 2-Methyl-2,4-pentanediol (MPD) boosts as detergent-substitute the performance of $\beta$-barrel hybrid catalyst for 
phenylacetylene polymerization. Beilstein J Org Chem 13:1498-1506. https: //doi.org/10.3762/bjoc.13.148

94. Philippart F, Arlt M, Gotzen S, Tenne S-J, Bocola M, Chen H-H, Zhu L, Schwaneberg U, Okuda J (2013) A hybrid ring-opening metathesis polymerization catalyst based on an engineered variant of the $\beta$-barrel protein FhuA. Chem Eur J 19:13865-13871. https://doi.org/10.1002/chem.2 01301515

95. Garber SB, Kingsbury JS, Gray BL, Hoveyda AH (2000) Efficient and recyclable monomeric and dendritic Ru-based metathesis catalysts. J Am Chem Soc 122:8168-8179. https://doi.org/10.1021/ja001179g

96. Jordan JP, Grubbs RH (2007) Small-molecule N-heterocyclic-carbenecontaining olefin-metathesis catalysts for use in water. Angew Chem Int Ed 46:5152-5155. https://doi.org/10.1002/anie.200701258

97. Sauer DF, Bocola M, Broglia C, Arlt M, Zhu L-L, Brocker M, Schwaneberg U, Okuda J (2015) Hybrid ruthenium ROMP catalysts based on an engineered variant of $\beta$-barrel protein FhuA $\triangle$ CVFtev: effect of spacer length. Chem Asian J 10:177-182. https://doi.org/10.1002/asia.201403005

98. Sauer DF, Himiyama T, Tachikawa K, Fukumoto K, Onoda A, Mizohata E, Inoue T, Bocola M, Schwaneberg U, Hayashi T, Okuda J (2015) A highly active biohybrid catalyst for olefin metathesis in water: impact of a hydrophobic cavity in a beta-barrel protein. ACS Catal 5:7519-7522. https:/ /doi.org/10.1021/acscatal.5b01792

99. Grimm AR, Sauer DF, Davari MD, Zhu L, Bocola M, Kato S, Onoda A, Hayashi T, Okuda J, Schwaneberg U (2018) Cavity size engineering of a beta-barrel protein generates efficient biohybrid catalysts for olefin metathesis. ACS Catal 8:3358-3364. https://doi.org/10.1021/acscatal.7b036 52

100. Ricca E, Brucher B, Schrittwieser JH (2011) Multi-enzymatic cascade reactions: overview and perspectives. Adv Synth Catal 353:2239-2262. htt ps://doi.org/10.1002/adsc.201100256 
101. O'Reilly E, Turner NJ (2015) Enzymatic cascades for the regio- and stereoselective synthesis of chiral amines. Perspect Sci 4:55-61. https://doi .org/10.1016/j.pisc.2014.12.009

102. Betanzos-Lara S, Liu Z, Habtemariam A, Pizarro AM, Qamar B, Sadler PJ (2012) Organometallic Ruthenium and Iridium transfer-hydrogenation catalysts using coenzyme NADH as a cofactor. Angew Chem Int Ed 51:3897-3900. https://doi.org/10.1002/anie.201108175

103. Wingstrand E, Laurell A, Fransson L, Hult K, Moberg C (2009) Minor enantiomer recycling: metal catalyst, organocatalyst and biocatalyst working in concert. Chem Eur J 15:12107-12113. https://doi.org/10.1002/c hem. 200901338

104. Simons C, Hanefeld U, Arends IWCE, Maschmeyer T, Sheldon RA (2006) Towards catalytic cascade reactions: asymmetric synthesis using combined chemo-enzymatic catalysts. Top Catal 40:35-44. https://doi.org/10.1007/s1 1244-006-0106-6

105. Wieczorek B, Träff A, Krumlinde P, Dijkstra HP, Egmond MR, van Koten G, Bäckvall J-E, Gebbink RJMK (2011) Covalent anchoring of a racemization catalyst to CALB-beads: towards dual immobilization of DKR catalysts. Tetrahedron Lett 52:1601-1604. https://doi.org/10.1016/j.te tlet.2011.01.106

106. Worsdorfer B, Woycechowsky KJ, Hilvert D (2011) Directed evolution of a protein container. Science 331:589-592. https://doi.org/10.1126/science.1 199081

107. Engström K, Johnston EV, Verho O, Gustafson KPJ, Shakeri M, Tai C-W, Bäckvall J-E (2013) Co-immobilization of an enzyme and a metal into the compartments of mesoporous silica for cooperative tandem catalysis: an artificial metalloenzyme. Angew Chem Int Ed 52:14006-14010. https://doi. org/10.1002/anie.201306487

108. Köhler V, Wilson YM, Dürrenberger M, Ghislieri D, Churakova E, Quinto T, Knörr L, Häussinger D, Hollmann F, Turner NJ, Ward TR (2012) 
Synthetic cascades are enabled by combining biocatalysts with artificial metalloenzymes. Nat Chem 5:93-99. https://doi.org/10.1038/nchem.1498

109. Okamoto Y, Köhler V, Ward TR (2016) An NAD(P)H-dependent artificial transfer hydrogenase for multienzymatic cascades. J Am Chem Soc 138:5781-5784. https://doi.org/10.1021/jacs.6b02470

110. Morra S, Pordea A (2018) Biocatalyst-artificial metalloenzyme cascade based on alcohol dehydrogenase. Chem Sci 9:7447-7454. https://doi.org/1 $0.1039 / \mathrm{C} 8 \mathrm{SC} 02371 \mathrm{~A}$

111. Jeschek M, Reuter R, Heinisch T, Trindler C, Klehr J, Panke S, Ward TR (2016) Directed evolution of artificial metalloenzymes for in vivo metathesis. Nature 537:661-665. https://doi.org/10.1038/nature19114

112. Vong K, Eda S, Kadota Y, Nasibullin I, Wakatake T, Yokoshima S, Shirasu K, Tanaka K (2019) An artificial metalloenzyme biosensor can detect ethylene gas in fruits and Arabidopsis leaves. Nat Commun 10:5746. https: //doi.org/10.1038/s41467-019-13758-2

113. Eda S, Nasibullin I, Vong K, Kudo N, Yoshida M, Kurbangalieva A, Tanaka K (2019) Biocompatibility and therapeutic potential of glycosylated albumin artificial metalloenzymes. Nat Catal 2:780-792. https ://doi.org/10.1038/s41929-019-0317-4

114. Grimm AR, Sauer DF, Polen T, Zhu L, Hayashi T, Okuda J, Schwaneberg U (2018) A whole cell E. coli display platform for artificial metalloenzymes: poly(phenylacetylene) production with a rhodiumnitrobindin metalloprotein. ACS Catal 8:2611-2614. https://doi.org/10.102 1/acscatal.7b04369

115. Völker T, Dempwolff F, Graumann PL, Meggers E (2014) Progress towards bioorthogonal catalysis with organometallic compounds. Angew Chem Int Ed 53:10536-10540. https://doi.org/10.1002/anie.201404547

116. Cheng Y, Zong L, López-Andarias J, Bartolami E, Okamoto Y, Ward TR, Sakai N, Matile S (2019) Cell-penetrating dynamic-covalent 
benzopolysulfane networks. Angew Chem Int Ed 58:9522-9526. https://doi .org/10.1002/anie.201905003

117. Heinisch T, Schwizer F, Garabedian B, Csibra E, Jeschek M, Vallapurackal J, Pinheiro VB, Marlière P, Panke S, Ward TR (2018) E. coli surface display of streptavidin for directed evolution of an allylic deallylase. Chem Sci 9:5383-5388. https://doi.org/10.1039/C8SC00484F

118. Szponarski M, Schwizer F, Ward TR, Gademann K (2018) On-cell catalysis by surface engineering of live cells with an artificial metalloenzyme. Commun Chem 1:84. https://doi.org/10.1038/s42004-0180087-y

119. Zhao J, Rebelein JG, Mallin H, Trindler C, Pellizzoni MM, Ward TR (2018) Genetic Engineering of an Artificial Metalloenzyme for Transfer Hydrogenation of a Self-Immolative Substrate in Escherichia coil's Periplasm. J Am Chem Soc 140:13171-13175. https://doi.org/10.1021/jacs. 8b07189

120. Tsutsumi H, Katsuyama Y, Izumikawa M, Takagi M, Fujie M, Satoh N, Shin-ya K, Ohnishi Y (2018) Unprecedented cyclization catalyzed by a cytochrome P450 in benzastatin biosynthesis. J Am Chem Soc 140:66316639. https://doi.org/10.1021/jacs.8b02769

121. Breslow R, Gellman SH (1982) Tosylamidation of cyclohexane by a cytochrome P-450 model. J Chem Soc Chem Commun 1400-1401. https:// doi.org/10.1039/c39820001400

122. Breslow R, Gellman SH (1983) Intramolecular nitrene carbon-hydrogen insertions mediated by transition-metal complexes as nitrogen analogs of cytochrome P-450 reactions. J Am Chem Soc 105:6728-6729. https://doi.o $\mathrm{rg} / 10.1021 / \mathrm{ja} 00360 \mathrm{a} 039$

123. Svastits EW, Dawson JH, Breslow R, Gellman SH (1985) Functionalized nitrogen atom transfer catalyzed by cytochrome P-450. J Am Chem Soc 107:6427-6428. https://doi.org/10.1021/ja00308a064 
124. Mansuy D, Mahy J-P, Dureault A, Bedi G, Battioni P (1984) Iron- and manganese-porphyrin catalysed aziridination of alkenes by tosyl- and acyliminoiodobenzene. J Chem Soc Chem Commun 1161-1163. https://doi.org/ 10.1039/c39840001161

125. Singh R, Kolev JN, Sutera PA, Fasan R (2015) Enzymatic C( $\left.\mathrm{sp}^{3}\right)-\mathrm{H}$ amination: P450-catalyzed conversion of carbonazidates into oxazolidinones. ACS Catal 5:1685-1691. https://doi.org/10.1021/cs501861 2

126. Singh R, Bordeaux M, Fasan R (2014) P450-catalyzed intramolecular sp 3 C-H amination with arylsulfonyl azide substrates. ACS Catal 4:546-552. h ttps://doi.org/10.1021/cs400893n

127. Dydio P, Key HM, Hayashi H, Clark DS, Hartwig JF (2017) Chemoselective, enzymatic $\mathrm{C}-\mathrm{H}$ bond amination catalyzed by a cytochrome P450 containing an Ir(Me)-PIX cofactor. J Am Chem Soc 139:1750-1753. https://doi.org/10.1021/jacs.6b11410

128. Arnold FH (2018) Directed evolution: bringing new chemistry to life. Angew Chem Int Ed 57:4143-4148. https://doi.org/10.1002/anie.20170840 8

129. Prier CK, Zhang RK, Buller AR, Brinkmann-Chen S, Arnold FH (2017) Enantioselective, intermolecular benzylic $\mathrm{C}-\mathrm{H}$ amination catalysed by an engineered iron-haem enzyme. Nat Chem 9:629-634. https://doi.org/10.10 $38 /$ nchem. 2783

130. Brandenberg OF, Miller DC, Markel U, Ouald Chaib A, Arnold FH (2019) Engineering chemoselectivity in hemoprotein-catalyzed indole amidation. ACS Catal 9:8271-8275. https://doi.org/10.1021/acscatal.9b02508

131. Farwell CC, Zhang RK, McIntosh JA, Hyster TK, Arnold FH (2015) Enantioselective enzyme-catalyzed aziridination enabled by active-site evolution of a cytochrome P450. ACS Cent Sci 1:89-93. https://doi.org/10. 1021/acscentsci.5b00056 
132. Roelfes G (2019) LmrR: a privileged scaffold for artificial metalloenzymes. Acc Chem Res 52:545-556. https://doi.org/10.1021/acs.a ccounts.9b00004

133. Bos J, Browne WR, Driessen AJM, Roelfes G (2015) Supramolecular assembly of artificial metalloenzymes based on the dimeric protein $1 \mathrm{mrr}$ as promiscuous scaffold. J Am Chem Soc 137:9796-9799. https://doi.org/10.1 021/jacs.5b05790

134. Villarino L, Splan KE, Reddem E, Alonso-Cotchico L, Gutiérrez de Souza C, Lledós A, Maréchal J-D, Thunnissen A-MWH, Roelfes G (2018) An artificial heme enzyme for cyclopropanation reactions. Angew Chem Int Ed 57:7785-7789. https://doi.org/10.1002/anie.201802946

135. Zhao J, Bachmann DG, Lenz M, Gillingham DG, Ward TR (2018) An artificial metalloenzyme for carbene transfer based on a biotinylated dirhodium anchored within streptavidin. Catal Sci Technol 8:2294-2298. h ttps://doi.org/10.1039/C8CY00646F

136. Coelho PS, Brustad EM, Kannan A, Arnold FH (2013) Olefin cyclopropanation via carbene transfer catalyzed by engineered cytochrome P450 enzymes. Science 339:307-310. https://doi.org/10.1126/science.1231 434

137. Vargas DA, Tinoco A, Tyagi V, Fasan R (2018) Myoglobin-catalyzed C-H functionalization of unprotected indoles. Angew Chem Int Ed 57:99119915. https://doi.org/10.1002/anie.201804779

138. Tinoco A, Steck V, Tyagi V, Fasan R (2017) Highly diastereo- and enantioselective synthesis of trifluoromethyl-substituted cyclopropanes via myoglobin-catalyzed transfer of trifluoromethylcarbene. J Am Chem Soc 139:5293-5296. https://doi.org/10.1021/jacs.7b00768

139. Tinoco A, Wei Y, Bacik J-P, Carminati DM, Moore EJ, Ando N, Zhang Y, Fasan R (2019) Origin of high stereocontrol in olefin cyclopropanation catalyzed by an engineered carbene transferase. ACS Catal 9:1514-1524. h ttps://doi.org/10.1021/acscatal.8b04073 
140. Reynolds EW, McHenry MW, Cannac F, Gober JG, Snow CD, Brustad EM (2016) An evolved orthogonal enzyme/cofactor pair. J Am Chem Soc 138:12451-12458. https://doi.org/10.1021/jacs.6b05847

141. Reynolds EW, Schwochert TD, McHenry MW, Watters JW, Brustad EM (2017) Orthogonal expression of an artificial metalloenzyme for abiotic catalysis. ChemBioChem 18:2380-2384. https://doi.org/10.1002/cbic.2017 00397

142. Oohora K, Onoda A, Hayashi T (2019) Hemoproteins reconstituted with artificial metal complexes as biohybrid catalysts. Acc Chem Res 52:945954. https://doi.org/10.1021/acs .accounts.8b00676

143. Oohora K, Meichin H, Zhao L, Wolf MW, Nakayama A, Hasegawa J, Lehnert N, Hayashi T (2017) Catalytic cyclopropanation by myoglobin reconstituted with iron porphycene: acceleration of catalysis due to rapid formation of the carbene species. J Am Chem Soc 139:17265-17268. https: //doi.org/10.1021/jacs.7b10154

144. Key HM, Dydio P, Clark DS, Hartwig JF (2016) Abiological catalysis by artificial haem proteins containing noble metals in place of iron. Nature 534:534-537. https://doi.org/10.1038/nature17968

145. Dydio P, Key HM, Nazarenko A, Rha JY-E, Seyedkazemi V, Clark DS, Hartwig JF (2016) An artificial metalloenzyme with the kinetics of native enzymes. Science 354:102-106. https://doi.org/10.1126/science.aah4427

146. Natoli SN, Hartwig JF (2019) Noble-metal substitution in hemoproteins: an emerging strategy for abiological catalysis. Acc Chem Res 52:326-335. https://doi.org/10.1021/acs.accounts.8b00586

147. Zhang J, Huang X, Zhang RK, Arnold FH (2019) Enantiodivergent $\alpha$ amino C-H fluoroalkylation catalyzed by engineered cytochrome P450s. J Am Chem Soc 141:9798-9802. https://doi.org/10.1021/jacs.9b04344

148. Otto S, Bertoncin F, Engberts JBFN (1996) Lewis Acid Catalysis of a Diels - Alder Reaction in Water. J Am Chem Soc 118:7702-7707. https://d 
oi.org/10.1021/ja960318k

149. Otto S, Engberts JBFN (1999) A systematic study of ligand effects on a lewis-acid-catalyzed Diels-Alder reaction in water: water-enhanced enantioselectivity. J Am Chem Soc 121:6798-6806. https://doi.org/10.1021 /ja984273u

150. Mubofu EB, Engberts JBFN (2004) Specific acid catalysis and Lewis acid catalysis of Diels-Alder reactions in aqueous media. J Phys Org Chem 17:180-186. https://doi.org/10.1002/poc.711

151. Reetz MT, Jiao N (2006) Copper-phthalocyanine conjugates of serum albumins as enantioselective catalysts in Diels-Alder reactions. Angew Chem Int Ed 45:2416-2419. https://doi.org/10.1002/anie.200504561

152. Reetz MT (2012) Artificial Metalloenzymes as Catalysts in Stereoselective Diels-Alder Reactions. Chem Rec 12:391-406. https://doi.org/10.1002/tcr. 201100043

153. Roelfes G, Boersma AJ, Feringa BL (2006) Highly enantioselective DNAbased catalysis. Chem Commun 635-637. https://doi.org/10.1039/b516552 $\mathrm{k}$

154. Filice M, Romero O, Gutiérrez-Fernández J, de las Rivas B, Hermoso JA, Palomo JM (2015) Synthesis of a heterogeneous artificial metallolipase with chimeric catalytic activity. Chem Commun 51:9324-9327. https://doi. org/10.1039/C5CC02450A

155. Ghattas W, Cotchico-Alonso L, Maréchal J-D, Urvoas A, Rousseau M, Mahy J-P, Ricoux R (2016) Artificial metalloenzymes with the neocarzinostatin scaffold: toward a biocatalyst for the Diels-Alder reaction. ChemBioChem 17:433-440. https://doi.org/10.1002/cbic.201500445

156. Talbi B, Haquette P, Martel A, de Montigny F, Fosse C, Cordier S, Roisnel T, Jaouen G, Salmain M (2010) ( $\eta 6$-Arene) ruthenium(II) complexes and metallo-papain hybrid as Lewis acid catalysts of Diels-Alder reaction in water. Dalton Trans 39:5605-5607. https://doi.org/10.1039/c001630f 
157. Di Meo T, Ghattas W, Herrero C, Velours C, Minard P, Mahy J-P J-P, Ricoux R, Urvoas A (2017) $\alpha$ Rep A3: a versatile artificial scaffold for metalloenzyme design. Chem Eur J 23:10156-10166. https://doi.org/10.10 02/chem.201701518

158. Di Meo T, Kariyawasam K, Ghattas W, Valerio-Lepiniec M, Sciortino G, Maréchal J-D, Minard P, Mahy J-P, Urvoas A, Ricoux R (2019) functionalized artificial bidomain proteins based on an $\alpha$-solenoid protein repeat scaffold: a new class of artificial Diels-Alderases. ACS Omega 4:4437-4447. https://doi.org/10.1021/acsomega.8b03448

159. Himiyama T, Taniguchi N, Kato S, Onoda A, Hayashi T (2017) A pyrenelinked cavity within a $\beta$-barrel protein promotes an asymmetric DielsAlder reaction. Angew Chem Int Ed 56:13618-13622. https://doi.org/10.10 02/anie.201704524

160. Deuss PJ, Popa G, Slawin AMZ, Laan W, Kamer PCJ (2013) Artificial copper enzymes for asymmetric Diels-Alder reactions. Chem Cat Chem 5:1184-1191. https://doi.org/10.1002/cetc.201200671

161. Bos J, Fusetti F, Driessen AJM, Roelfes G (2012) Enantioselective artificial metalloenzymes by creation of a novel active site at the protein dimer interface. Angew Chem Int Ed 51:7472-7475. https://doi.org/10.100 2/anie. 201202070

162. Podtetenieff J, Taglieber A, Bill E, Reijerse EJ, Reetz MT (2010) An artificial metalloenzyme: creation of a designed copper binding site in a thermostable protein. Angew Chem Int Ed 49:5151-5155. https://doi.org/1 0.1002/anie. 201002106

163. Ghattas W, Dubosclard V, Tachon S, Beaumet M, Guillot R, Réglier M, Simaan AJ, Mahy J-P (2019) Cu II -Containing 1-aminocyclopropane carboxylic acid oxidase is an efficient stereospecific Diels-Alderase. Angew Chem Int Ed 58:14605-14609. https://doi.org/10.1002/anie.201909 407

164. Ghattas W, Dubosclard V, Wick A, Bendelac A, Guillot R, Ricoux R, Mahy 
J-P (2018) Receptor-based artificial metalloenzymes on living human cells. J Am Chem Soc 140:8756-8762. https://doi.org/10.1021/jacs.8b04326 